\title{
Revision, phylogeny and phylogeography of the cicada genus Auritibicen (Hemiptera: Cicadidae), with descriptions of ten new species
}

\author{
Xu WANG ${ }^{1}$, MASAmI HAYASHI ${ }^{2}$ and Cong WEI ${ }^{1, *}$ \\ ${ }^{1}$ Key Laboratory of Plant Protection Resources and Pest Management, Ministry of Education, Entomological Museum, \\ Northwest A\&F University, Yangling, Shaanxi 712100, China; e-mails: wlxyf1314@126.com, congwei@nwsuaf.edu.cn \\ ${ }^{2}$ Laboratory of Entomology, Tokyo University of Agriculture, Atsugi 243-0034, Japan; e-mail: kecera-ymhc@jcom.home.ne.jp
}

Key words. Cicadidae, Auritibicen, Lyristes, Tibicen, taxonomy, new species, phylogenetic analysis, phylogeographic analysis, divergence time

\begin{abstract}
We review the cicada genus Auritibicen Lee, 2015 based on the description of ten new species: $A$. aethus sp. n., $A$. daoxianensis sp. n., A. pallidus sp. n., A. rotundus sp. n., A. curvatus sp. n., A. purus sp. n., A. parvus sp. n., $A$. gracilis sp. n., $A$. septatus sp. n. and A. lijiangensis sp. n. Auritibicen shikokuanus (Kato, 1959) is confirmed to be a synonym of Auritibicen kyushyuensis (Kato, 1926). Diagnoses and descriptions, along with illustrations of the structure of male genitalia, are provided for all Auritibicen species. The systematics of Auritibicen is elucidated using both morphological and molecular characterization. Thirtyfive morphological characters of the 24 species of Auritibicen and one outgroup taxon, Chremistica ochracea (Walker, 1850), were scored. Morphological phylogenetic analyses reveal the relationships among related species of Auritibicen, which are supported by a number of morphological characters. The mitochondrial gene fragments of Cytochrome Oxidase I (COI) of 11 species of $A u-$ ritibicen and two outgroup Lyristes species were analyzed and yielded identical robust phylogenetic trees. The phylogram based on a Bayesian analysis of both morphological and molecular data is similar to the ML/BI topologies based only on the molecular data. The molecular phylogenetic analysis indicates that species of Auritibicen are structured phylogeographically, with related species clustered into three lineages. The divergence time estimated based on molecular data indicates that the divergence of Auritibicen from Lyristes occurred during the Miocene, and the most recent common ancestor (tMRCA) of Auritibicen evolved during the Pliocene. However, the time when the main divergence events of species of Auritibicen occurred was the Pleistocene. From the combination of the phylogeny and updated geographical distributions, we infer that the center of distribution of Auritibicen could be Southwest China (e.g., Sichuan and Yunnan Provinces), from where species of this genus spreaded northeastwards to Shaanxi, Hubei and other provinces along the Qinling and Daba Mountains, then further northeastwards to Hebei Province in China and also to Far East Russia, the Korean Penisula, and Japan.
\end{abstract}

ZooBank Article LSID: 71C688C7-41B9-4852-B9EF-4ADAE9A2EB1E

\section{INTRODUCTION}

The genera Tibicen Latreille, 1825 and Tibicina Kolenati, 1857 in the family Cicadidae differ not only in their spelling, but are distantly related, thereby causing many difficulties and chaos in cicada systematics. A third name, Lyristes, was created by Horváth in 1926, with Cicada plebeja Scopoli, 1763 as the type species, to replace the former, but was not universally adopted (Boulard \& Puissant, 2014; Marshall \& Hill, 2014; Sanborn, 2014). Boulard (1988a, b, 1998) convincingly argues that Lyristes is not an objective junior synonym of Tibicen, because the latter does not share Cicada plebeja as its type species, as was widely proclaimed. Lee (2008) follows Boulard and retains Lyristes over Tibicen. Lee (2015) transfers 14 East Asian species from Lyristes to a newly established genus,
Auritibicen, i.e., L. atrofasciatus (Kirkaldy, 1909), L. bihamatus (Motschulsky, 1861), L. chujoi (Esaki, 1935), L. esakii (Kato, 1958), L. flammatus (Distant, 1892), L. flavomarginatus (Hayashi, 1977), L. intermedius (Mori, 1931), L. jai (Ouchi, 1938), L. japonicus (Kato, 1925), L. kyushyuensis (Kato, 1926), L. leechi (Distant, 1890), L. pekinensis (Haupt, 1924), L. slocumi (Chen, 1943) and $L$. tsaopaonensis (Chen, 1943). Moulds (in Hill et al., 2015) created a new genus Subsolanus for the Asian species of Lyristes, which is now a junior synonym of Auritibicen Lee, 2015 (Sanborn, 2015).

Gomez-Menor (1961) erected the tribe Lyristini to accommodate the genus Lyristes. However, Boulard (1979) and Hayashi (1987) include the Lyristini as part of the tribe Cryptotympanini, a concept also maintained by Boulard

\footnotetext{
* Corresponding author; e-mail: congwei@nwsuaf.edu.cn
} 
(1996a, b). Chou et al. (1997) also follow this broader tribal concept, but erroneously retain the name Lyristini to accommodate Chinese species of Lyristes (now belonging to the genus Auritibicen). Puissant et al. (2015) clearly distinguish the genera Tibicen, Tibicina and Lyristes and place Lyristes in the subtribe Cryptotympanina of the Cryptotympanini. Lee (2015) also puts Auritibicen in Cryptotympanini.

Recently, there have been some taxonomic and phylogenetic studies on the genus Auritibicen and its allies (Lyristes and Tibicen). Wang et al. (2015) redress the two species of Lyristes described by Schmidt, and synonymize Lyristes wui Schmidt, 1932 and Lyristes altaiensis Schmidt, 1932 to Salvazana mirabilis Distant, 1913 and Neotibicen resh (Haldeman, 1852), respectively. Hill et al. (2015) investigate the molecular phylogenetics, diversification and systematics of Tibicen and related taxa, and describe three new genera (Neotibicen Hill \& Moulds, 2015, Hadoa Moulds, 2015 and Subsolanus Moulds, 2015). Sanborn (2015) treats Subsolanus as a junior synonym of Auritibicen and reassigns six species from Tibicen to other genera. Sota et al. (2016) investigate the phylogenetic relationships and divergence times within the genus Auritibicen based on eight species. Later, Lee (2017) resurrects A. shikokuanus (Kato, 1959) and treats A. ishiharai (Kato, 1959) from Honshu as a junior synonym of $A$. shikokuanus. Although many problems have been solved successfully in the genus Auritibicen and its allies, the taxonomy, biodiversity and phylogeny of Auritibicen are far from clear.

In the present paper, we review the genus Auritibicen based on widely collected material, including ten new species: A. aethus sp. n., A. daoxianensis sp. n., A. pallidus sp. n., A. rotundus sp. n., A. curvatus sp. n., A. purus sp. n., A. parvus sp. n., A. gracilis sp. n., A. septatus sp. n. and $A$. lijiangensis sp. n. The systematics of Auritibicen is elucidated based on both morphological characterization and molecular data, and the divergence time of Auritibicen was estimated based on a mitochondrial gene fragment of Cytochrome Oxidase I (COI) of related species. Based on the results of the phylogenetic analyses, we discuss the evolution and phylogeography of species of Auritibicen. These results are needed for future research on the phylogenetics, biogeography and evolution of taxa in the tribe Cryptotympanini.

\section{MATERIALS AND METHODS}

\section{Specimens examined and terminology}

A total of 24 species of Auritibicen were included in the morphological study and morphological phylogenetic analysis (see detailed taxa list in Table 1). Chremistica ochracea (Walker, 1850) (Cicadinae: Cryptotympanini: Cryptotympanina) was selected as the outgroup. In addition, we sampled the mitochondrial gene fragment of Cytochrome Oxidase I (COI) of 11 species of Auritibicen and two outgroup species of Lyristes for the molecular phylogenetic analysis (see detailed taxa list in Table 2).

Specimens examined in this study are deposited in the following institutions: Entomological Museum, Northwest A\&F University, Yangling, China (NWAFU); The Natural History Museum, London, UK (BMNH); Entomological Laboratory, Kyushu University, Fukuoka, Japan (ELKU); Institut Royal des Sciences Naturelles de Belgique, Bruxelles, Belgique (ISNB); Muséum National d'Histoire Naturelle, Paris, France (MNHN); Museum für Tierkunde, Senckenberg Naturhistorische Sammlung, Dresden, Germany (SNSD); Museum für Naturkunde, Humboldt-Universität zu Berlin, Germany (MFNB); Museum Malang Tempo Doeloe (Indonesia) (MTD); National Museum of Nature and Science, Tsukuba, Japan (NSMT); Zoological Institute, Russian Academy of Sciences, Saint Petersburg (ZIN), Moravian Mu-

Table 1. Data matrix of the species of Auritibicen used in the morphological phylogenetic analysis.

\begin{tabular}{|c|c|c|c|c|c|c|c|}
\hline & $\begin{array}{l}00000 \\
01234\end{array}$ & $\begin{array}{l}00000 \\
56789\end{array}$ & $\begin{array}{l}11111 \\
01234\end{array}$ & $\begin{array}{l}11111 \\
56789\end{array}$ & $\begin{array}{l}22222 \\
01234\end{array}$ & $\begin{array}{l}22222 \\
56789\end{array}$ & $\begin{array}{l}33333 \\
01234\end{array}$ \\
\hline Chremistica ochracea & 02015 & 10111 & 02201 & 10000 & 21100 & 21000 & 00210 \\
\hline Auritibicen atrofasciatus & 01015 & 00000 & 10021 & 11110 & 10101 & 11013 & 10021 \\
\hline Auritibicen bihamatus & 10002 & 01011 & 00041 & 00010 & 01112 & 02101 & 02101 \\
\hline Auritibicen chujoi & 11005 & 01000 & 01141 & 10000 & 01101 & 21003 & 10200 \\
\hline Auritibicen esakii & 10002 & 10010 & 00041 & 01011 & 00112 & 21112 & 10201 \\
\hline Auritibicen flammatus & 20003 & 00110 & 10041 & 10000 & 11010 & 21003 & 10210 \\
\hline Auritibicen flavomarginatus & 10105 & 01000 & 00121 & 10000 & 00100 & 21103 & 00000 \\
\hline Auritibicen intermedius & 10005 & 01010 & 00131 & 10001 & 00112 & 21001 & 00201 \\
\hline Auritibicen jai & 21003 & 01010 & 01011 & 00011 & 10110 & 21112 & 10000 \\
\hline Auritibicen japonicus & 11104 & 01110 & 00041 & 00000 & 10001 & 21112 & 00000 \\
\hline Auritibicen kyushyuensis & 21001 & 10110 & 12131 & 00000 & 00001 & 21002 & 11201 \\
\hline Auritibicen leechi & 20000 & 01010 & 02021 & 00110 & 10100 & 20111 & 11000 \\
\hline Auritibicen pekinensis & 11100 & 00111 & 00021 & 01000 & 00101 & 20012 & 10101 \\
\hline Auritibicen slocumi & 11000 & 00110 & 00031 & 01001 & 10101 & 21102 & 02101 \\
\hline Auritibicen tsaopaonensis & 11112 & 00000 & 02050 & 01111 & 11001 & 20103 & 10021 \\
\hline Auritibicen aethus sp. $\mathrm{n}$. & 20004 & 01010 & 00041 & 00010 & 00111 & 02111 & 12000 \\
\hline Auritibicen daoxianensis sp. $\mathrm{n}$. & 20001 & 00000 & 02011 & 00001 & 10111 & 20101 & 12121 \\
\hline Auritibicen pallidus sp. $\mathrm{n}$. & 10012 & 00001 & 00011 & 11100 & 10001 & 20100 & 00020 \\
\hline Auritibicen rotundus sp. $\mathrm{n}$. & 20000 & 01100 & 11011 & 10010 & 10002 & 21002 & 10200 \\
\hline Auritibicen gracilis sp. $\mathrm{n}$. & 10001 & 11000 & 01011 & 10100 & 10101 & 11011 & 00001 \\
\hline Auritibicen septatus sp. $\mathrm{n}$. & 20001 & 00000 & 02111 & 10001 & 20100 & 01100 & 10021 \\
\hline Auritibicen lijiangensis sp $\mathrm{n}$. & 10001 & 01010 & 00011 & 10001 & 10001 & 21002 & 00010 \\
\hline Auritibicen curvatus sp. $\mathrm{n}$. & 20015 & 01010 & 00141 & 00001 & 00100 & 01101 & 01001 \\
\hline Auritibicen purus sp. $\mathrm{n}$. & 11115 & 10101 & 01101 & 10010 & 10101 & 11110 & 10121 \\
\hline Auritibicen parvus sp. $\mathrm{n}$. & 02115 & 00001 & 01011 & 01001 & 10100 & 20110 & 01121 \\
\hline
\end{tabular}


Table 2. List of species used in the molecular analysis in this study and GenBank accession numbers of $C O /$ sequences.

\begin{tabular}{|c|c|c|c|}
\hline Taxa & Sample collected & Date & $\begin{array}{c}\text { GenBank acc. } \\
\text { numbers }\end{array}$ \\
\hline Lyristes plebejus (Scopoli, 1763) & Cuges Les Pins, France & July 9, 2007 & KR674238 \\
\hline L. gemellus (Boulard, 1988) & Island Ikaria, Pezi, Mt Melissa, Greece & July 14, 2011 & KR674232 \\
\hline Auritibicen atrofasciatus * & Linzhi, Tibet, China & July, 2005 & LC099991 \\
\hline A. atrofasciatus- 1 & Mt. Zhougong, Ya'an, Sichuan, China & July 7, 2009 & KY782334 \\
\hline A. bihamatus* & Karuizawa, Gunma, Honshu, Japan & Aug. 26, 2007 & LC099999 \\
\hline A. bihamatus -1 * & Mt. Hachibuse, Hyogo, Honshu, Japan & Aug. 4, 2012 & LC099980 \\
\hline A. bihamatus-2* & Mt. Hachibuse, Hyogo, Honshu, Japan & July 27, 2003 & LC099988 \\
\hline A. bihamatus-3 * & Memuro, Hokkaido, Japan & Aug. 18, 2007 & LC099993 \\
\hline A. bihamatus-4 * & Kumakogen, Ehime, Shikoku, Japan & Aug. 9, 2008 & LC099994 \\
\hline A. chujoi* & Lishan, Taiwan, China & July 23, 2010 & LC099987 \\
\hline A. chujoi-1 * & Lishan, Taiwan, China & July 23, 2010 & LC099990 \\
\hline A. curvatus sp. $\mathrm{n}$. & Mts. Qinling, Shaanxi, China & July, 2010 & KY782336 \\
\hline A. curvatus sp. n.-1 & Mt. Huashan, Weinan, Shaanxi, China & July 29, 2014 & KY782337 \\
\hline A. esakii * & Yakushima I., Kyushu, Japan & July 27, 2012 & LC099983 \\
\hline A. esakii-1 * & Yakushima I., Kyushu, Japan & July 25, 2012 & LC099997 \\
\hline A. flammatus * & Kumakogen, Ehime, Shikoku, Japan & Aug. 13, 2011 & LC099982 \\
\hline A. flammatus -1 * & Mt. Kongo, Osaka, Honshu, Japan & Aug. 14, 2013 & LC099989 \\
\hline A. intermedius * & Mt. Godaesan, Yeoncheon-gun, Gyeonggi-do, Korea & Aug. 15, 2003 & LC099992 \\
\hline A. japonicus* & Nobusawa, Nagano, Honshu, Japan & Aug. 25, 2007 & LC100000 \\
\hline A. japonicus-1 * & Mt. Rokko, Hyogo, Honshu, Japan & Aug. 12, 2012 & LC099981 \\
\hline A. japonicus-2 * & Memuro, Hokkaido, Japan & Aug. 18, 2007 & LC099995 \\
\hline A. japonicus-3 * & Mt. Sefuri, Fukuoka, Kyushu, Japan & Aug. 7, 2013 & LC099996 \\
\hline A. kyushyuensis* & Makinoto-toge, Kokonoe, Ohita, Kyushu, Japan & July 20, 2013 & LC099984 \\
\hline A. kyushyuensis-1 * & Kumakogen, Ehime, Shikoku, Japan & Aug. 13, 2011 & LC099985 \\
\hline A. kyushyuensis-2* & Kumakogen, Ehime, Shikoku, Japan & Aug. 13, 2011 & LC099998 \\
\hline A. kyushyuensis-3 * & Kitahiroshima, Hiroshima, Honshu, Japan & Aug. 7, 2013 & LC099986 \\
\hline A. parvus sp. n. & Mt. Lu Shan, Xichang, Sichuan, China & Aug. 12, 2014 & KY782339 \\
\hline A. purus sp. n. & Mt. Yulong, Lijiang, Yunnan, China & Aug. 10, 1962 & KY782338 \\
\hline
\end{tabular}

* Sequences of $A$. atrofasciatus from Tibet, $A$. bihamatus, $A$. chujoi, $A$. esakii, $A$. flammatus, $A$. intermedius, $A$. japonicus and $A$. kyushyuensis were downloaded from the GenBank.

seum, Brno (MZM); Tokyo University of Agriculture, Atsugi, Japan (TUA); The University Museum, University of Tokyo, Tokyo, Japan (UMUT).

The types of $A$. aethus sp. n., A. daoxianensis sp. n., A. pallidus sp. n., A. rotundus sp. n., A. curvatus sp. n., A. purus sp. n. and $A$. parvus sp. n. are deposited in NWAFU; those of $A$. gracilis $\mathrm{sp} . \mathrm{n}$. in SNSD, of A. septatus sp. n. in MNHN and A. lijiangensis sp. n. in TUA.

Terminology for morphological features follows that of Moulds (2005, 2012).

\section{Morphological investigation}

External morphology was observed using an Olympus SZX10 stereomicroscope (Olympus Corporation, Tokyo, Japan), and photographed using a Nikon Coolpix P100 digital camera (Nikon Corporation, Indonesia). Male genitalia were observed and photographed using a Scientific Digital micrography system equipped with an Auto-montage imaging system and a highly sensitive QIMAGING Retiga 4000R digital camera (CCD) (QImaging, Surrey, BC, Canada), and were drawn using Adobe Illustrator CS6.0. Photographs were modified using Adobe Photoshop CS3.0. All measurements are in millimeters.

\section{Selection of morphological characters}

In the present study, we examined male specimens of all the 24 species of Auritibicen and the females of the nine species that were available. Based on our survey, 35 morphological characters of adult morphology were included in the analysis. All characters were treated as unordered and of equal weight.

\section{Body size}

0. Body size of male. (0) small, body $<31.0 \mathrm{~mm}$ in length; (1) median, body between $32.0-37.0 \mathrm{~mm}$ in length; (2) large, body $>$ $38.0 \mathrm{~mm}$ in length.

\section{Head}

1. Yellowish spot between lateral ocellus and corresponding eye: (0) small; (1) large; (2) absent.

2. Length of rostrum: (0) just reaching posterior margin of mid coxa; (1) reaching mid trochanter; (2) reaching hind coxa.

\section{Thorax}

3. Central longitudinal fascia on pronotum: (0) present; (1) absent.

4. Markings on pronotal collar: (0) a spot on median part and a pair of spots on margins of pronotal collar; (1) a pair of spots on margins of pronotal collar; (2) a spot on each posterolateral area; (3) a pair of spots on posterolateral area; (4) a pair of spots on median part; (5) without markings.

5. Poster margin of pronotal collar: (0) heterochromous, usually dark coloured; (1) concolorous.

6. Colouration of inner area and pronotal collar: (0) concolorous; (1) heterochromous.

7. Length of median part of pronotal collar: (0) less than one third as long as inner area of pronotum; (1) at least one third as long as inner area of pronotum.

8. Pair of large yellow tongue-shaped markings on lateral sigilla of mesonotum: (0) present; (1) absent.

9. Longitudinal fasciae along lateral margins of mesonotum: (0) present; (1) absent. 
10. Colouration of posterior angles of cruciform elevation: (0) yellow; (1) black.

11. Length of posterior angles of cruciform elevation: (0) shorter than anterior angles; (1) equal to anterior angles (2) slightly longer than anterior angles.

12. Black spot on the median of cruciform elevation: (0) large, at least half of the area of cruciform elevation; (1) small, lesser than half of the area of cruciform elevation; (2) absent. Wings

13. Infuscation on crossveins of fore wing: (0) absent; (1) on $r$ and r-m crossveins; (2) on r, r-m, m and m-cu crossveins; (3) on r, $\mathrm{r}-\mathrm{m}$ crossveins, base of apical cell $3, \mathrm{~m}$ and $\mathrm{m}$-cu crossveins; (4) on $r, r-m$ crossveins, base of apical cell 3 , base of apical cell $4, m$ and $\mathrm{m}$-cu crossveins; (5) zigzag infuscated band coincides with bases of apical cells, only broken at base of apical cell 6 .

14. A marginal series of fuscous spots near apices of longitudinal veins to apical cells: (0) present; (1) absent.

15. Black markings in basal cell of fore wing: (0) present; (1) absent.

16. Length of base of ulnar cell 2: (0) shorter than the length of base of ulnar cell 3; (1) as long as the length of base of ulnar cell 3 .

17. Length of base of apical cell 1 in fore wing: (0) as long as or longer than the length of base of apical cell 2; (1) shorter than the length of base of apical cell 2 .

18. Base of apical cell 4 in fore wing: (0) very long, twice length of r-m vein; (1) shorter than twice length of r-m vein.

\section{Abdomen}

19. Lateral length of tergite 4: (0) shorter than median length; (1) about equal to median length.

20. Colouration of timbal covers: (0) all black or with thin yellow lateral margins; (1) black with broad yellow lateral margin; (2) yellow or green.

21. Longitudinal series of white pollinosity spots sublaterally on abdomen: (0) present; (1) absent.

Only some individuals of Auritibicen flammatus from Mt. Qingling have a series of white pollinosity spots sublaterally on abdomen while others lack these spots. Thus A. flammatus is scored as lacking pollinosity spots.

22. Length of tergite 8: (0) as long as or shorter than tergites 6 and 7 combined; (1) distinctly longer than tergites 6 and 7 combined.

23. Length of sternite VIII: (0) as long as or longer than sternite VII; (1) shorter than sternite VII.

24. Colouration of sternites: (0) yellow or ochraceous; (1) black basally and ochraceous or red distally; (2) black mostly or just with thin yellow posterior margins.

25. Situation of overlap of the inner margins of male opercula: (0) separated; (1) inner margins contiguous but not overlapping; (2) inner margins overlapping.

26. Shape of male opercula: (0) angulated apically; (1) rounded apically; (2) truncated apically.

27. Length of male opercula: (0) not extending beyond posterior margins of abdominal sternite II; (1) extending beyond posterior margins of abdominal sternite II.

28. Colouration of male opercula: (0) mostly yellow or green; (1) mostly ochraceous.

\section{Male genitalia}

29. Colouration of uncal lobe: (0) mostly yellow; (1) mostly black; (2) mostly ochraceous; (3) heterochromous.

30. Shape of uncal lobe in ventral view: (0) rounded apically; (1) truncated apically.
31. Colouration of basal lobes of pygofer: (0) concolorous (yellow); (1) heterochromous (yellow, with apex fuscous); (2) heterochromous (yellow, with apex black).

32. Shape of basal lobes in ventral view: (0) erect; (1) curved outwardly; (2) curved inwardly.

33. Dorsal beak in lateral view: (0) lower than distal shoulders; (1) higher than distal shoulders; (2) undeveloped.

34. Shape of dorsal beak in lateral view: (0) pointed apically; (1) rounded apically.

\section{Morphological phylogenetic analysis}

The phylogenetic analysis was conducted using TNT 1.1 (Tree Analysis using New Technology; Goloboff et al., 2003, 2008) and the size of the dataset was sufficient for traditional searches with 1,000 replications. The branch support values were calculated with the function implemented in TNT (tree bisection and reconnection, TBR, from existing trees). Bootstrap replicates (Felsenstein, 1985) were used to assess support for the nodes with 1,000 replicates and $50 \%$ as the cut off value. Character states were mapped on the most parsimonious tree (MPT) using WinClada 1.0 (Nixon, 2002). The illustrated cladograms were edited using Adobe illustrator CS6.0.

\section{Molecular data}

DNA was extracted from leg muscles using Biospin Insect Genomic DNA Extraction Kit (Bioer Technology Co., Ltd, Hangzhou, China). The Cytochrome Oxidase I (COI) was amplified using the previously reported oligonucleotide primers (Simon et al., 1994; Sota et al., 2016). All polymerase chain reactions (PCR) were performed in $25 \mu \mathrm{l}$ reaction volumes with the following cycling protocol: an initial denaturation step of $3 \mathrm{~min}$ at $94^{\circ} \mathrm{C}$, followed by $20-60 \mathrm{~s}$ at $94^{\circ} \mathrm{C}, 35$ cycles of $1 \mathrm{~min}$ at $49-52^{\circ} \mathrm{C}, 1 \mathrm{~min}$ at $72^{\circ} \mathrm{C}$, ending with $7 \mathrm{~min}$ incubation at $72^{\circ} \mathrm{C}$. The PCR products were inspected using $1 \%$ agarose gel electrophoresis with ethidium-bromide staining. Sequencing was carried out using the same primers as used for amplification on both strands by Sangon Biotech (Shanghai) Co., Ltd. In total, the COI gene fragment of 11 species of Auritibicen and two outgroup species of Lyristes were sampled (see detailed taxa list in Table 2). Pairwise corrected genetic distances $(\mathrm{K} 2 \mathrm{P})$ of the $C O I$ gene for related species were calculated using MEGA version 6.05 (Tamura et al., 2013). New sequences were submitted to GenBank (Accession Nos: KY782334, KY782336-KY782339).

\section{ML analysis for molecular phylogeny}

ML analysis was conducted using RaxmlGUI 1.3 (Silvestro \& Michalak, 2012) and the appropriate models. The COI sequence was partitioned according to the three codon positions. We applied the substitution model GTR $+\mathrm{G}$ (general time reversible model with gamma distribution for rate heterogeneity) for each partition. We carried out RAPID ML analyses with 1,000 bootstrapping analysis to obtain ML trees and bootstrap percentages of nodes for $C O I$.

\section{Bayesian analysis for molecular phylogeny}

Separate analyses of DNA sequences and the concatenated dataset of both morphology and DNA were conducted using MrBayes 3.1.2 (Ronquist \& Huelsenbeck, 2003). The mixedmodel Bayesian analysis was run for 5 million generations, with model parameters unlinked and estimated independently across partitions. Two independent runs were performed, each with four chains (three heated and one cold), with uninformative priors and trees sampled at intervals of 100 generations. To determine stationarity, log-likelihood scores were plotted across generations and standard deviation of split frequencies between the two in- 


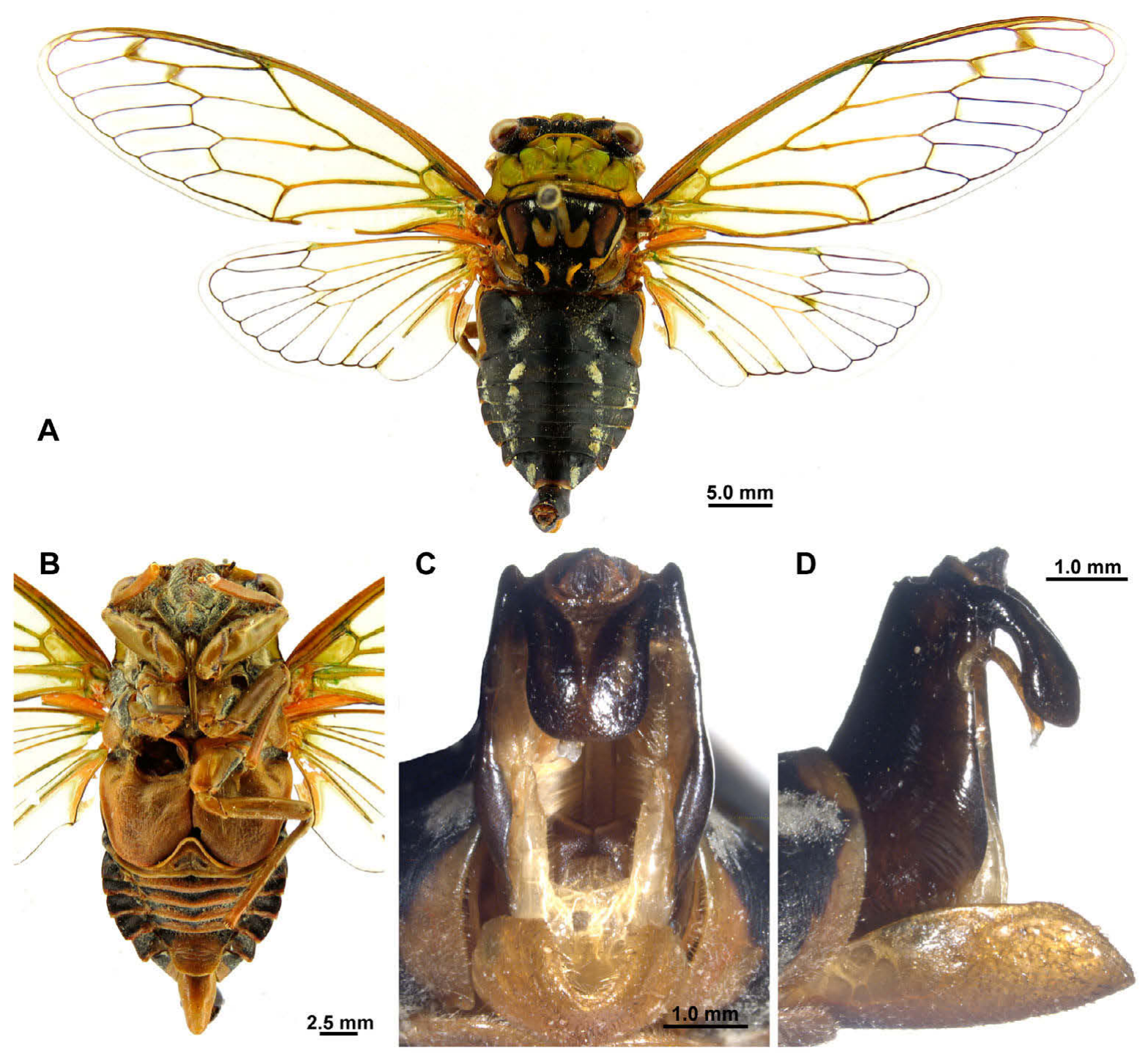

Fig. 1. Auritibicen atrofasciatus (male). A - habitus, dorsal view; B - head, thorax and abdomen, ventral view; C - male pygofer, ventral view; D - male pygofer, lateral view.

dependent runs were examined for convergence. Of the 50,000 trees sampled in each run, the first $25 \%$ of trees were discarded as burn-in, and the remaining trees were used to construct a $50 \%$ majority rule consensus tree. Posterior probability values (PP) are used as node support values. All tree topologies are displayed in Figtree 1.4 and rooted using outgroups.

\section{Estimates of divergence dates}

Estimates of the times of divergence were obtained using BEAST 1.8.0 (Drummond et al., 2012), the strict clock model and a speciation Yule process. We used a data set of 28 specimens (including two outgroup taxa) that contained $C O I$ gene sequences. Substitution model $($ GTR $+\mathrm{G})$ was the same as in the ML analysis. The clock rate of COI was set to 0.0177 (Papadopoulou et al., 2010). Default settings were used for other parameters and priors. Chains were run for 10 million generations, with sampling every 1000 generations. Tracer 1.6.0 was used to verify the posterior distribution and to ensure the effective size of samples (ESSs) $>200$ from the Markov Chain Monte Carlo (MCMC) output. TreeAnnotator in the BEAST package was used to summarize tree data with "mean height" and discarded the first $25 \%$ of trees as the "burn-in" period. The results are visualized in FigTree.

\section{RESULTS}

Taxonomy

Family Cicadidae Latreille, 1802

\section{Subfamily Cicadinae Latreille, 1802}

Tribe Cryptotympanini Handlirsch, 1925

\section{Genus Auritibicen Lee, 2015}

Auritibicen Lee, 2015: 241.

Type species. Tibicen intermedius Mori, 1931.

Diagnosis. Medium to large cicadas with robust bodies, black colouration with pale yellow to orange markings. Head including eyes slightly wider than base of mesonotum; distance between lateral ocellus and corresponding eye more than twice the distance between lateral ocelli. Pronotum distinctly longer than head, with lateral margin ampliated, not dentate; mesonotum black and/or castaneous, usually with central yellowish W-shaped marking. Male abdomen distinctly longer than head and thorax combined; epipleurites reflexed to ventral surface; abdominal segment II wider than head including eyes. Timbal covers 


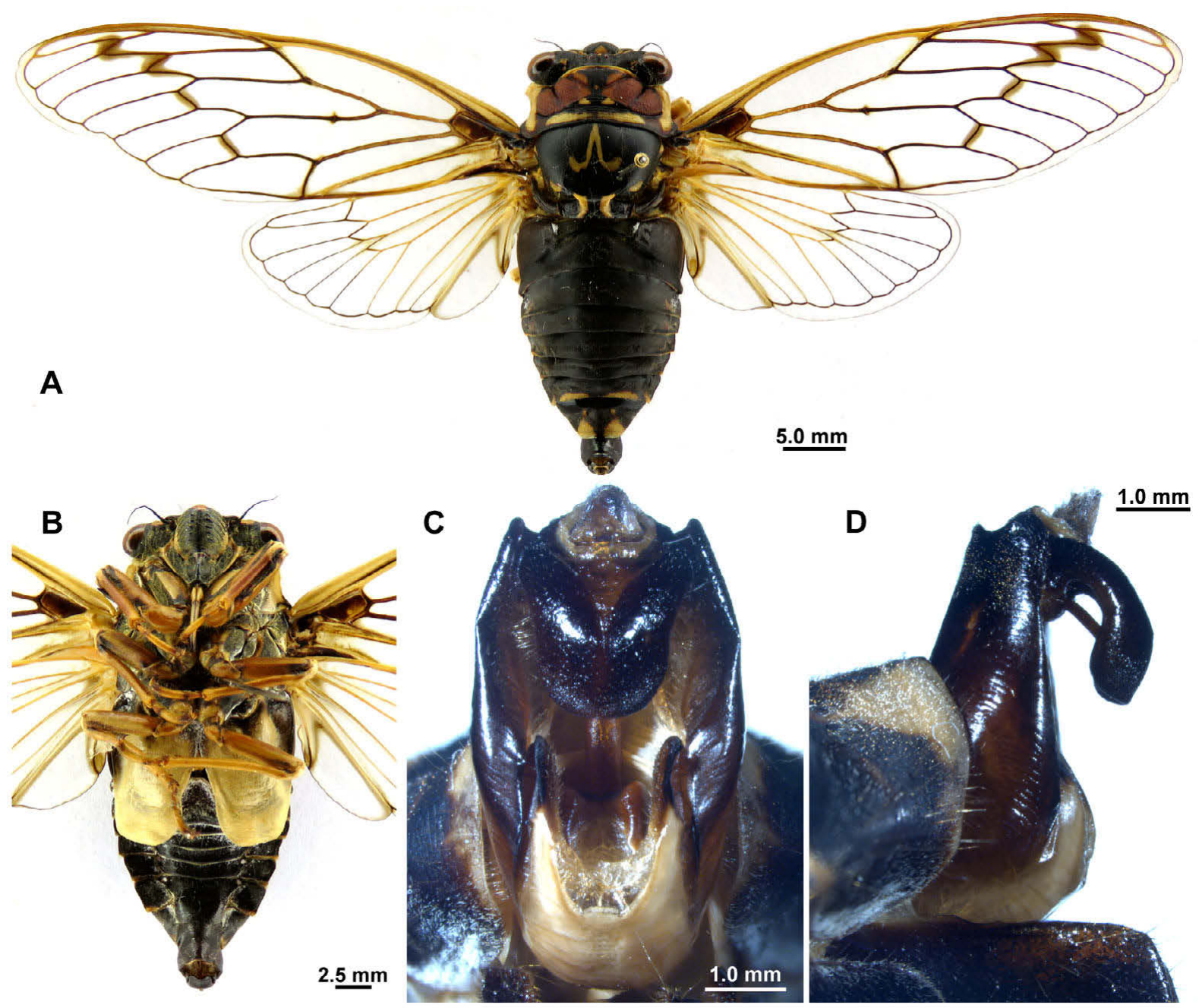

Fig. 2. Auritibicen bihamatus (male). A - habitus, dorsal view; B - head, thorax and abdomen, ventral view; C - male pygofer, ventral view; $\mathrm{D}$ - male pygofer, lateral view.

present, very slightly domed, completely covering timbal. Inner margins of male opercula separate, contiguous or overlapping. Wings hyaline, fore wing with 8 apical cells; ulnar cell 3 angled to radial cell; basal cell broad, tending to be rounded; vein $\mathrm{CuA}$ weakly bowed so that cubital cell no larger than medial cell; veins $\mathrm{M}$ and $\mathrm{CuA}$ widely separated in basal cell. Hind wings with 6 apical cells; no infuscation on ambient vein; width of $1^{\text {st }}$ cubital cell at distal end greater than $2^{\text {nd }}$ cubital cell; $2^{\text {nd }}$ cubital cell width at distal end less than $1^{\text {st }}$ anal cell; veins RP and $M$ fused basally. Pygofer barrel-shaped in ventral view; distal shoulders broad, rounded; basal lobes moderately developed, tight against pygofer margin in lateral view and apically rounded; upper pygofer lobes absent; dorsal beak present. Uncus large, about one-third the length of pygofer or more. Uncal lobes fused into one, not bifurcate, rounded or truncate apically; apical half curved inwardly in lateral view.

\section{Key to the species of Auritibicen (males)}

1 Inner margins of male opercula seperate.....

Inner margins of male opercula contiguous or overlapping. 5

2 Mesonotum with a pair of large tongue-shaped markings on lateral sigillae. A. septatus sp. $\mathrm{n}$.

- Mesonotum without markings on lateral sigillae ................... 3
3 Male opercula rounded apically A. slocumi Male opercula truncated apically............................................ 4

4 Male opercula extending beyond anterior margin of abdominal sternite $\mathrm{V}$................................................ aethus sp. n.

- Male opercula extending beyond anterior margin of abdominal sternite IV .................................................... A. bihamatus

5 Inner margins of male opercula contiguous........................... 6

- Inner margins of male opercula overlapping ......................... 8

6 Fore wing without infuscation.......................... A. purus sp. n. Fore wing with infuscation.................................................. 7

7 Lateral length of tergite 4 about equal to median length......... A. curvatus sp. $\mathrm{n}$.

- Lateral length of tergite 4 shorter than median length............. .. . gracilis sp. $\mathrm{n}$.

8 Male opercula comparatively long, extending beyond posterior margin of abdominal sternite II..................................... 9

- Male opercula comparatively short, not extending to posterior margin of abdominal sternite II...................................... 18

9 Length of base of apical cell 1 shorter than that of apical cell

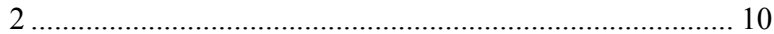

- Length of base of apical cell 1 as long as or longer than that of apical cell 2 .

10 Length of base of ulnar cell 2 as long as the length of base of ulnar cell 3 ............................................................ jai

- Length of base of ulnar cell 2 shorter than the length of base of ulnar cell 3 .. 

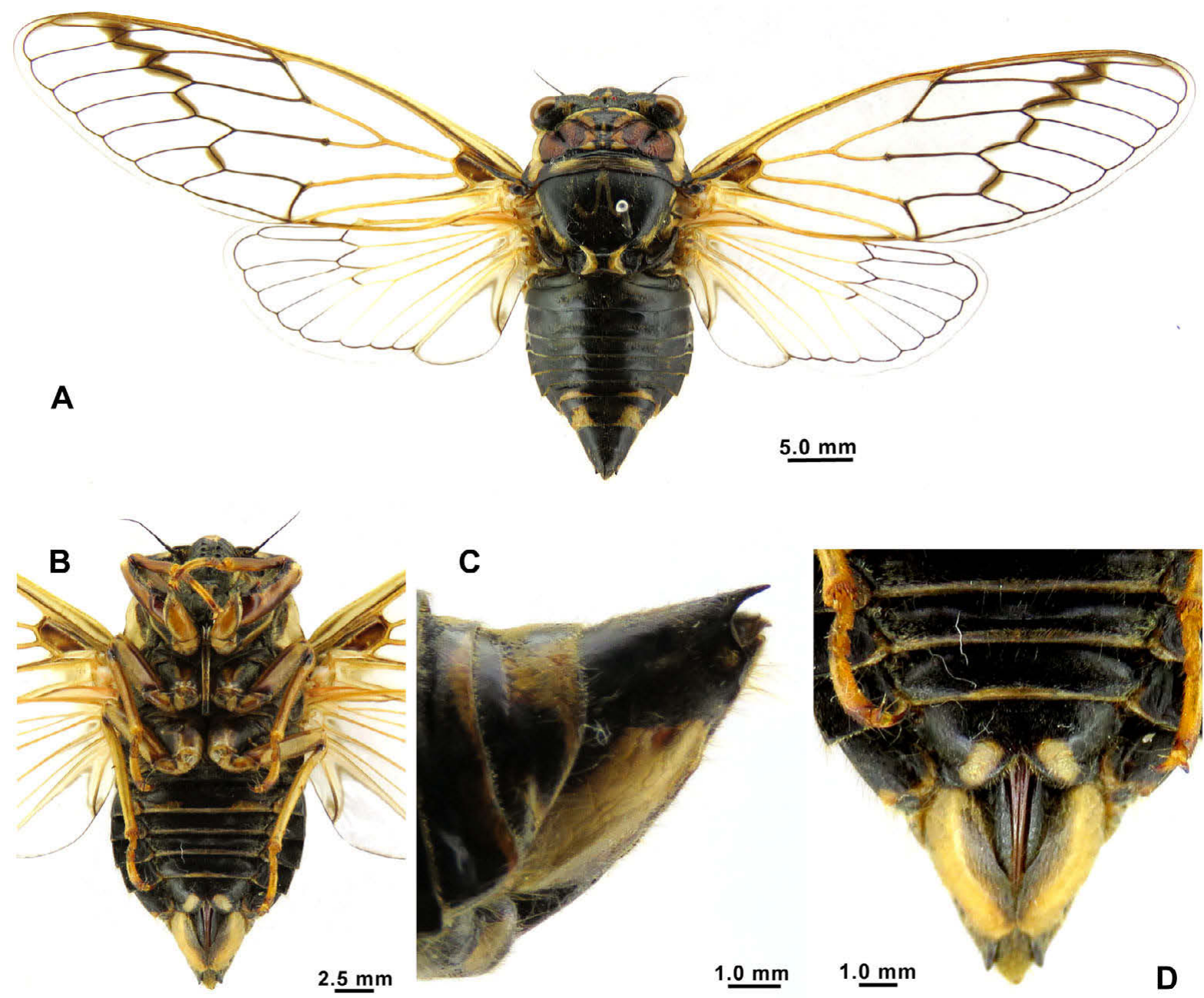

Fig. 3. Auritibicen bihamatus (female). A - habitus, dorsal view; B - head, thorax and abdomen, ventral view; C - female terminalia, lateral view; $\mathrm{D}$ - female terminalia, ventral view.

11 Pronotum without central longitudinal fascia... ...A. pallidus sp. $\mathrm{n}$.

- Pronotum with central longitudinal fascia.

12 Male opercula reaching posterior margin of abdominal sternite VI .................................................A. daoxianensis $\mathrm{sp} . \mathrm{n}$.

- Male opercula reaching posterior margin of abdominal sternite $\mathrm{V}$. A. leechi

13 Rostrum just reaching mid coxa.

... 14

- Rostrum reaching mid trochanter .... 17

14 Length of median part of pronotal collar less than one third as long as inner area of pronotum..... 15

- Length of median part of pronotal collar at least one third as long as inner area of pronotum 16

15 Dorsal beak in lateral view pointed apically ............. A. chujo

- Dorsal beak in lateral view rounded apically ............... esakii

16 Basal lobes erect in ventral view ........................ A. japonicus

- Basal lobes curved inwardly in ventral view. A. kyushyuensis

17 Inner area of pronotum yellow ..........................parvus sp. n. Inner area of pronotum reddish brown ......A. flavomarginatus

18 Fore wing with infuscation only on $\mathrm{r}$ and $\mathrm{r}-\mathrm{m}$ crossveins .. 19 Fore wing with infuscations other than those on $r$ and $r-m$ crossveins

.. 20

19 Mesonotum without markings on lateral sigillae A. lijiangensis sp. $\mathrm{n}$.

- Mesonotum with a pair of large tongue-shaped markings on lateral sigillae. A. rotundus sp. $\mathrm{n}$.
20 Wings richly tinged with yellow A. pekinensis

- Wings slightly tinged 21

21 Dorsal beak higher than distal shoulders in lateral view ........ A. flammatus

Dorsal beak lower than distal shoulders in lateral view .... 22

22 Male opercula angulated apically...... A. tsaopaonensis

- Male opercula rounded apically 23

23 Inner area and pronotal collar of pronotum concolourous; postclypeus scarcely prominent anteriad.......A. atrofasciatus

- Inner area and pronotal collar of pronotum heterochromous; postclypeus prominent anteriad A. intermedius

\section{Auritibicen atrofasciatus (Kirkaldy, 1909)}

Cicada sinensis Distant, 1890: 90 (nec Gmelin, 1789).

Tibicen sinensis: Kato, 1931: 65.

Lyristes sinensis: Schmidt, 1932: 119.

Talainga sinensis: Jacobi, 1944: 9.

Cicada atrofasciata Kirkaldy, 1909: 391 nom. nov. pro Cicada sinensis Distant, 1890.

Tibicen atrofasciatus: Metcalf, 1963: 240.

Lyristes atrofasciatus: Hua, 2000: 62.

Auritibicen atrofasciatus: Lee, 2015: 241.

Subsolanus atrofasciatus: Hill et al., 2015: 229.

Material examined. $1 \delta$ (BMNH), Type (in a red circle), Chian Kou Ho, 1700 ft, July (Leech); $1 \delta^{\lambda}$ (NWAFU), China: Bazhou District, Sichuan Province, 2400 m, 15.viii.1984; 1ठ (MNHN): 

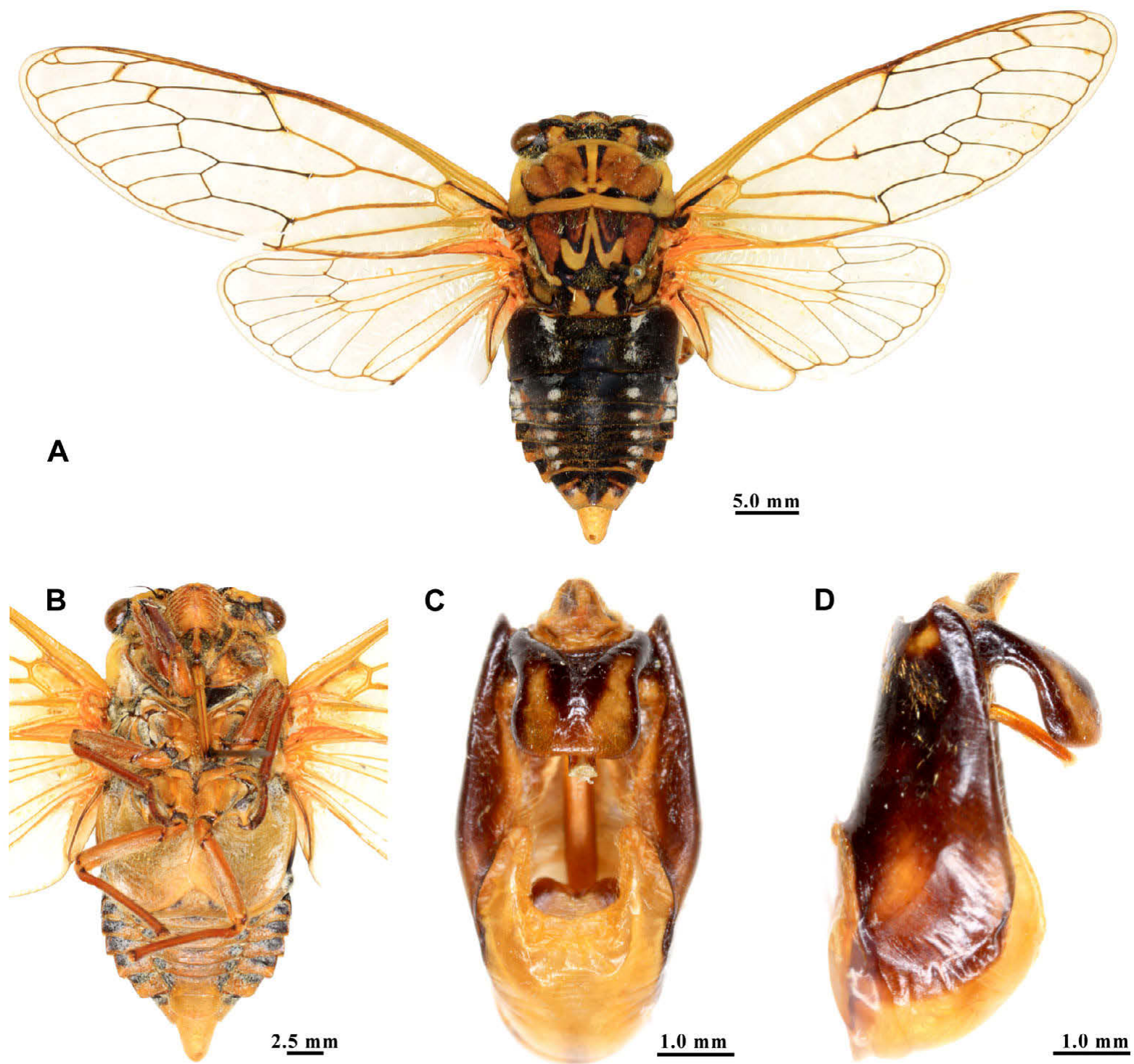

Fig. 4. Auritibicen chujoi (male). A - habitus, dorsal view; B - head, thorax and abdomen, ventral view; C - male pygofer, ventral view; $\mathrm{D}$ - male pygofer, lateral view.

Ta-tsien-Loû, Chasseurs Thibétains, 1896, Museum Paris; $4{ }^{\lambda}$, 1 우 (SNSD), China: Szetschwan, Omisien, Exp. Stötzner, 1923 3, A. Jacobi leg., Cicada sinensis Dist. det. Haupt; $1 \overbrace{}^{\Uparrow}$ (MFNB), China: Omi-shan, Westchina, Kricheldorff S., Cicada sinensis Dist.; $1 \delta^{\lambda}$ (NWAFU), China: Mt. Zhougong, Ya'an City, Sichuan Province, 650 m, 27.vii.2009, Huo Weixin leg.

Measurements. $(2 \precsim)$. Body length: 28.6-30.3; fore wing length: $34.5-36.9$; fore wing width: 12.0-12.5; width of head including eyes: 10.3-11.1; pronotum width (including pronotal collar): 10.8-11.3; mesonotum width: 8.0-8.2; expanse of fore wings: 75.4-80.5.

Description of male. Head (Fig. 1A, B). Black, with a pair of yellowish rectangular spots on posterolateral angles of vertex. Eyes fuscous; ocelli red. Supra-antennal plates yellow. Postclypeus moderately swollen and ochraceous. Transverse grooves black with yellow hairs. Lora black with yellow margins. Rostrum yellow with apical part black, just reaching mid coxae.
Thorax (Fig. 1A). Inner area of pronotum green, with pairs of small irregular black spots. Anterior margin of inner area yellow. Pronotal collar yellow to green, with a large brown spot on each posterolateral area. Posterior margin of pronotal collar black. Mesonotum black, with the following yellow markings: a broad, continuous Wshaped marking in front of cruciform elevation; a pair of large tongue-shaped markings on lateral sigilla; longitudinal fasciae along lateral margins. Cruciform elevation yellow with a large black spot medially.

Wings (Fig. 1A). Hyaline. Fore wing with distinct infuscation on $\mathrm{r}, \mathrm{r}-\mathrm{m}$ crossveins, $\mathrm{m}$ and $\mathrm{m}$-cu crossveins and those along the latter two much weaker; base of ulnar cell 2 as long as base of ulnar cell 3; base of apical cell 1 shorter than base of apical cell 2. Hind wing without infuscation. Basal half of wing veins yellow.

Abdomen (Fig. 1A, B). Cylindrical. Tergites black, with longitudinal series of white pollinosity spots sublaterally 

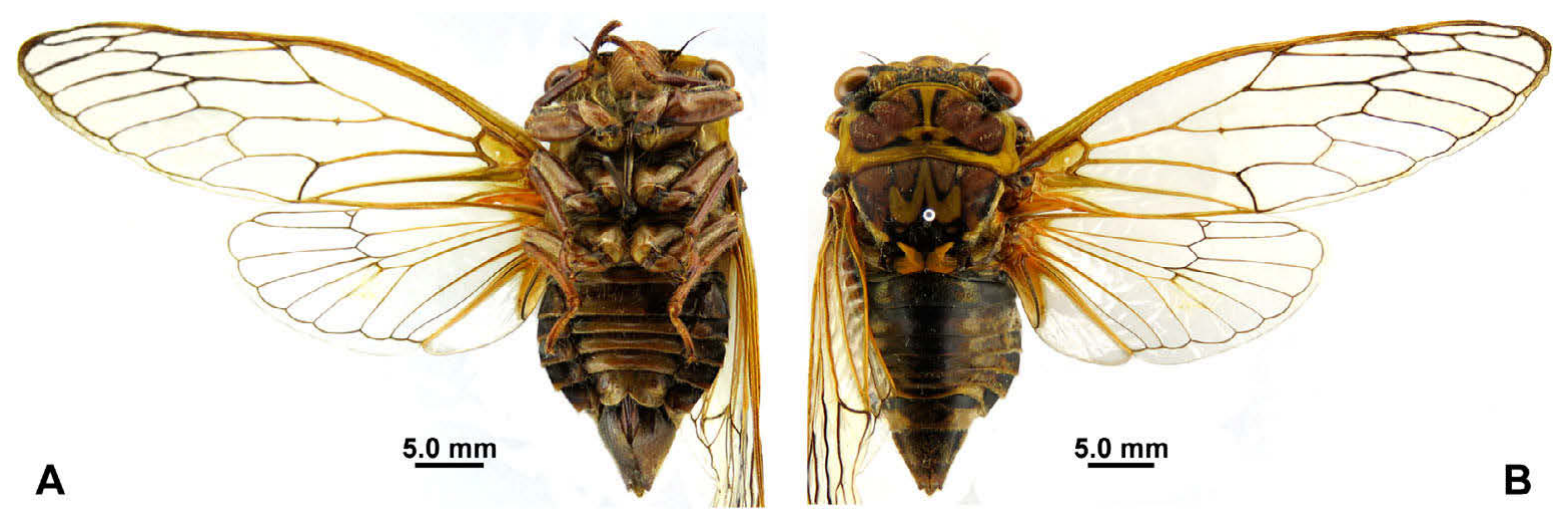

Fig. 5. Auritibicen chujoi (female). A - habitus, ventral view; B - habitus, dorsal view.

on each tergite; lateral length of tergite 4 shorter than median length; tergite 8 as long as tergites 6 and 7 combined. Abdominal sternites black basally and red distally; epipleurites black with yellow posterior margins; sternite VIII longer than VII. Timbal covers black with yellow lateral margins. Opercula yellow, in most cases with inner margins overlapping, rounded apically, and not extending beyond posterior margin of abdominal sternite II.

Male genitalia (Figs 1C, D, 37A, 38A). Pygofer barrelshaped. Basal lobes of pygofer yellow and erect in ventral view. Uncal lobe ochraceous to black and truncated apically.

Female. Unknown.

Distribution. China (Sichuan, Yunnan, Fujian, Tibet).

Remarks. This species is similar to $A$. chujoi in length of opercula and markings on mesonotum, but can be distinguished by its smaller body size, colour of pronotum and white pollinosity spots sublaterally on each tergite. Inner margins of the male opercula of $A$. atrofasciatus overlap in most cases, but in some individuals are just contiguous.

\section{Auritibicen bihamatus (Motschulsky, 1861)}

Cicada bihamata Motschulsky, 1861: 24.

Lyristes bihamata: Schmidt, 1932: 122.

Tibicen bihamatus var. harutai Kato, 1939: 8.

Tibicen bihamatus var. tsuguonis Kato, 1940: 2.

Lyristes bihamatus: Hayashi \& Saisho, 2015: 57.

Auritibicen bihamatus: Lee, 2015: 241.

Subsolanus bihamatus: Hill et al., 2015: 229.

Cicada andrewsi Distant, 1904: 330.

Cicada nagashimai Kato, 1925: 7.

Material examined. $1 \curvearrowright, 1 \uparrow(\mathrm{NWAFU})$, Japan: Koshikirizuka, Susono, Shizuka, Kuyushu, 1450 m, 1.viii.2000, M. Hayashi leg.; $1{ }^{\lambda}$ (NWAFU), Japan: Yawata, Nasu, Tochigi, $1330 \mathrm{~m}$, 6.viii.1975, M. Hayashi leg.

Measurements. $(2 \hat{\jmath}, 1$ ㅇ). Body length: male 35.4-36.2, female 31.5; fore wing length: male 43.0-43.4, female 42.8; fore wing width: male 14.2-14.5, female 14.1 ; width of head including eyes: male 12.0-12.6, female 12.1; pronotum width (including pronotal collar): male 13.1-13.2, female 13.3; mesonotum width: male 10.4-11.3, female 10.3; expanse of fore wings: male 96.1, female 94.8 .

Description of male. Head (Fig. 2A, B). Black, with a pair of small yellowish rounded spots on posterolateral angles of vertex. Eyes fuscous; ocelli red. Supra-antennal plates yellow. Postclypeus moderately swollen and ochraceous. Transverse grooves black with yellow pollinosity. Lora black with yellow margins. Rostrum yellow with apical part black, extending to the anterior margin of mid coxae.

Thorax (Fig. 2A). Inner area of pronotum reddish brown, with central longitudinal funnel shaped markings black. A pair of yellow triangular spots near posterior margin of inner area. Anterior margin of inner area yellow. Pronotal collar broad and yellow, with a large brown spot on each posterolateral area. Posterior margin of pronotal collar black. Mesonotum black, with the following yellow markings: a thin, continuous W-shaped marking in front of cruciform elevation; intermittent yellow spots along lateral margins. Cruciform elevation yellow with a large black spot medially.

Wings (Fig. 2A). Hyaline. Fore wing with distinct infuscation on $\mathrm{r}, \mathrm{r}-\mathrm{m}$ crossveins, base of apical cell 3 , base of apical cell 4, $\mathrm{m}$ and m-cu crossveins; base of ulnar cell 2 as long as base of ulnar cell 3; length of base of apical cell 1 as long as base of apical cell 2 . Hind wing without infuscation. Basal half of wing veins fuscous.

Abdomen (Fig. 2A, B). Cylindrical. Tergites black, with yellow markings on tergites 7-8; lateral length of tergite 4 shorter than median length; tergite 8 shorter than tergites 6 and 7 combined. Abdominal sternites and epipleurites opaque, black with posterior margins yellow; sternite VIII as long as VII. Timbal covers black. Opercula yellow, seperated from base, truncated apically, and extending beyond posterior margin of abdominal sternite III.

Male genitalia (Figs 2C, D, 37B, 38B). Pygofer barrelshaped. Basal lobes of pygofer yellow with apex black and curved outwardly in ventral view. Uncal lobe mostly black and rounded apically.

Female (Fig. 3). Opercula small, posterior margin not reaching abdominal sternite II. Abdominal segment 9 black in dorsal view and yellow in ventral view; ovipositor sheath black, not protruding beyond segment 9, posterior margin of abdominal sternite VII incised at middle with a pair of yellow spots medially. Other characteristics similar to male.

Distribution. Japan, Russia.

Remarks. This species varies greatly, including in body colour and W-shaped marking on mesonotum, which is 


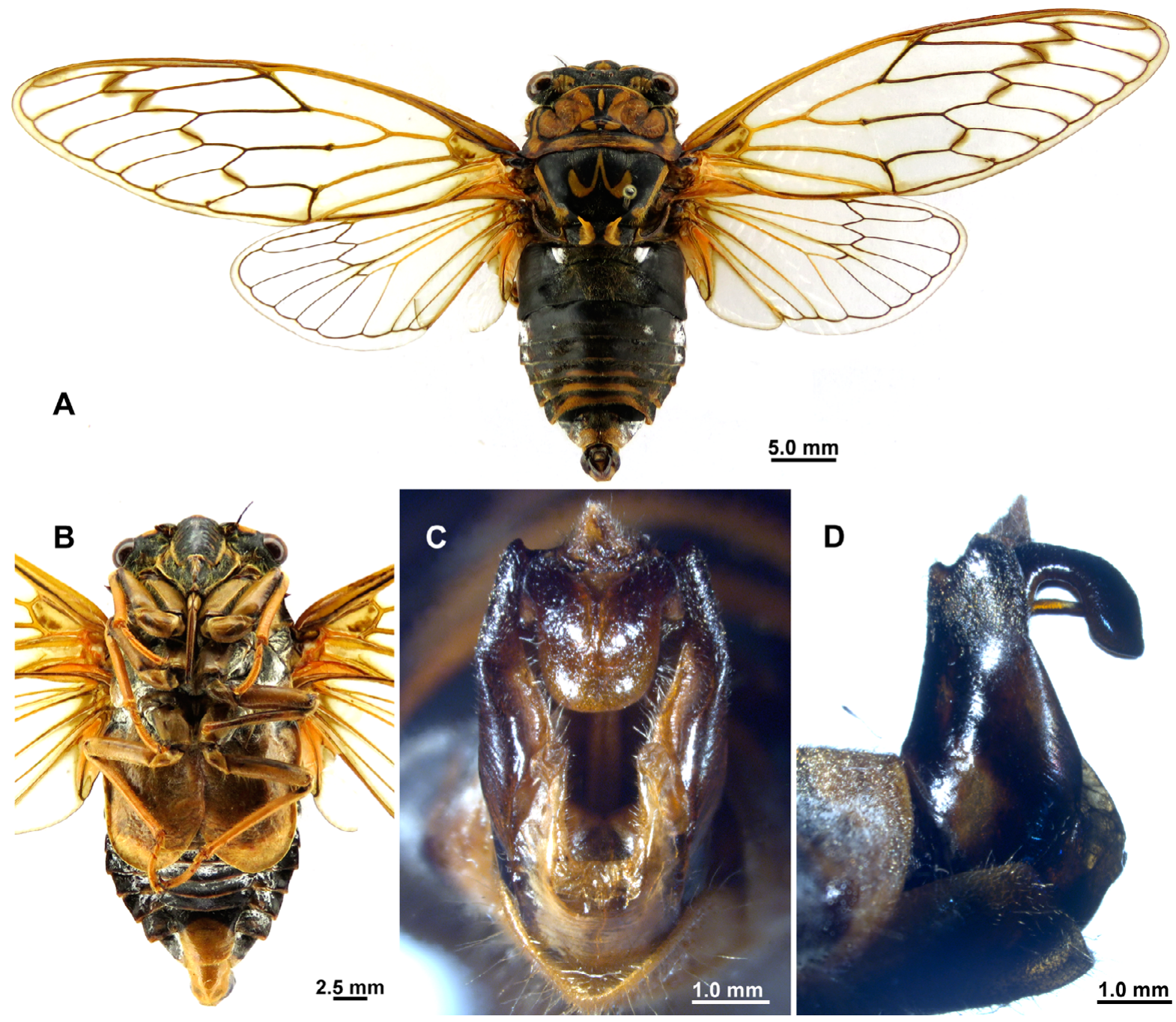

Fig. 6. Auritibicen esakii (male). A - habitus, dorsal view; B - head, thorax and abdomen, ventral view; C - male pygofer, ventral view; $\mathrm{D}$ - male pygofer, lateral view.

recorded by Hayashi \& Saisho (2015) based on material collected in Japan.

\section{Auritibicen chujoi (Esaki, 1935)}

Tibicen chujoi Esaki, 1935: 201.

Lyristes chujoi: Matsumura, 1939: 48.

Auritibicen chujoi: Lee, 2015: 241.

Subsolanus chujoi: Hill et al., 2015: 229.

Tibicen atrofasciatus Okada, 2000: 18 (nec Kirkaldy, 1909).

Material examined. Holotype $\widehat{\delta}$ (ELKU): China: Mt Alishan, Taichung, Taiwan Province, 23.v.1934, Michio Chujo leg.; 1ठ, $1 q$ (TUA), China: Fushoushan, Lishan, Taichung, Taiwan, 18 viii.1998, M. Okada leg.

Measurements. $(2 \hat{\jmath}, 1$ 으. Body length: male 34.3-34.4, female 32.6; fore wing length: male 41.0-43.0, female 40.6; fore wing width: male 12.8-14.6, female 13.2; width of head including eyes: male 12.8-13.2, female 13.9; pronotum width (including pronotal collar): male 13.0-13.8, female 14.0; mesonotum width: male 10.4-10.9, female 11.6; expanse of fore wings: male 89.3-92.8, female 93.0.

Description of male. Head (Fig. 4A, B). Black, with a pair of yellowish rectangular spots on posterolateral an- gles of vertex. Eyes fuscous; ocelli red. Supra-antennal plates yellow. Postclypeus moderately swollen and yellow. Transverse grooves reddish brown. Lora black with yellow margins. Rostrum yellow with apical part black, extending to the anterior margin of mid coxae.

Thorax (Fig. 4A). Inner area of pronotum ochraceous; central longitudinal yellow funnel shaped markings with black margins. Posterior margin of inner area black. Anterior margin of inner area yellow. Pronotal collar broad and yellow, with posterior margin black. Mesonotum black, with the following yellow markings: a distinct, continuous W-shaped marking in front of cruciform elevation; a pair of large tongue-shaped markings on lateral sigilla; longitudinal fasciae along lateral margins. Cruciform elevation yellow with a small black spot medially.

Wings (Fig. 4A). Hyaline. Fore wing with faint infuscation on $\mathrm{r}, \mathrm{r}-\mathrm{m}$ crossveins, base of apical cell 3 , base of apical cell 4, m and m-cu crossveins; base of ulnar cell 2 shorter than base of ulnar cell 3; base of apical cell 1 shorter than base of apical cell 2 . Hind wing without infuscation. Basal half of wing veins yellow. 


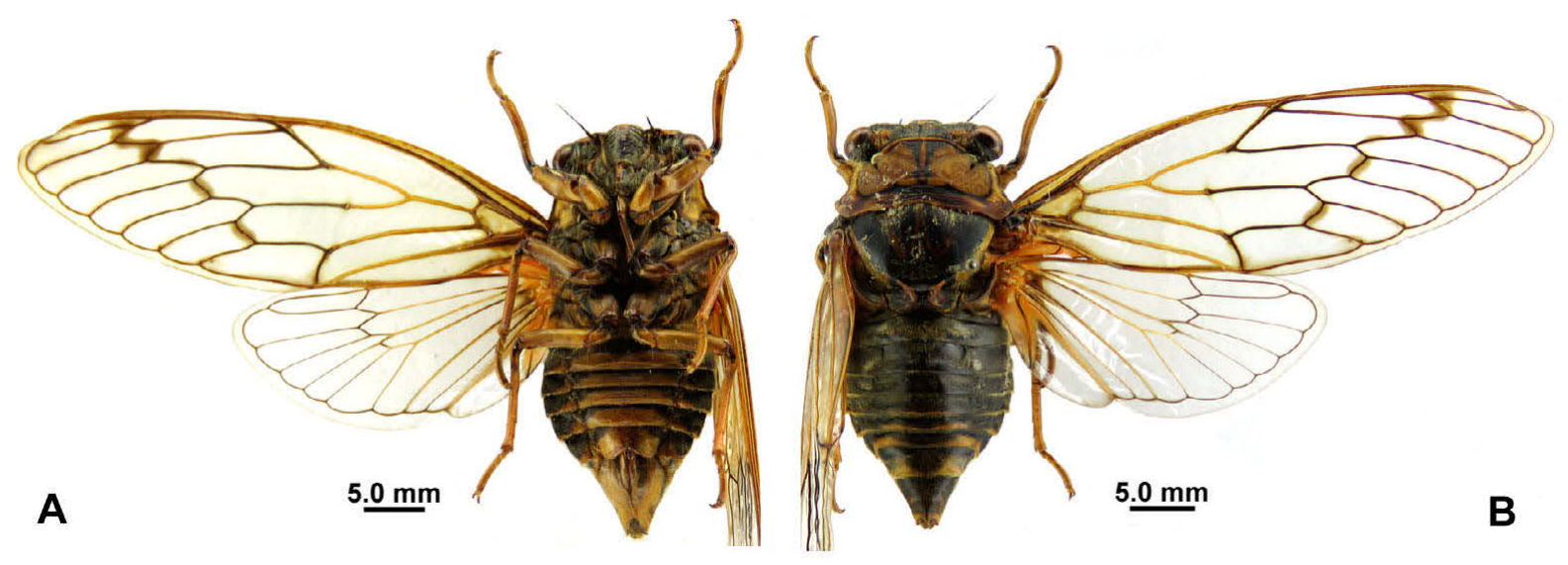

Fig. 7. Auritibicen esakii (female). A - habitus, ventral view; B - habitus, dorsal view.

Abdomen (Fig. 4A, B). Cylindrical. Tergites black, with white pollinosity spots sublaterally on each tergite; tergites 3-8 with yellow markings sublaterally; lateral length of tergite 4 shorter than median length; tergite 8 about as long as tergites 6 and 7 combined. Abdominal sternites opaque, mostly yellow; sternite VIII as long as sternite VII; epipleurites black with yellow posterior margins. Timbal covers black with lateral margins yellow. Opercula yellow, inner margins overlapping, rounded apically, and not extending beyond posterior margin of abdominal sternite II.

Male genitalia (Figs 4C, D, 37C, 38C). Pygofer barrelshaped. Basal lobes of pygofer yellow and erect in ventral view. Uncal lobe widened behind and rounded apically, the apical half curved inwardly at about $120^{\circ}$.

Female (Fig. 5). Opercula small, posterior margin not reaching abdominal sternite II. Abdominal segment 9 black with yellow patches; ovipositor sheath not protruding beyond segment 9 , posterior margin of abdominal sternite VII incised at middle. Other characteristics similar to male.

Distribution. China (Taiwan).

\section{Auritibicen esakii (Kato, 1958)}

Tibicen esakii Kato, 1958: 247.

Lyristes esakii: Hayashi \& Saisho, 2015: 68.

Auritibicen esakii: Lee, 2015: 241.

Subsolanus esakii: Hill et al., 2015: 229.

Cicada bihamata Ishihara, 1968: 134 (nec Motschulsky, 1861).

Material examined. $1 \hat{\partial}$ (NWAFU), Japan: Hananoego, Yakushima, 28.vii.1974, M. Hayashi leg.; 19 (TUA), same locality except 25.vii.1974, S. Shinonaga leg.

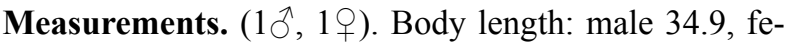
male 34.2 ; fore wing length: male 42.1 , female 46.3 ; fore wing width: male 14.2 , female 13.7 ; width of head including eyes: male 12.6, female 13.2; pronotum width (including pronotal collar): male 13.4 , female 14.3 ; mesonotum width: male 11.1, female 11.9; expanse of fore wings: male 97.3.

Description of male. Head (Fig. 6A, B). Black, with a pair of yellowish rectangular spots on posterolateral angles of vertex. Eyes fuscous; ocelli red. Supra-antennal plates yellow. Postclypeus black with a yellow rounded spot on the middle part in dorsal view. Transverse grooves black with yellow pollinosity. Lora black with yellow margins.
Rostrum yellow with apical part black, just reaching mid coxae.

Thorax (Fig. 6A). Inner area of pronotum ochraceous, with three rounded yellow spots surrounded by broad black margins. Anterior margin of inner area yellow; lateral and posterior margin black. Pronotal collar ochraceous to black, with two large brown spots on each posterolateral area. Mesonotum black, with the following yellow markings: a thin, continuous $\mathrm{W}$-shaped marking in front of cruciform elevation; longitudinal fasciae along lateral margins. Cruciform elevation yellow with a large black spot medially.

Wings (Fig. 6A). Hyaline. Fore wing with distinct infuscation on r, r-m crossveins, base of apical cell 3 , base of apical cell $4, \mathrm{~m}$ and $\mathrm{m}$-cu crossveins; base of ulnar cell 2 as long as base of ulnar cell 3; base of apical cell 1 as long as base of apical cell 2. Hind wing without infuscation. Basal half of wing veins yellow.

Abdomen (Fig. 6A, B). Cylindrical. Tergites black, with series of white pollinosity spots sublaterally on each tergite; tergites 5-8 with yellow markings; lateral length of tergite 4 as long as median length; tergite 8 longer than tergites 6 and 7 combined. Abdominal sternites and epipleurites black with yellow posterior margins; sternite VIII shorter than sternite VII. Timbal covers black with yellow lateral margins. Opercula yellow, with overlapping inner margins, rounded apically, and extending beyond posterior margin of abdominal sternite III.

Male genitalia (Figs 6C, D, 37D, 38D). Pygofer barrelshaped. Basal lobes of pygofer yellow and curved inwardly in ventral view. Uncal lobe ochraceous and truncated apically.

Female (Fig. 7). Opercula small, posterior margin not reaching abdominal sternite II. Abdominal segment 9 black with yellow patches in dorsal view and yellow in ventral view; ovipositor sheath not protruding beyond segment 9 , posterior margin of abdominal sternite VII incised at middle. Other characteristics similar to male.

Distribution. Japan (endemic to Yakushima Is. south of Kyushu).

Remarks. This species varies greatly, including the markings on pronotum and $\mathrm{W}$-shaped marking on mesonotum, which is recorded by Hayashi \& Saisho (2015). 


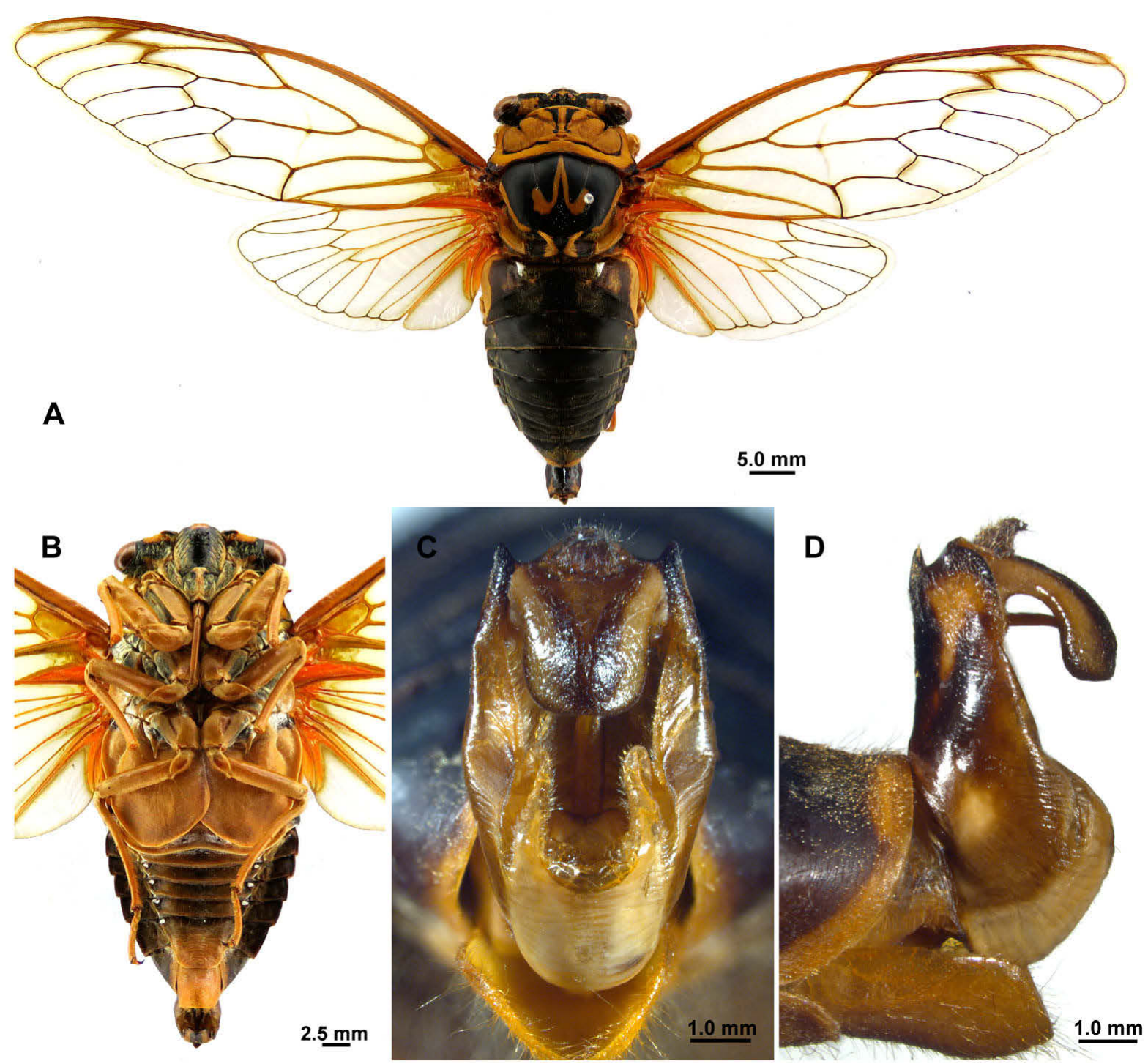

Fig. 8. Auritibicen flammatus (male). A - habitus, dorsal view; B - head, thorax and abdomen, ventral view; C - male pygofer, ventral view; $\mathrm{D}$ - male pygofer, lateral view.

\section{Auritibicen flammatus (Distant, 1892)}

Cicada flammata Distant, 1892: 99.

Lyristes flammata: Schmidt, 1932: 118.

Tibicen flammatus Kato, 1933a: 32.

Lyristes flammatus: Hayashi \& Saisho, 2015: 72.

Auritibicen flammatus: Lee, 2015: 241.

Subsolanus flammatus: Hill et al., 2015: 229.

Cicada pyroga Matsumura, 1904: 53.

Material examined. 1 ㅇ (NWAFU), China: Mt. Taibai, Shaanxi Province, 20.viii.1951; 1 (NWAFU), same data except 9.viii.1955; 1 ( (NWAFU), Japan: Mt. Tsukuba, Ibaraki Pref., Honshu, 19.viii.1976, M. Hayashi leg.; 1 ㅇ (NWAFU), China: Mt. Taibai, Shaanxi Province, 24.vii.1986; $1 \widehat{\jmath}$ (NWAFU), China: Mt. Taibai, Shaanxi Province, 18.ix.1982; $1 \jmath^{\lambda}$ (NWAFU), Japan: Irikawa Valley (700-750 m), Okuchichibu Mts, Satitama Pref., Honshu, 12.viii.1982; 10^, 4ㅇ (NWAFU), China: Shennongjia, Hubei Province, $1200 \mathrm{~m}, 11 .-13 . v i i i .2004 ; 1 \hat{\jmath}, 1$ 우 (NWAFU), China: Huoditang Experimental Forest Station of the Northwest A\&F University, Ningshan County, Shaanxi Province, $1650 \mathrm{~m}$, 5.-6.viii.2008, Wei Cong leg.

Measurements. $(13 \hat{\partial}, 9 \bigcirc)$. Body length: male 39.241.3, female 37.6-38.6; fore wing length: male 49.7-52.0, female 50.4-50.9; fore wing width: male 16.6-17.4, female 15.5-16.6; width of head including eyes: male 14.1-14.7, female 13.7-14.4; pronotum width (including pronotal collar): male 14.7-16.0, female 14.7-15.7; mesonotum width: male 11.8-12.7, female 12.1-12.5; expanse of fore wings: male 110.0-117.8, female 114.0-116.8.

Description of male. Head (Fig. 8A, B). Black, with a pair of yellowish rectangular spots on posterolateral angles of vertex. Eyes fuscous; ocelli red. Supra-antennal plates yellow. Postclypeus black with a yellow rounded spot on the middle part in dorsal view. Transverse grooves black with yellow pollinosity. Lora black with yellow margins. Rostrum yellow with apical part ochraceous, just reaching mid coxae.

Thorax (Figs 8A, 9). Inner area of pronotum orange or rarely green, with a pair of black longitudinal fascia medially. Anterior margin of inner area yellow or green; lateral and posterior margins black. Pronotal collar yellow or green, with a black spot on each posterolateral area. Mesonotum black, with the following yellow markings: a thin, continuous $\mathrm{W}$-shaped marking in front of cruciform eleva- 

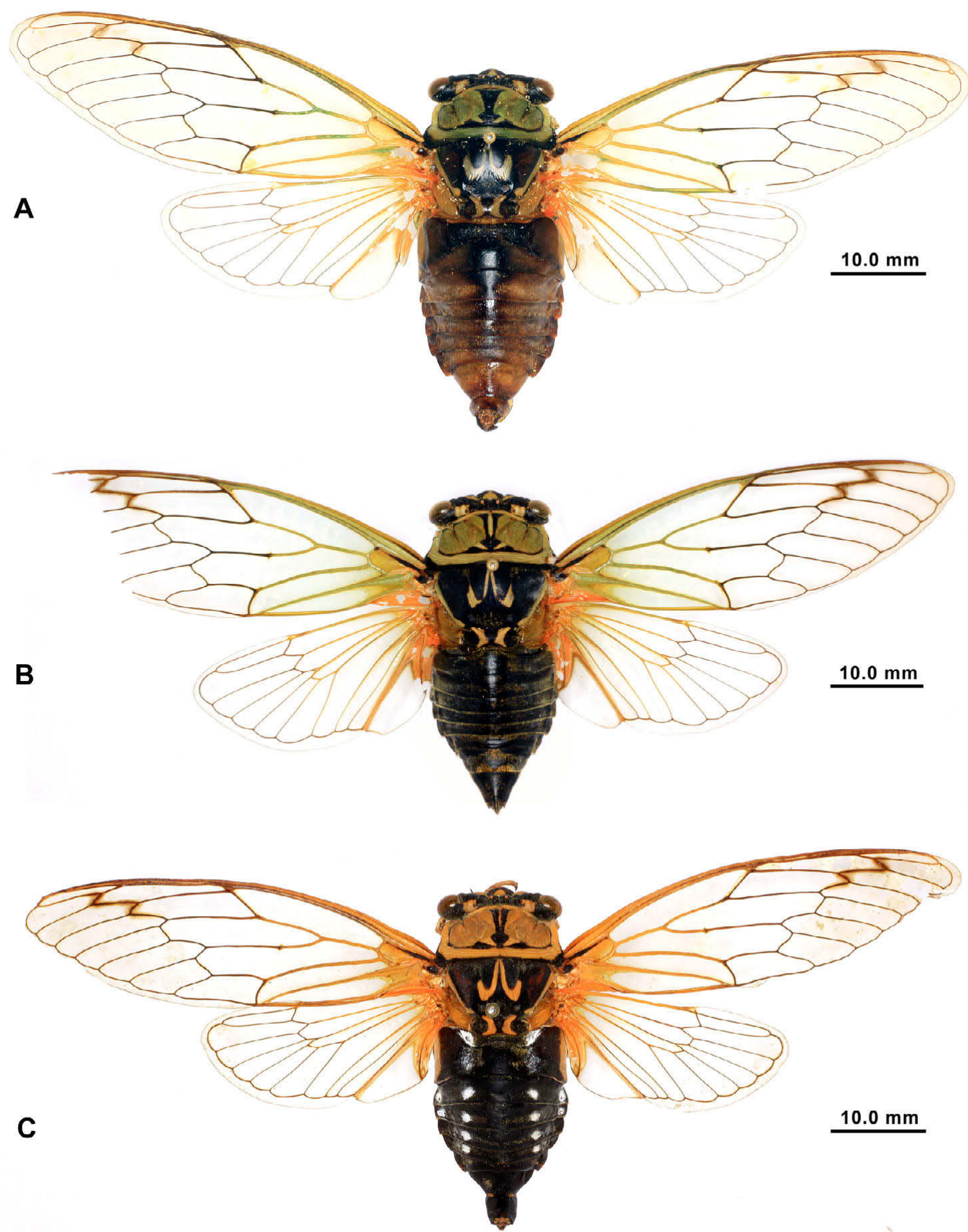

Fig. 9. Auritibicen flammatus (males). Habitus, dorsal view, showing different colour-types. A \& B - material from Huoditang Experimental Forest Station of the Northwest A\&F University, Ningshan County, Shaanxi Province; C - material from Mt. Taibai, Shaanxi Province.

tion; longitudinal fasciae along lateral margins. Cruciform elevation yellow with a black spot medially.

Wings (Figs 8A, 9). Hyaline. Fore wing with infuscation on $\mathrm{r}, \mathrm{r}-\mathrm{m}$ crossveins, base of apical cell 3 , base of apical cell $4, \mathrm{~m}$ and $\mathrm{m}$-cu crossveins and those along the latter three much weaker; base of ulnar cell 2 shorter than base of ulnar cell 3; base of apical cell 1 longer than base of apical cell 2; base of apical cell 4 twice length of r-m vein. Veins on fore wing green or orange to node then becoming ochraceous distally. Hind wing without infuscation. Basal half of wing veins yellow.

Abdomen (Figs 8A, B, 9). Cylindrical. Tergites ochraceous or entirely black (some individuals from Mt. Qingling with series of small white pollinosity spots sublaterally on each tergite); lateral length of tergite 4 shorter than median length; tergite 8 as long as tergites 6 and 7 combined. Abdominal sternites ochraceous; sternite VIII shorter than sternite VII; epipleurites fuscous with ochra- 

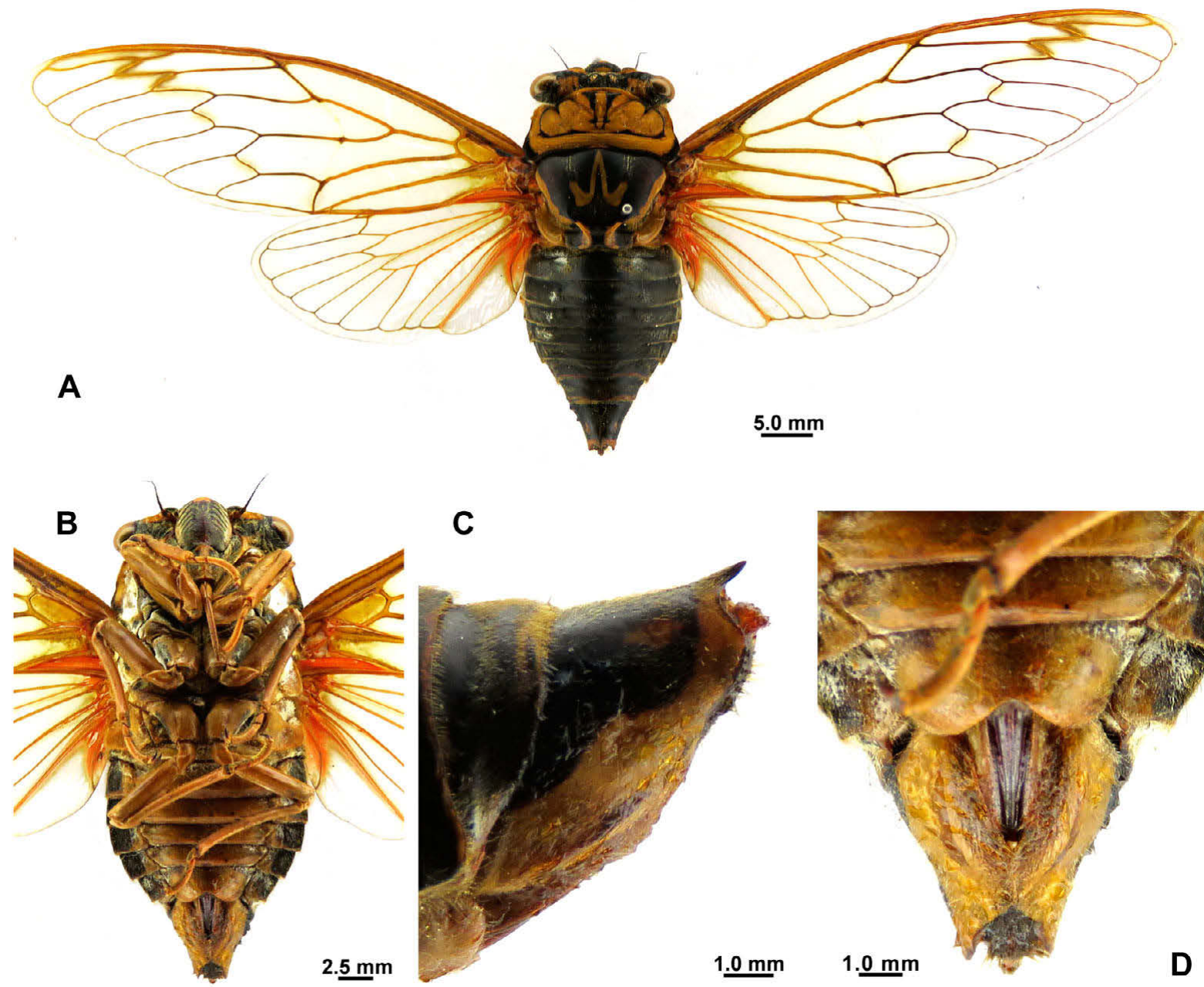

Fig. 10. Auritibicen flammatus (female). A - habitus, dorsal view; B - head, thorax and abdomen, ventral view; C - female terminalia, lateral view; $\mathrm{D}$ - female terminalia, ventral view.

ceous posterior margins. Timbal covers variegated with yellow lateral margins. Opercula yellow, with overlapping inner margins, rounded apically, and not extending beyond posterior margin of abdominal sternite II.

Male genitalia (Figs 8C, D, 37E, 38E). Pygofer barrelshaped. Basal lobes of pygofer yellow and curved inwardly in ventral view. Uncal lobe ochraceous with fuscous paramedian ridges and apex truncated.

Female (Fig. 10). Opercula small, posterior margin not reaching abdominal sternite II. Abdominal segment 9 black in dorsal view and yellow in ventral view; ovipositor sheath black, not protruding beyond segment 9, posterior margin of abdominal sternite VII incised at middle with a pair of yellow spots medially. Other characteristics similar to male.

Distribution. China (Hubei, Sichuan, Shaanxi); Japan, Korea.

Remarks. Liu (1940) decribes specimens collected from Mt. Lushan, Kiangsi (Jiangxi Province) as this species. However, as shown in the figure of Liu (1940), it is not identical to the true A. flammatus because of the different W-shaped markings, and the series of white powdery spots sublaterally on the abdomen, etc. Two types of in- traspecific variation mainly on the thorax and wings of $A$. flammatus are recorded: (1) green-coloured type (limited to specimens from China): inner area of pronotum green and veins of fore wing green to node (Fig. 9A, B); (2) orange-coloured type (normal type): inner area of pronotum orange and veins of fore wing orange to node (Figs 8, 9C). In a few orange-coloured forms, there are a series of white pubescent spots on the 3rd-6th abdominal tergites (Fig. 9C).

\section{Auritibicen flavomarginatus (M. Hayashi, 1977)}

Tibicen flavomarginatus Hayashi, 1977a: 185.

Auritibicen flavomarginatus: Lee, 2015: 241.

Subsolanus flavomarginatus: Hill et al., 2015: 229.

Material examined. Holotype $\hat{\sigma}$ (ELKU): Formosa, Taihokushu (Taipei Co.), 7.viii.1935, Shinichi Ueno.

Measurements. $\left(1 \delta^{\Uparrow}\right)$. Body length: 35.3 ; fore wing length: 40.9; fore wing width: 13.3; width of head including eyes: 13.2; pronotum width (including pronotal collar):13.5; mesonotum width: 10.7; expanse of fore wings: 93.8 .

Description of male. Head (Fig. 11A, B). Black, including tip of frontoclypeus; a pair of yellowish spots on pos- 
A

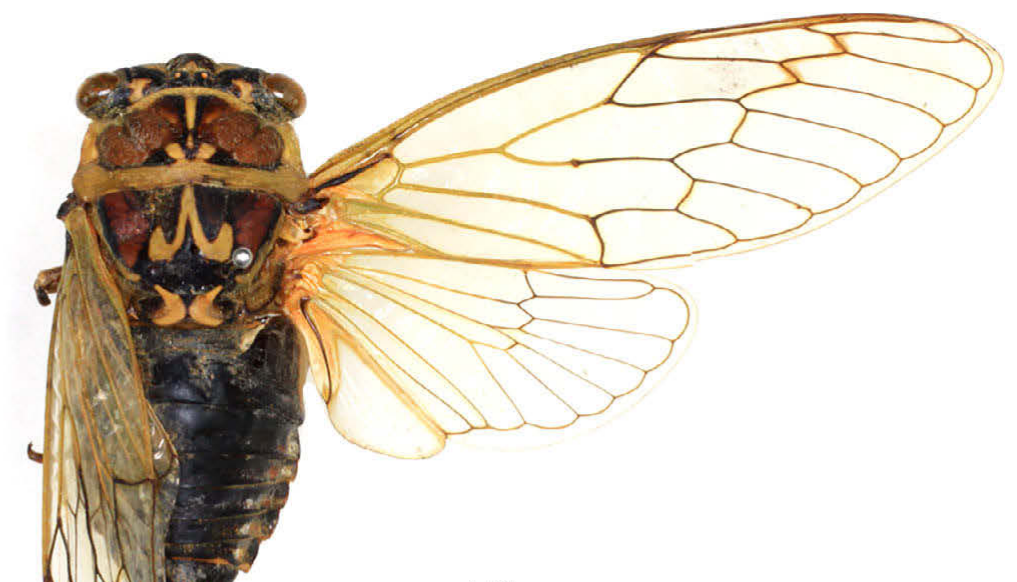

$\underline{5.0 \mathrm{~mm}}$
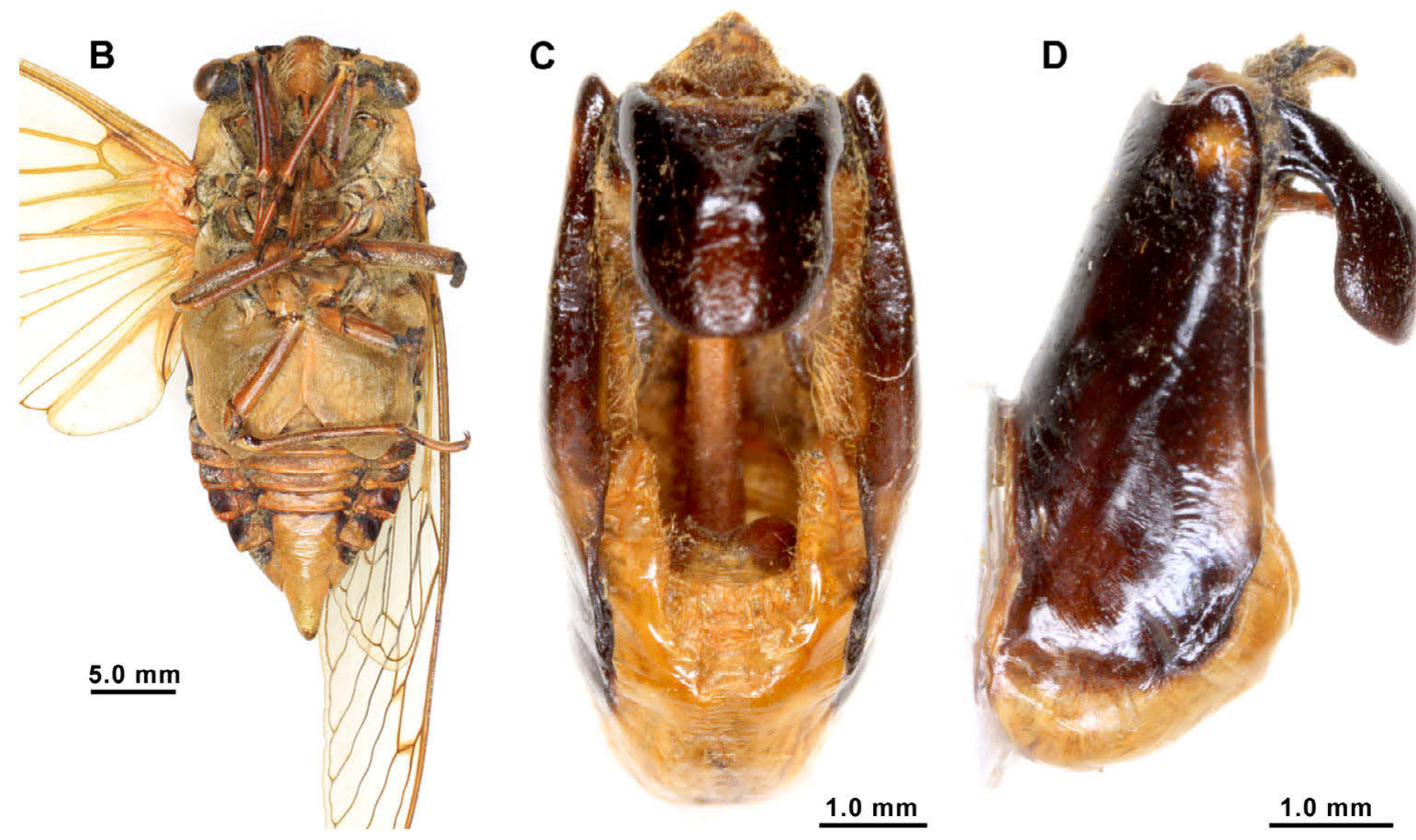

Fig. 11. Auritibicen flavomarginatus (male). A - habitus, dorsal view; B - habitus, ventral view; $C$ - male pygofer, ventral view; D - male pygofer, lateral view.

terolateral angles of vertex; two pairs of black spots within yellowish markings. Eyes fuscous; ocelli carmine. Supraantennal plates yellow. Postclypeus castaneous with a black spot at base in dorsal view. Transverse grooves concolorous with postclypeus and covered with yellow hairs. Lora black with yellow margins. Rostrum brown with apical part infuscated, extending a little beyond mid coxae.

Thorax (Fig. 11A). Inner area of pronotum castaneous, with a pair of central triangular fasciae and outer margin of inner area (narrowly and irregularly) black; a yellow cen- tral longitudinal stripe separated into three parts by black spots. Anterior margin of inner area yellow. Pronotal collar green, with a large brown spot on each posterolateral area. Posterior margin of pronotal collar black. Mesonotum black, with the following markings: a yellow, broad, continuous W-shaped marking in front of cruciform elevation; a pair of reddish tongue-shaped markings on lateral sigilla; yellow longitudinal fasciae along lateral margins. Cruciform elevation yellow interrupted by a thin black stripe. 


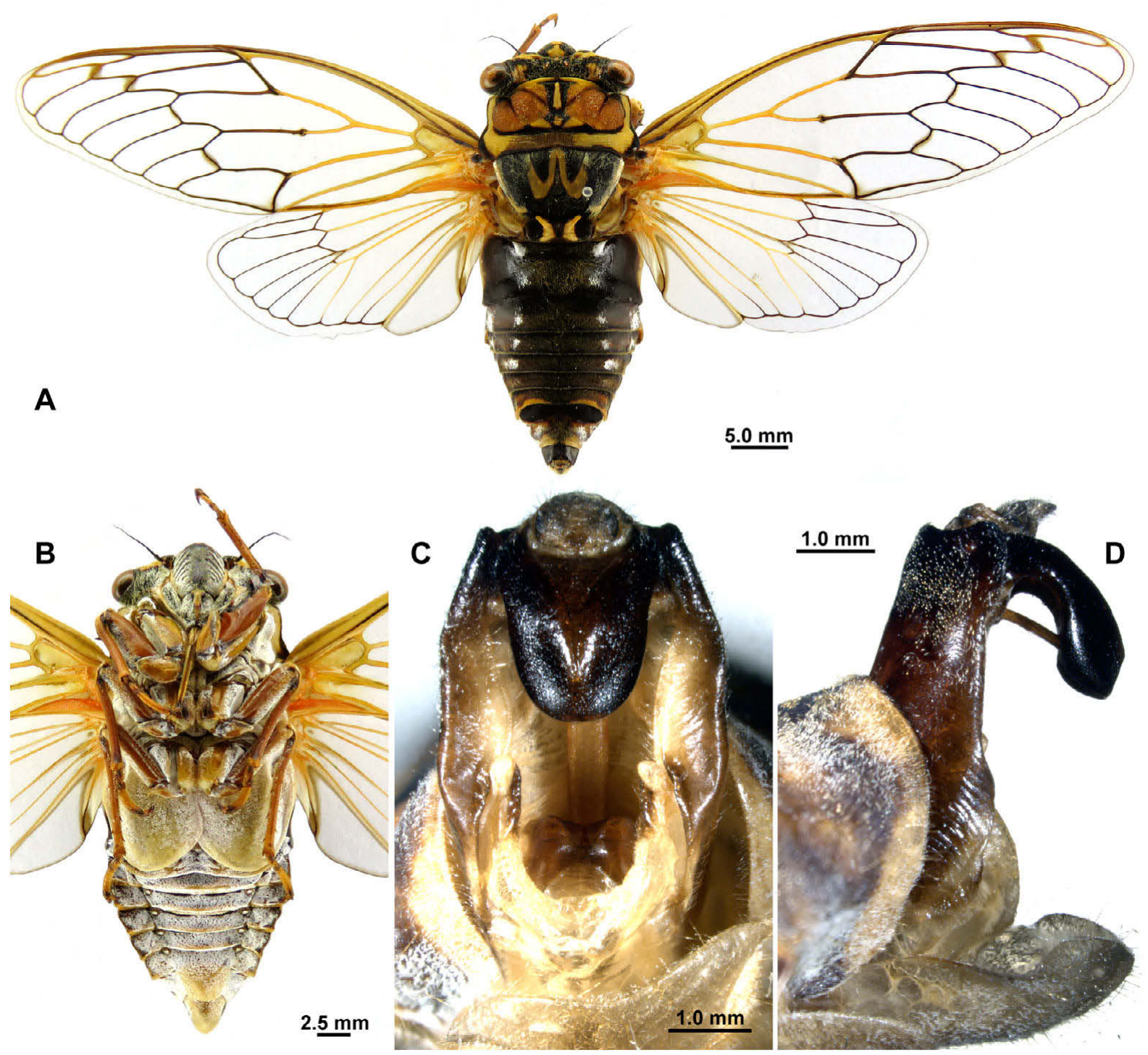

Fig. 12. Auritibicen intermedius (male). A - habitus, dorsal view; B - head, thorax and abdomen, ventral view; $C$ - male pygofer, ventral view; D - male pygofer, lateral view.

Wings (Fig. 11A). Hyaline. Fore wing with distinct infuscation on $\mathrm{r}, \mathrm{r}-\mathrm{m}, \mathrm{m}$ and $\mathrm{m}-\mathrm{cu}$ crossveins and those along the latter two much weaker; base of ulnar cell 2 shorter than base of ulnar cell 3; base of apical cell 1 longer than base of apical cell 2; base of apical cell 4 about twice length of r-m vein; basal membrane orange. Hind wing without infuscation. Basal half of wing veins yellow.

Abdomen (Fig. 11A, B). Cylindrical. Tergites black with brown spots on lateral parts of tergites 3-7; apical margins of tergites 7 and 8 irregularly ochraceous; a pair of white pollinosity spots sublaterally on tergites $1,5-7$; lateral length of tergite 4 shorter than median length; tergite 8 longer than tergites 6 and 7 combined. Abdominal sternites ochraceous mostly; sternite VIII as long as sternite VII; epipleurites half ochraceous and half black. Timbal covers black with lateral one-third ochraceous. Opercula yellow, with overlaping inner margins, longer than wide, extending to middle of abdominal sternite IV, obtuse apically.

Male genitalia (Figs 11C, D, 37F, 38F). Pygofer barrelshaped, wider near middle; Basal lobes of pygofer yellow erect in ventral view. Uncal lobe stout and rounded apically with the apical half curved inwardly at about $110^{\circ}$ (Hayashi, 1977a).

Female. Unknown.

Distribution. China (Taiwan).

Remarks. This species is similar to A. chujoi in body size, colouration, markings on thorax, etc., but can be easily separated from the latter mainly by the shape of the opercula and genitalia.

\section{Auritibicen intermedius (Mori, 1931)}

Tibicen japonica Mori, 1931: 11 (nec Kato, 1925).

Tibicen intermedia Mori, 1931: 13.

Lyristes intermedia: Matsumura, 1939: 48.

Tibicen intermedius: Kato, 1933b: 3.

Auritibicen intermedius: Lee, 2015: 241.

Subsolanus intermedius: Hill et al., 2015: 229.

Lyristes horni Schmidt, 1932: 121.

Tibicen horni: Kato, 1937: 382.

Material examined. 1 ㅇ (ZIN), Korea: Oliganca (?), Schmidt, 20.vii.1900; $1 \delta^{\widehat{N}}$ (UMUT), Fusenrei, 27.vii.1933, by Cho, Insecta 


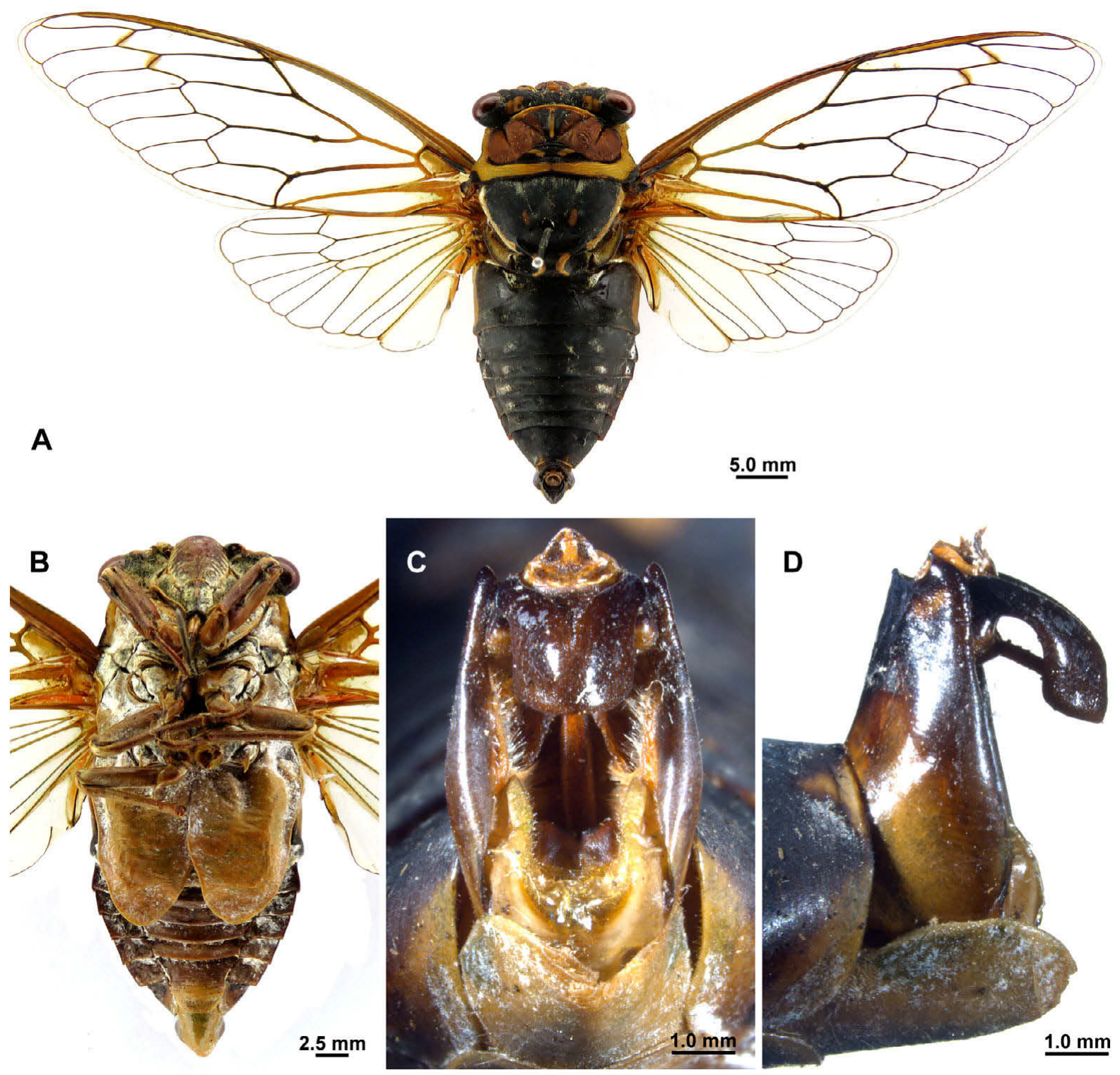

Fig. 13. Auritibicen jai (male). A - habitus, dorsal view; B - head, thorax and abdomen, ventral view; C - male pygofer, ventral view; D male pygofer, lateral view.

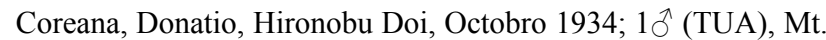
Sudo (800 m), Korea, 23.viii.1990, K. Yamagishi leg.; $1 \delta^{\wedge}(\mathrm{ZIN})$, Russia: S. Primorje, Kedrovaya Pad Reserve, vii.1959, Pankratjev leg.

Measurements. $\left(1 \delta^{\Uparrow}\right)$. Body length: 36.8 ; fore wing length: 41.3; fore wing width: 13.8; width of head including eyes: 12.7 ; pronotum width (including pronotal collar): 13.0; mesonotum width: 10.7; total length: 49.9; expanse of fore wings: 101.5 .

Description of male. Head (Fig. 12A, B). Black, with a pair of irregular yellowish spots on posterolateral angles of vertex. Eyes fuscous; ocelli ochraceous. Supra-antennal plates yellow. Postclypeus moderately black with a yellow spot in dorsal view. Transverse grooves black with white pollinosity. Lora black with yellow margins. Rostrum ochraceous with apical part fuscous, just reaching mid coxae.
Thorax (Fig. 12A). Inner area of pronotum reddish, with a central longitudinal fascia yellow; two large triangular and one small yellow spot near posterior margin of inner area; black fascia surrounding the three aforementioned yellow spots. Anterior margin of inner area yellow. Pronotal collar yellow, without markings. Posterior margin of pronotal collar black. Mesonotum black, with the following yellow markings: a broad, continuous W-shaped marking in front of cruciform elevation; longitudinal fasciae along lateral margins. Cruciform elevation yellow with a large black spot medially.

Wings (Fig. 12A). Hyaline. Fore wing with distinct infuscation on $\mathrm{r}, \mathrm{r}-\mathrm{m}$ crossveins, base of apical cell $3, \mathrm{~m}$ and $\mathrm{m}$-cu crossveins; base of ulnar cell 2 shorter than base of ulnar cell 3; length of base of apical cell 1 longer than base of apical cell 2. Hind wing without infuscation. Basal half of wing veins yellow. 

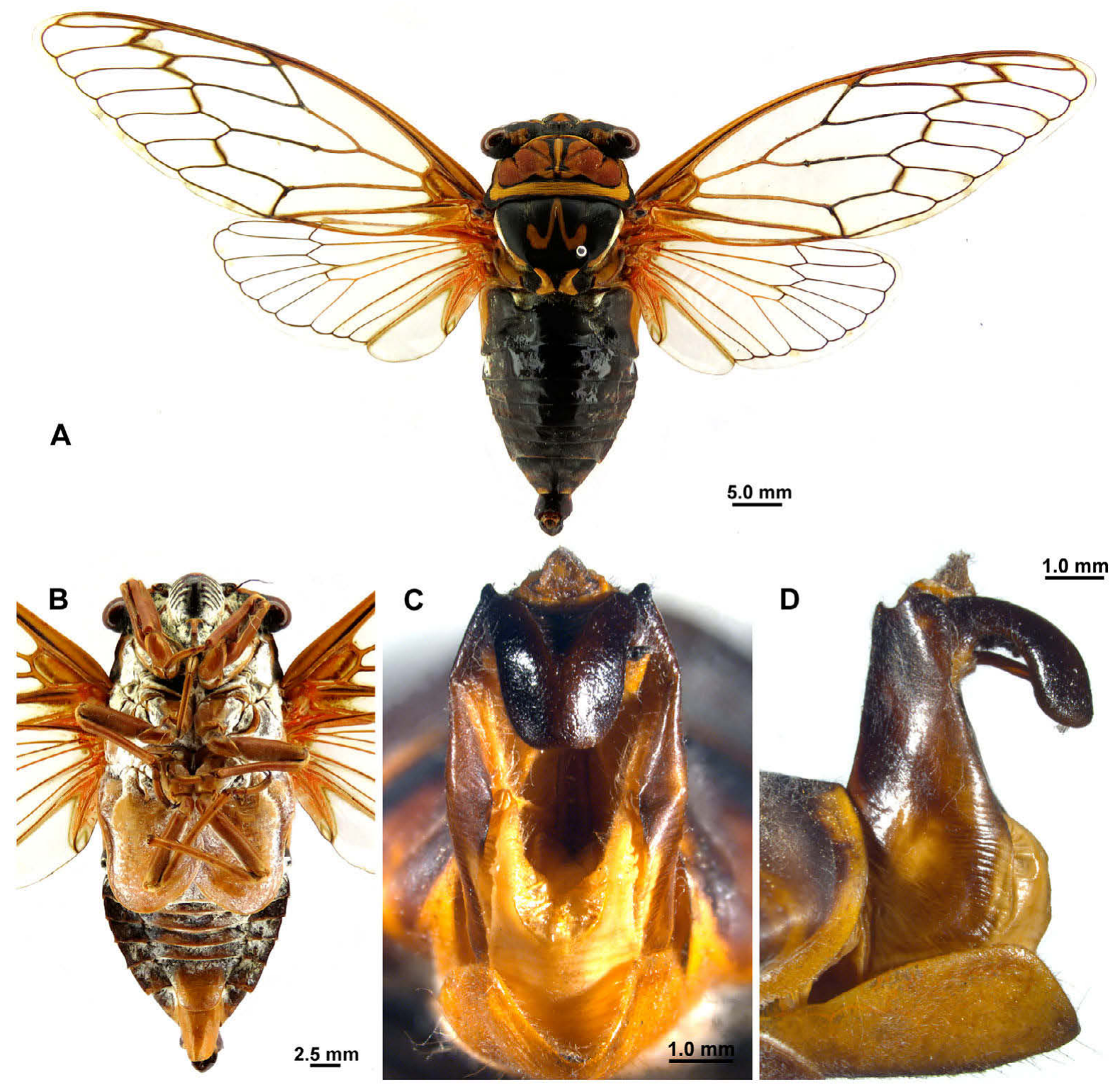

Fig. 14. Auritibicen japonicus (male). A - habitus, dorsal view; B - head, thorax and abdomen, ventral view; $C$ - male pygofer, ventral view; D - male pygofer, lateral view.

Abdomen (Fig. 12A, B). Cylindrical. Tergites black, with series of white pollinosity spots sublaterally on each tergite; lateral length of tergite 4 as long as median length; tergite 8 as long as tergites 6 and 7 combined. Abdominal sternites and epipleurites black with dense white pollinosity; sternite VIII shorter than sternite VII. Timbal covers black with faint yellow lateral margins. Opercula yellow, with inner margins overlaping, rounded apically, and not extending beyond posterior margin of abdominal sternite II.

Male genitalia (Figs 12C, D, 37G, 38G). Pygofer barrelshaped. Basal lobes of pygofer yellow and curved inwardly in ventral view. Uncal lobe ochraceous rounded apically and apical half curved inwardly at about $120^{\circ}$ in lateral view.

Female. Unknown.

Distribution. Russia (Primorsky Region), Korea.
Remarks. This species is very similar and probably allied to A. kyushyuensis occurring in western Japan. Morphological and molecular analyses indicate they may be identical, which is suggested in Sota et al. (2016). However, A. intermedius can be distinguished from A. kyushyuensis by the following characteristics: length of sternite VIII shorter than sternite VII (length of sternite VIII as long as or longer than sternite VII in A. kyushyuensis); uncal lobe of pygofer black and mostly rounded apically (uncal lobe of pygofer ochraceous mostly truncated apically in $A$. $k y$ ushyuensis); fore wing without black markings in basal cell (fore wing with black markings in basal cell in A. kyushyuensis). The relationship between these two species needs further investigation when more material becomes available in the future.

\section{Auritibicen jai (Ouchi, 1938)}

Tibicen jai Ouchi, 1938: 78.

Lyristes jai: Chou et al., 1997: 283. 

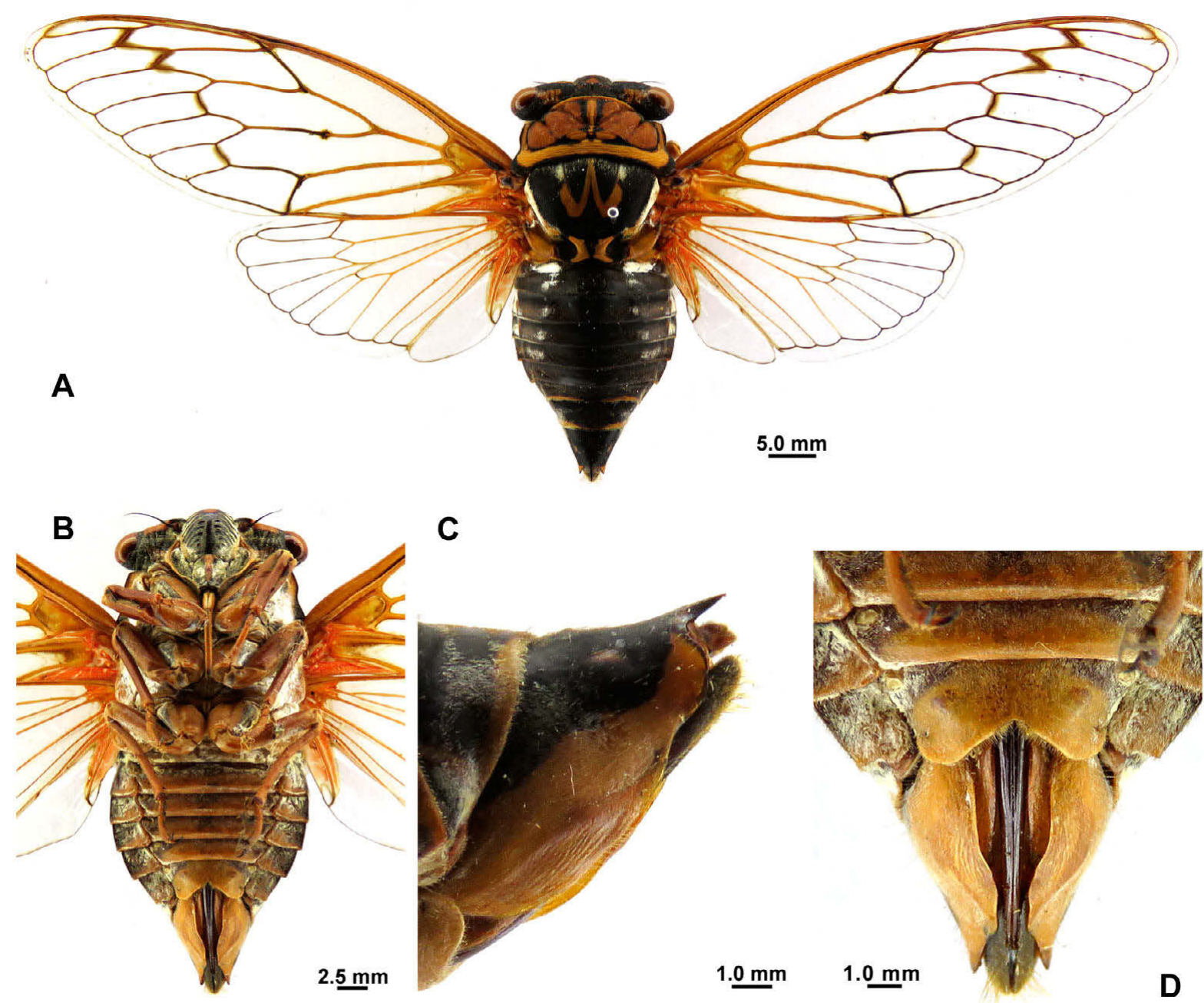

Fig. 15. Auritibicen japonicus (female). A - habitus, dorsal view; B - head, thorax and abdomen, ventral view; C - female terminalia, lateral view; $\mathrm{D}$ - female terminalia, ventral view.

Auritibicen jai: Lee, 2015: 241.

Subsolanus jai: Hill et al., 2015: 229.

Tibicen wui Kato, 1934: 150 (nec Schmidt, 1932, misid.).

Tibicen orientalis Ouchi, 1938: 79.

Lyristes katoi Liu, 1939: 150.

Material examined. $1 \delta^{\lambda}$ (UMUT), China: Kuling, Jiujiang City, Jiangxi Province, 21.viii.1935, O. Piel leg.; $10^{-1}$ (BMNH), without locality, Cica 17, Brit. Mus. 1931-113.

Measurements. $\left(1 \delta^{\Uparrow}\right)$. Body length: 44.4; fore wing length: 51.6; fore wing width: 18.2; width of head including eyes: 17.1; pronotum width (including pronotal collar): 17.6; mesonotum width: 14.7; expanse of fore wings: 115.4 .

Description of male. Head (Fig. 13A, B). Black, with a pair of yellowish rectangular spots on posterolateral angles of vertex; small black spot within each yellowish spot. Eyes red; ocelli orange. Supra-antennal plates yellow. Postclypeus reddish brown. Transverse grooves black with white pollinosity. Lora black with yellow margins. Rostrum yellow with apical part black, just reaching mid coxae.

Thorax (Fig. 13A). Inner area of pronotum reddish, with a central longitudinal fascia yellow; a pair of rectangular spots near posterior margin of inner area yellow; black fascia surrounding three aforementioned yellow spots. Anterior margin of inner area yellow. Pronotal collar yellow, with a spot on each posterolateral area. Posterior margin of pronotal collar black. Mesonotum black, with the following yellow markings: an obscure interrupted W-shaped marking in front of cruciform elevation; longitudinal fasciae along lateral margins. Cruciform elevation yellow with a large black spot medially.

Wings (Fig. 13A). Hyaline. Fore wing with distinct infuscation on $\mathrm{r}$ and $\mathrm{r}-\mathrm{m}$ crossveins; base of ulnar cell 2 as long as base of ulnar cell 3; base of apical cell 1 shorter than base of apical cell 2. Hind wing without infuscation. Basal half of wing veins black.

Abdomen (Fig. 13A, B). Cylindrical. Tergites black, with longitudinal series of white powdery spots sublaterally; lateral length of tergite 4 as long as median length; tergite 8 longer than tergites 6 and 7 combined. Abdominal sternites and epipleurites ochraceous with white pollinosity; sternite VIII shorter than sternite VII. Timbal covers black with yellow lateral margins. Opercula ochraceous, with inner margins overlapping, rounded apex, and extending beyond posterior margin of abdominal sternite III. 


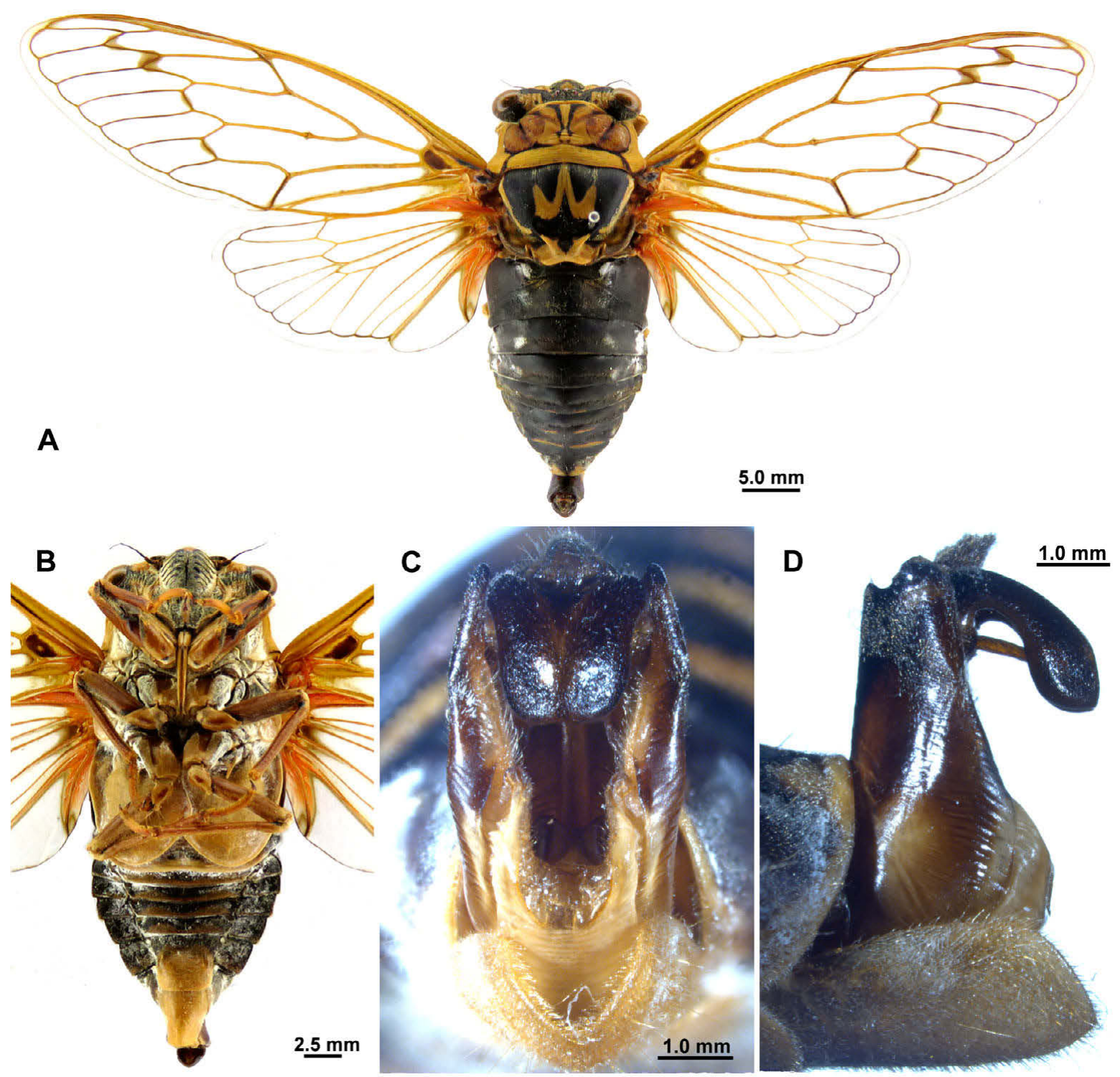

Fig. 16. Auritibicen kyushyuensis (male). A - habitus, dorsal view; B - head, thorax and abdomen, ventral view; C - male pygofer, ventral view; D - male pygofer, lateral view.

Male genitalia (Figs 13C, D, 37H, 38H). Pygofer barrelshaped. Basal lobes of pygofer yellow and erect in ventral view. Uncal lobe ochraceous and truncated apically.

Female. Unknown.

Distribution. China (Hebei, Shaanxi, Zhejiang, Jiangxi).

\section{Auritibicen japonicus (Kato, 1925)}

Cicada flammata sensu Matsumura, 1898: 13 (nec Distant, 1892). Cicada japonica Kato, 1925: 8.

Tibicen japonica: Kato, 1930: 149.

Lyristes japonica: Matsumura, 1939: 48.

Lyristes japonicus: Hayashi \& Saisho, 2015: 62.

Auritibicen japonicus: Lee, 2015: 241.

Subsolanus japonicus: Hill et al., 2015: 229.

Tibicen dolichoptera Mori, 1931: 14.

Lyristes hooshiana Matsumura, 1936: 38.

Material examined. $1 \hat{\delta}$ (NWAFU), China: Mt. Nanwutai, Shaanxi Province, viii.1957; $1 \hat{\jmath}, 1 \propto$ (NWAFU), Japan: Kurokawa, Niigata Pref., Honshu, 23.-24.viii.1980, M. Hayashi leg.; $11 \widehat{\jmath}$ (NWAFU), Japan: Mt. Jômine 930-1030 m, Saitama Pref.,
Honshu, 28.viii.1986, M. Hayashi leg.; $1 \delta^{\Uparrow}$ (NWAFU), China: Mt. Lushan, Jiangxi Province, viii.1994.

Measurements. (2 $\curvearrowright, 1$ ). Body length: male 41.042.2, female 41.7; fore wing length: male 51.9-52.1, female 52.6; fore wing width: male 16.0-17.7, female 18.3; width of head including eyes: male 15.6-16.4, female 16.7; pronotum width (including pronotal collar): male 15.616.1, female 16.6; mesonotum width: male 13.2-13.3, female 12.9; expanse of fore wings: male 113.1, female 120.3 .

Description of male. Head (Fig. 14A, B). Black, with a pair of yellowish spots on posterolateral angles of vertex; small black spot within each yellowish spot. Eyes fuscous; ocelli yellow. Supra-antennal plates yellow. Postclypeus black with an ochraceous spot medially in dorsal view. Transverse grooves black with white pollinosity; lorum black with yellow margins. Rostrum yellow with apical part black, and reaching mid coxa. 

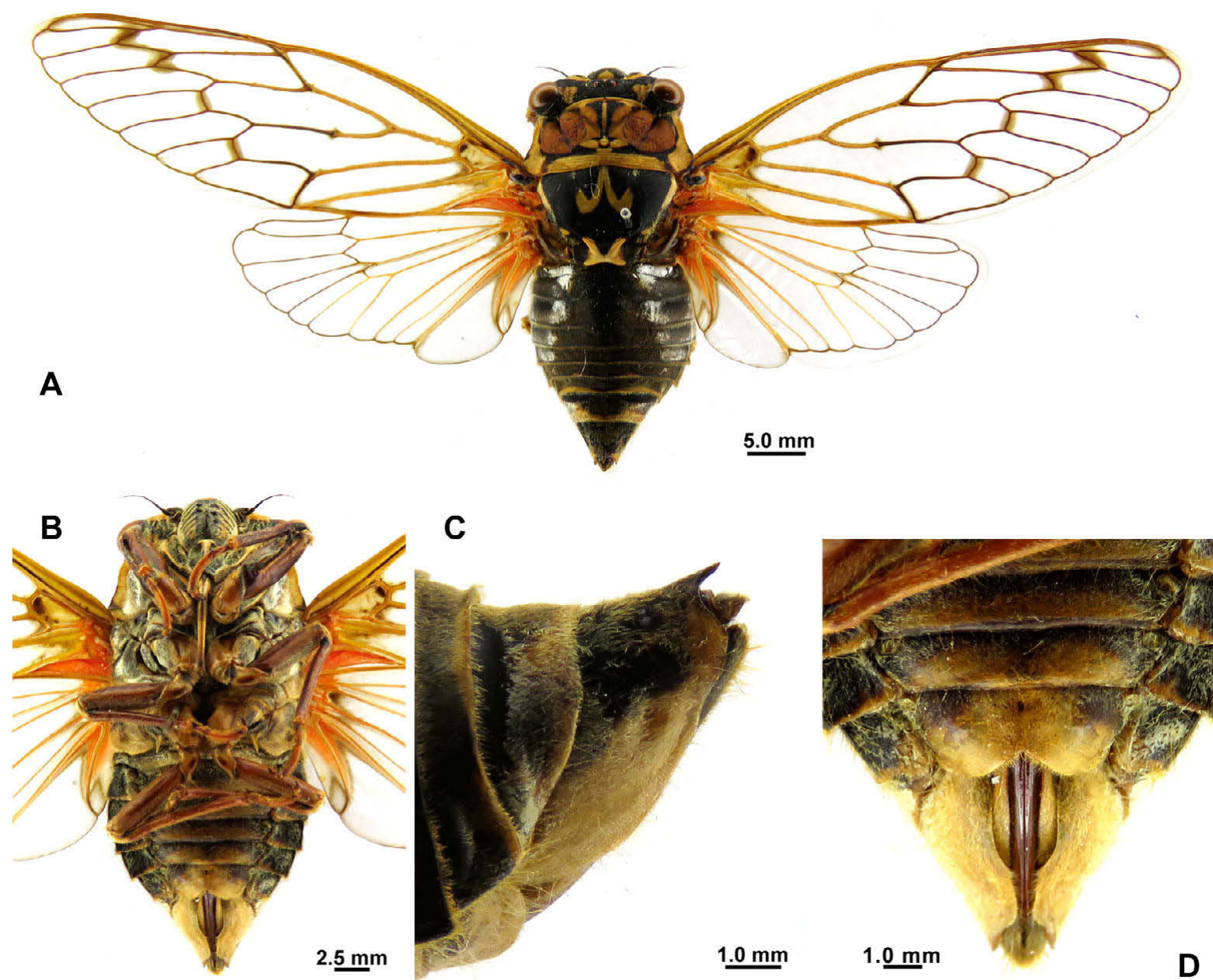

Fig. 17. Auritibicen kyushyuensis (female). A - habitus, dorsal view; B - head, thorax and abdomen, ventral view; C - female terminalia, lateral view; D - female terminalia, ventral view.

Thorax (Fig. 14A). Inner area of pronotum reddish, with a central longitudinal fascia yellow; a pair of rectangular spots near posterior margin of inner area yellow; black fascia surrounding the three aforementioned yellow spots. Anterior margin of inner area yellow. Pronotal collar yellow, without markings. Posterior margin of pronotal collar black. Mesonotum black, with the following yellow markings: a continuous W-shaped marking in front of cruciform elevation; longitudinal fasciae along lateral margins. Cruciform elevation yellow with a large black spot medially.

Wings (Fig. 14A). Hyaline. Fore wing with distinct infuscation on $\mathrm{r}, \mathrm{r}-\mathrm{m}$ crossveins, base of apical cell 3, base of apical cell 4, m and m-cu crossveins; base of ulnar cell 2 shorter than base of ulnar cell 3; base of apical cell 1 shorter than base of apical cell 2. Hind wing without infuscation. Basal half of wing veins yellow.

Abdomen (Fig. 14A, B). Cylindrical. Tergites black, with series of white powdery spots sublaterally; lateral length of tergite 4 as long as median length; tergite 8 longer than tergites 6 and 7 combined. Abdominal sternites and epipleurites black with yellow margins; sternite VIII as long as sternite VII. Timbal covers black with yellow lateral margins. Opercula ochraceous, inner margins overlapping, rounded apically, and extending beyond posterior margin of abdominal sternite II.
Male genitalia (Figs 14C, D, 37I, 38I). Pygofer barrelshaped. Basal lobes of pygofer yellow and erect in ventral view. Uncal lobe ochraceous and rounded apically.

Female (Fig. 15). Opercula small, posterior margin not reaching abdominal sternite II. Abdominal segment 9 black in dorsal view and yellow in ventral view; ovipositor sheath black, not protruding beyond segment 9, posterior margin of abdominal sternite VII incised at middle and a pair of yellow spots medially. Other characteristics similar to male.

Distribution. China (Shaanxi, Jiangxi); Japan, Korea

Remarks. This species varies greatly in terms of the Wshaped marking on mesonotum and colour of abdomen, which is recorded by Hayashi \& Saisho (2015) based on material collected from Japan.

\section{Auritibicen kyushyuensis (Kato, 1926)}

Cicada kyushyuensis Kato, 1926: 171.

Tibicen kyushynensis (sic!): Kato, 1930: 149.

Lyristes kyushuensis (sic!): Matsumura, 1939: 49.

Lyristes kyushyuensis: Chou et al., 1997: 286; Hayashi \& Saisho, 2015: 78.

Auritibicen kyushyuensis: Lee, 2015: 241.

Subsolanus kyushyuensis: Hill et al., 2015: 229.

Tibicen tsukushiensis Kato, 1959: 24.

Tibicen shikokuanus Kato, 1959: 26. 


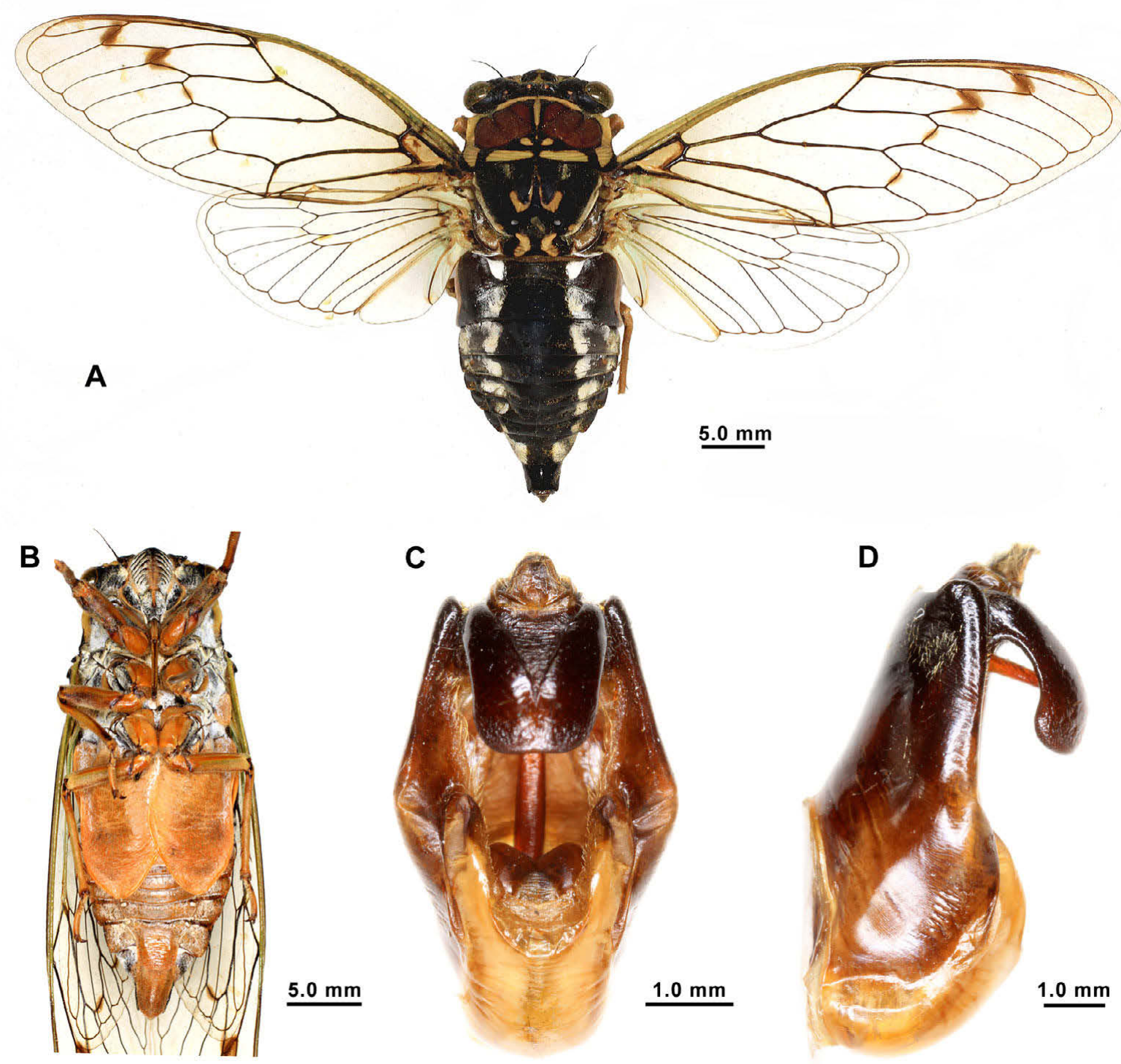

Fig. 18. Auritibicen leechi (male). A - habitus, dorsal view; B - habitus, ventral view; C - male pygofer, ventral view; D - male pygofer, lateral view.

Auritibicen shikokuanus: Lee, 2017: 59.

Tibicen ishiharai Kato, 1959: 27.

Material examined. $1 \delta^{\Uparrow}$ (NWAFU), Japan: Makinoto Pass 1330m, Mts Kuju, Oita Pref., Kyushu, 27.vii.1976, M. Hayashi leg.; 1§̂, 1 (NWAFU), same data except 28.vii.1977.

Measurements. (2 $\hat{\sigma}, 1$ $)$. Body length: male 38.038.6, female 35.3; fore wing length: male 42.3-44.1, female 45.2; fore wing width: male 14.0-15.2, female 14.8; width of head including eyes: male 13.1-13.3, female 13.2; pronotum width (including pronotal collar): male 13.8 14.0, female 14.7; mesonotum width: male 11.7-13.4, female 11.4; expanse of fore wings: male 96.4, female 102.2.

Description of male. Head (Fig. 16A, B). Black, with a pair of yellowish spots on posterolateral angles of vertex; small black spot within each yellowish spot. Eyes fuscous; ocelli red. Supra-antennal plates yellow. Postclypeus slightly prominent anteriad, black with an ochraceous spot medially in dorsal view. Transverse grooves black with white pollinosity. Lora black with yellow margins. Rostrum yellow with apical part black, and reaches mid coxa.

Thorax (Fig. 16A). Inner area of pronotum ochraceous, with a pair of central longitudinal fascia black; markings along lateral fissures black. Anterior margin of inner area yellow. Pronotal collar yellow, with a pair of black markings on margins of pronotal collar. Mesonotum black, with the following yellow markings: a continuous W-shaped marking in front of cruciform elevation; longitudinal fasciae along lateral margins. Cruciform elevation yellow with a small black spot medially.

Wings (Fig. 16A). Hyaline. Fore wing with distinct infuscation on $\mathrm{r}, \mathrm{r}-\mathrm{m}$ crossveins, base of apical cell $3, \mathrm{~m}$ and m-cu crossveins; base of ulnar cell 2 shorter than base of ulnar cell 3; base of apical cell 1 longer than base of apical cell 2. Hind wing without infuscation. Basal half of wing veins yellow.

Abdomen (Fig. 16A, B). Cylindrical. Tergites black, with a series of white powdery spots sublaterally on each ter- 

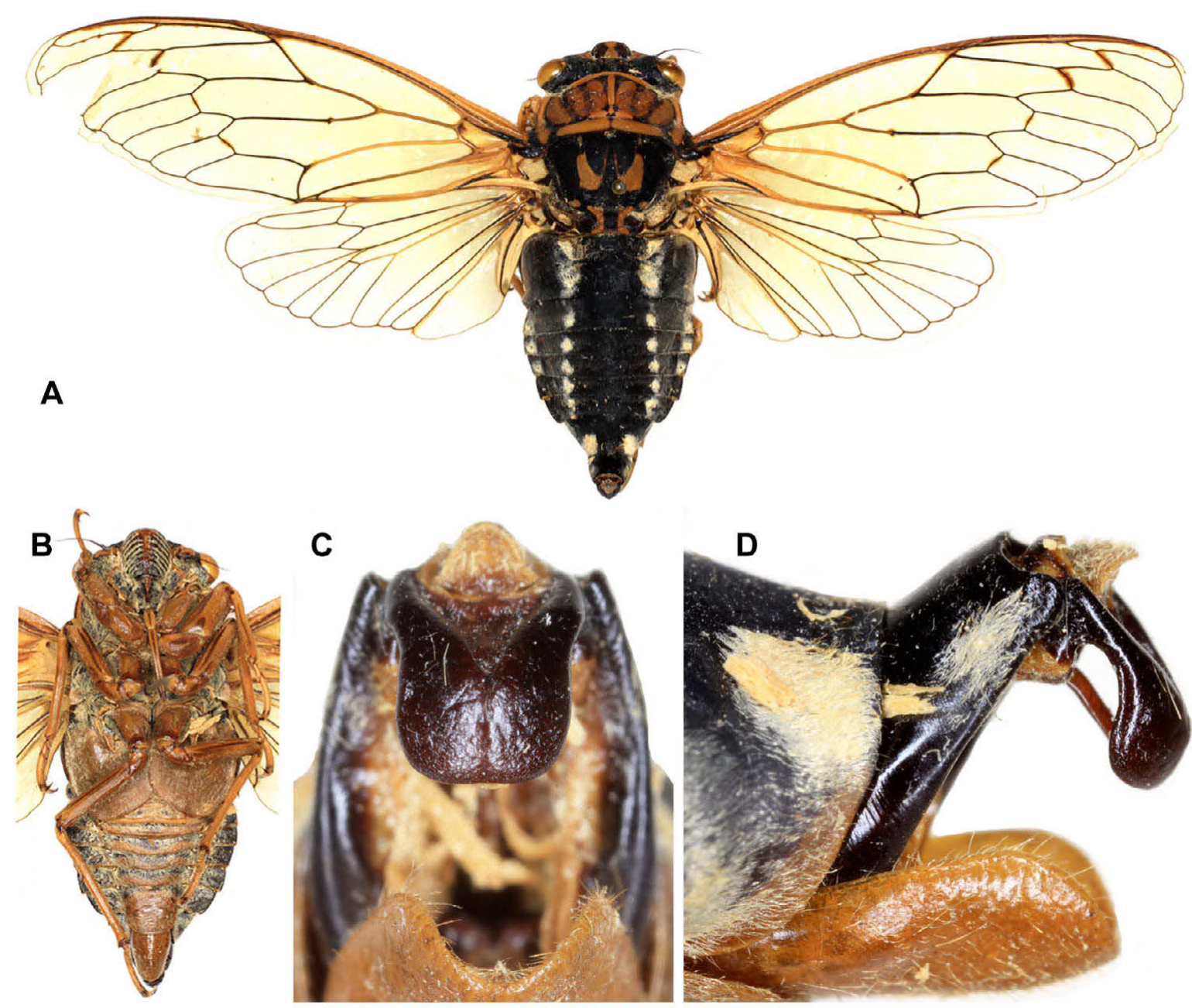

Fig. 19. Auritibicen pekinensis (male, lectotype). A - habitus, dorsal view; B - head, thorax and abdomen, ventral view; C - male pygofer, ventral view; D - male pygofer, lateral view.

gite; lateral length of tergite 4 shorter than median length; tergite 8 as long as tergites 6 and 7 together. Abdominal sternites black basally and ochraceous distally; sternite VIII as long as sternite VII; epipleurites black with yellow posterior margins. Timbal covers black, without markings. Opercula yellow, inner margins overlapping, rounded apically, not extending beyond posterior margin of abdominal sternite II.

Male genitalia (Figs 16C, D, 37J, 38J). Pygofer barrelshaped. Basal lobes of pygofer yellow with apex fuscous and curved inwardly in ventral view. Uncal lobe ochraceous to black, truncated apically and apical half curved inwardly at about $100^{\circ}$.

Female (Fig. 17). Opercula small, posterior margin not reaching abdominal sternite II. Abdominal segment 9 black in dorsal view and yellow in ventral view; ovipositor sheath black, not protruding beyond segment 9, posterior margin of abdominal sternite VII incised at middle and with a pair of yellow spots medially. Other characteristics similar to male.

Distribution. Japan.

Remarks. Chou et al. (1997) include A. kyushyuensis in the Chinese fauna, but do not provide any detailed infor- mation on its distribution. In our study, we checked collections of various institutes, including that of NWAFU, but found no related material. Therefore, we exclude this species from the Chinese fauna. Ishihara (1961), Kurosawa (1969), Nast (1972) and Hayashi \& Saisho (2015) indicate that the three species formerly described by Kato (1959), i.e., Tibicen tsukushiensis, T. shikokuanus and T. ishiharai, are all synonyms of T. kyushyuensis, viz. currently $A u$ ritibicen kyushyuensis. However, Lee (2017) resurrects Auritibicen ishiharai (Kato, 1959) (=T. ishiharai) from junior synonymy with $A$. kyushyuensis based on extremely limited material (one male from Honshu and another male from Shikoku) which is attributed to Auritibicen. Species of Auritibicen often vary in colour and/or marking pattern, and $A$. kyushyuensis is also very variable, including the $\mathrm{W}$ shaped marking on the mesonotum and length ratio of abdomen and wings, which is recorded by Hayashi \& Saisho (2015). According to our investigations based on nearly 200 specimens (mostly from Kyushu, about 10 each from Shikoku or Honshu), we found no morphological differences to separate A. kyushyuensis from A. shikokuanus and A. ishiharai. Here, we follow Ishihara (1961), Kurosawa (1969), Nast (1972) and Hayashi \& Saisho (2015), and 


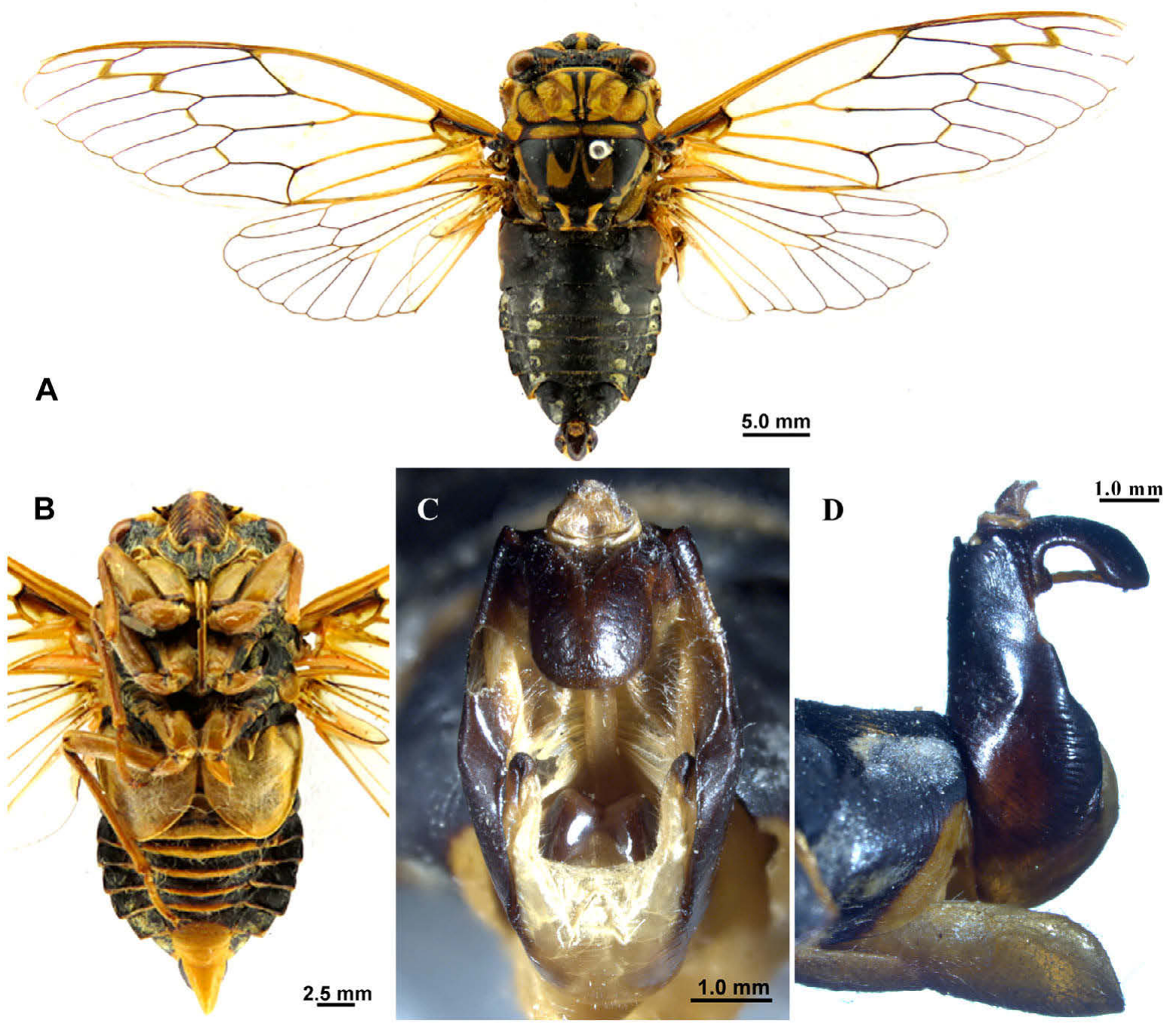

Fig. 20. Auritibicen slocumi (male). A - habitus, dorsal view; B - head, thorax and abdomen, ventral view; $\mathrm{C}$ - male pygofer, ventral view; $\mathrm{D}$ - male pygofer, lateral view.

confirm Auritibicen shikokuanus (Kato, 1959) as a junior synonymy of Auritibicen kyushyuensis (Kato, 1926).

\section{Auritibicen leechi (Distant, 1890)}

Cicada leechi Distant, 1890: 90.

Tibicen leechi: Kato, 1931: 65.

Lyristes leechi: Schmidt, 1932: 122.

Auritibicen leechi: Lee, 2015: 241.

Subsolanus leechi: Hill et al., 2015: 229.

Material examined. $1 \delta(\mathrm{BMNH})$, China: Wa shan, China (Leech), Type, Distant Coll. 1911-383; 10 (SNSD), China: Wa shan, Pratt C., 1911, A. Jacobi leg.; $1 \widehat{\partial}$ (MNHN), China: Wa shan; $1 \hat{\jmath}(\mathrm{MNHN})$, W. China (Pratt), Cicada leechi Dist.; $3 \hat{\jmath}$ (ISNB), Chine: W. China, Cicada leechi Dist., Détermin. W.L. Distant, Type; $2 \widehat{\jmath}, 1$ ( (ISNB), China, Type, Coll. R.I.Sc.N.B.;

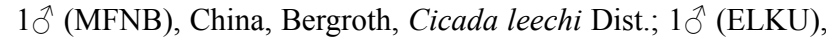
China: Tianwanhe (1680 m), Heping, Caoke, Simian, Ya'an, Sichuan, 26.viii.2016, S. Kamitani leg.

Measurements. (2 $\precsim$ ). Body length: 38.0-42.6; fore wing length: 45.3-47.7; fore wing width: 15.5-16.0; width of head including eyes: 13.3-14.5; pronotum width (including pronotal collar): 13.6-15.0; mesonotum width:
11.5-12.0; total lengh: 53.7-57.2; expanse of fore wings: $105.0-110.0$.

Description of male. Head (Fig. 18A, B). Black, with a pair of small yellowish spots on posterolateral angles of vertex. Eyes green; ocelli red. Supra-antennal plates yellow. Postclypeus black basally ochraceous apically with a pair of green spots medially in dorsal view. Transverse grooves black with white pollinosity. Lora black with yellow margins. Rostrum yellow with apical part black, and reaching mid coxa.

Thorax (Fig. 18A). Inner area of pronotum reddish, with a central longitudinal fascia yellow; a pair of large and one small spot near posterior margin of inner area yellow; black fascia surrounding the three aforementioned yellow spots. Anterior margin of inner area yellow. Pronotal collar yellow, with a black spot in the middle and a pair of black spots on margins. Posterior margin of pronotal collar black. Mesonotum black, with the following yellow markings: a faint interrupted $\mathrm{W}$-shaped marking in front of cruciform elevation; longitudinal fasciae covered with white pollinosity along lateral margins. Cruciform elevation yellow with a large black spot medially. 

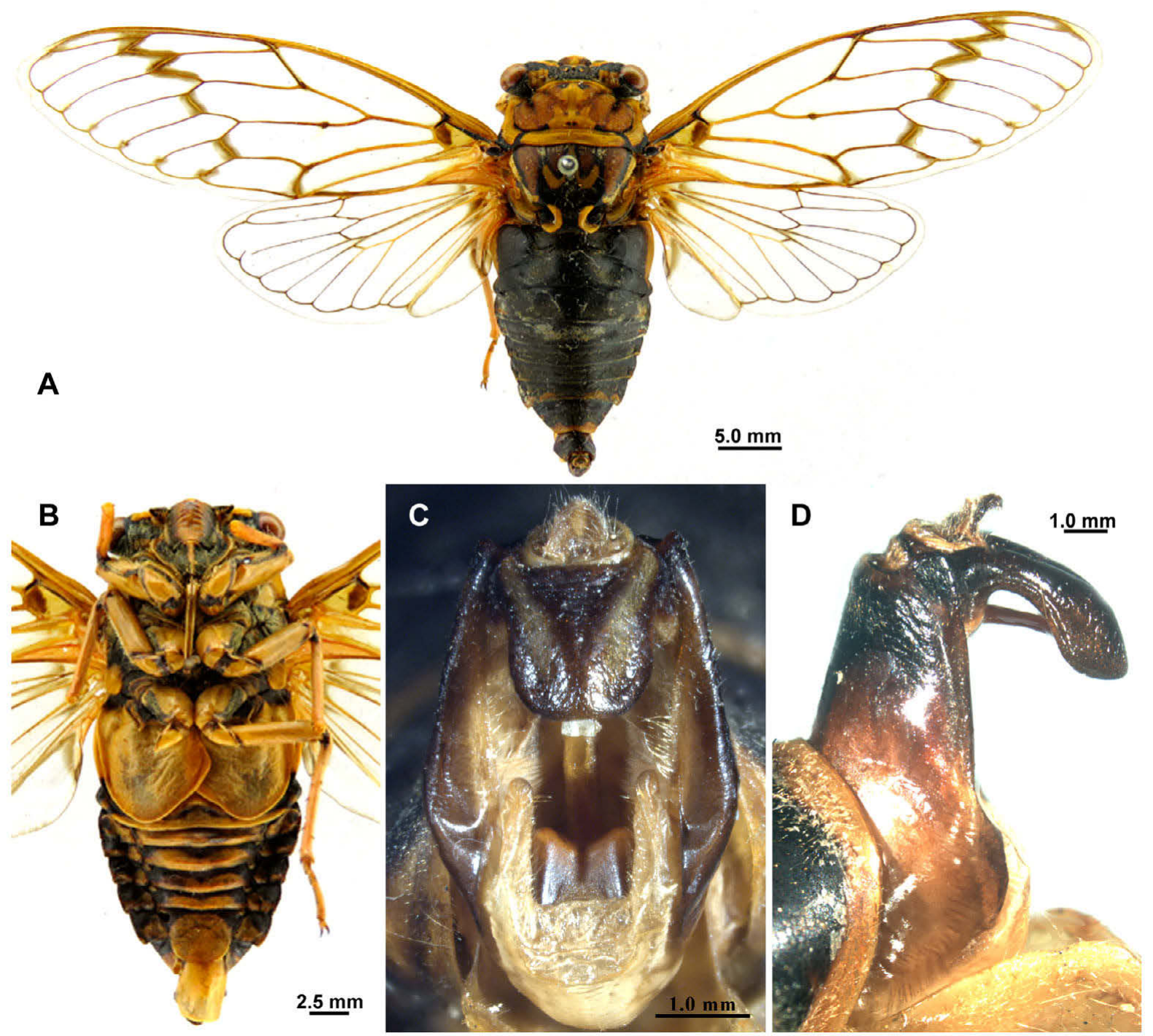

Fig. 21. Auritibicen tsaopaonensis (male). A - habitus, dorsal view; B - head, thorax and abdomen, ventral view; $\mathrm{C}$ - male pygofer, ventral view; D - male pygofer, lateral view.

Wings (Fig. 18A). Hyaline. Fore wing with distinct infuscation on r, r-m, $\mathrm{m}$ and $\mathrm{m}$-cu crossveins; base of ulnar cell 2 shorter than base of ulnar cell 3; base of apical cell 1 shorter than base of apical cell 2. Hind wing without infuscation. Basal half of wing veins black.

Abdomen (Fig. 18A, B). Cylindrical. Tergites black, with longitudinal series of white powdery spots sublaterally; lateral length of tergite 4 as long as median length; tergite 8 longer than tergites 6 and 7 combined. Abdominal sternites and epipleurites ochraceous without markings; sternite VIII as long as sternite VII. Timbal covers black with yellow lateral margins. Opercula ochraceous to fuscous, inner margins overlapping, angulated apically and extending to posterior margin of abdominal sternite IV.

Male genitalia (Figs 18C, D, 37K, 38K). Pygofer barrelshaped. Basal lobes of pygofer yellow with apex fuscous and erect in ventral view. Uncal lobe black, with truncated apex.

Female. Unknown.

Distribution. China (Sichuan, Yunnan).
Remarks. Distant (1890) described this species based on the material collected from Wa Shan, China, but did not designate the holotype. In the present paper, we do not designate the lectotype of $A$. leechi because we were unable to check and examine all syntypes.

\section{Auritibicen pekinensis (Haupt, 1924)}

Cicada pekinensis Haupt, 1924: 296.

Lyristes pekinensis: Schmidt, 1932: 119.

Tibicen pekinensis: Chen, 1933: 10.

Auritibicen pekinensis: Lee, 2015: 241.

Subsolanus pekinensis: Hill et al., 2015: 229.

Haupt (1924) describes this species on the basis of 5 male and 4 female syntypes collected from E. Tibet (Ost-Tibet); this material was dispersed to various institutions. Among the syntypes, we here formally designate a male deposited at SNSD bearing a lectotype label by R. Remane (designation unpublished and thus invalid) as the lectotype.

Lectotype. $\widehat{\partial}$ (SNSD), Peking, Westberge, Exp. Stötzner, 1923 3, Type, Cicada pekinensis Hpt. det. Haupt, coll. A. Jacobi, "Lec-

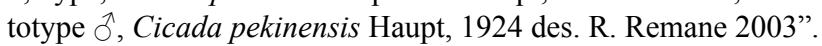



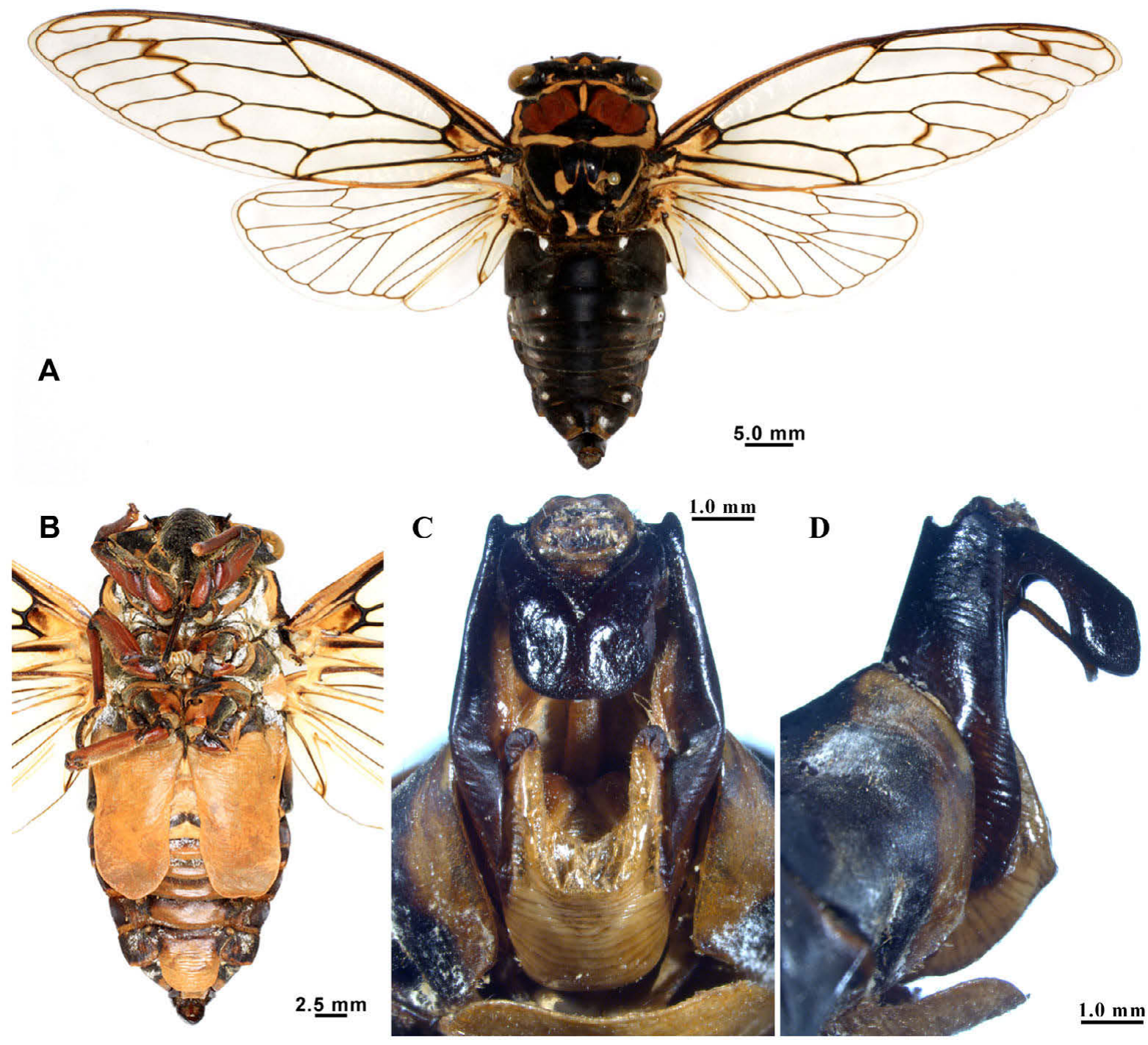

Fig. 22. Auritibicen aethus sp. n. (male, holotype). A- habitus, dorsal view; B - head, thorax and abdomen, ventral view; C - male pygofer, ventral view; D - male pygofer, lateral view.

Paralectotypes. $2 \hat{\jmath}, 2 q$ (SNSD), Peking, Westberge, Exp. Stotzner; $1 \hat{\jmath}, 1$ 우 (MFNB), same data. Two syntypes $(1 \hat{\jmath}, 1$ 웅 preserved in the Zoological Museum, Polish Academy of Sciences, Warsaw, also become paralectotypes (cf. Lee, 2015).

Measurements. $\left(1 \delta^{\Uparrow}\right)$. Body length: 34.2 ; fore wing length: 40.2; fore wing width: 13.4; width of head including eyes: 11.1; pronotum width (including pronotal collar): 12.1; mesonotum width: 9.4; expanse of fore wings: 89.2.

Description of male. Head (Fig. 19A, B). Black, without distinct markings. Eyes ochraceous; ocelli red. Supra-antennal plates yellow. Postclypeus ochraceous with a pair of black spots near frontoclypeal suture. Transverse grooves black with white pollinosity. Lora black with yellow margins. Rostrum ochraceous and reaching mid trochanter.

Thorax (Fig. 19A). Inner area of pronotum ochraceous, with a pair of black disrupted central longitudinal fascia; fasciae along paramedian fissures and lateral fissures black. Anterior margin of inner area yellow. Pronotal collar yellow, a spot on median part and a pair of spots on margins. Posterior margin of pronotal collar black. Mesonotum black, with the following yellow markings: a disrupted W- shaped mark in front of cruciform elevation; lateral margins without longitudinal fasciae. Cruciform elevation yellow with a large black spot medially.

Wings (Fig. 19A). Hyaline. Fore wing with faint infuscation on $\mathrm{r}, \mathrm{r}-\mathrm{m}, \mathrm{m}$ and $\mathrm{m}$-cu crossveins; base of ulnar cell 2 as long as base of ulnar cell 3; base of apical cell 1 shorter than base of apical cell 2. Hind wing without infuscation. Basal half of wing veins yellow.

Abdomen (Fig. 19A, B). Cylindrical. Tergites black, with longitudinal series of white powdery spots sublaterally; lateral length of tergite 4 shorter than median length; tergite 8 as long as tergites 6 and 7 combined. Abdominal sternites black basally and ochraceous distally; sternite VIII as long as sternite VII; epipleurites black with yellow margins. Timbal covers black with yellow lateral margins. Opercula ochraceous, inner margins overlapping, angulated apically, just extending to posterior margin of abdominal sternite II.

Male genitalia (Figs 19C, D, 37L, 38L). Pygofer barrelshaped. Basal lobes of pygofer yellow and curved outwardly in ventral view. Uncal lobe ochraceous and truncat- 


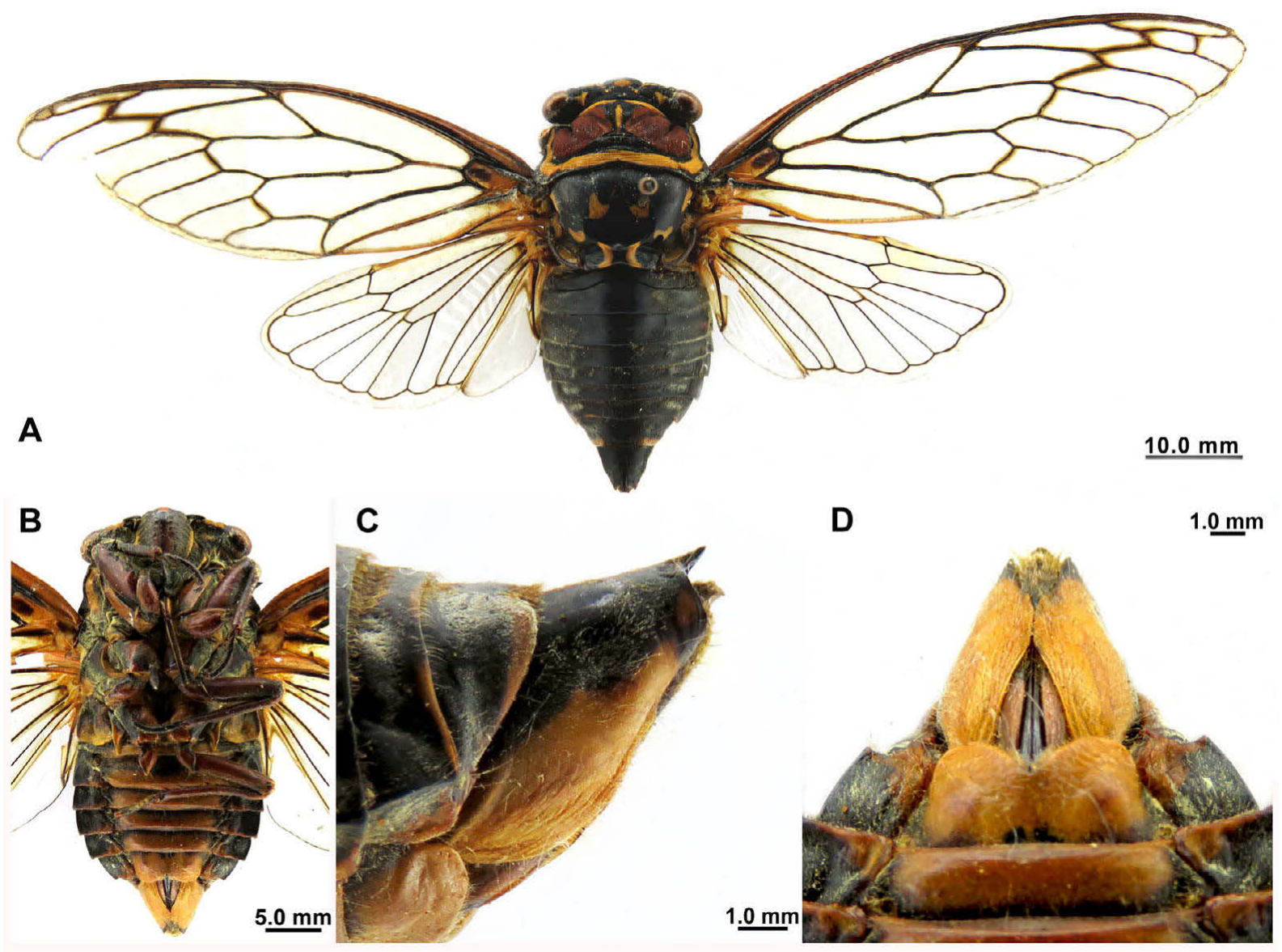

Fig. 23. Auritibicen aethus sp. n. (female, paratype). A - habitus, dorsal view; B - head, thorax and abdomen, ventral view; C - female terminalia, lateral view; D - female terminalia, ventral view.

ed apically with apical half of uncal lobe curved inwardly at about $140^{\circ}$ in lateral view.

Female. Opercula short and obtusely triangulate, with outer $2 / 3$ of posterior margin oblique; posterior margin of abdominal sternite VII truncate, with wide and triangular incision. Other characteristics similar to male.

Distribution. China (East Tibet).

Remarks. No holotype (only syntypes) of $A$. pekinensis exist, but a male specimen (see Fig. 19) deposited in the Museum für Tierkunde Dresden (MTD) was labelled as the lectotype by R. Remane. However, this designation is not mentioned in any publication. Therefore, the lectotype designation by Remane is invalid. In order to define this species, we here formally designate this specimen as the lectotype of $A$. pekinensis.

\section{Auritibicen slocumi (Chen, 1943)}

Cicada flammata sensu Melichar, 1902: 79 (nec Distant, 1892). Tibicen slocumi Chen, 1943: 24.

Lyristes slocumi: Chou et al., 1997: 285.

Auritibicen slocumi: Lee, 2015: 241.

Subsolanus slocumi: Hill et al., 2015: 229.

Material examined. $1 \delta^{\widehat{N}}$ (NWAFU), China: Maerkang County, Sichaun Province, 2600 m, 9.vii.1983; 1ð̄, 1ㅇ (MZM): Shitsuan, Wenchunsien-Sinpuguan, Potan. 10.-18.viii.1993, Cicada leechi Dist. det. Melichar; $1 \hat{\jmath}, 1$ ( 1 (ZIN), same data, Cicada flammata det. Melichar; $1 \hat{\jmath}$ (NWAFU), China: Bobai County, Guangxi Province, 2.v.1987.
Measurements. $(1 \precsim)$. Body length: 35.2 ; fore wing length: 40.7; fore wing width: 14.1; width of head including eyes: 12.1; pronotum width (including pronotal collar): 13.3; mesonotum width: 10.3; expanse of fore wings: 96.0 .

Description of male. Head (Fig. 20A, B). Black, with a pair of yellowish spots on posterolateral angles of vertex; small black spot within each yellowish spot. Eyes and ocelli yellowish brown. Supra-antennal plates yellow. Postclypeus prominently produced anteriad; ochraceous with a pair of black spots near frontoclypeal suture. Transverse grooves black with yellow pollinosity. Lora black with yellow margins. Rostrum yellow with apical part black, reaching mid coxa.

Thorax (Fig. 20A). Inner area of pronotum ochraceous, with a pair of narrow black central longitudinal fasciae much widened laterally at the anterior ends, and terminating posteriorly in a circular spot. Lateral and posterior margins of inner area black. Pronotal collar yellow, with a spot on median part and a pair of spots on margins. Posterior margin of pronotal collar fuscous. Mesonotum black, with the following yellow markings: a continuous W-shaped marking in front of cruciform elevation; longitudinal fasciae along lateral margins. Cruciform elevation yellow with a large black spot medially.

Wings (Fig. 20A). Hyaline. Fore wing with costal membrane and basal cell greenish ochraceous; basal cell about twice as long as wide, and with fuscous spot; infuscation on 


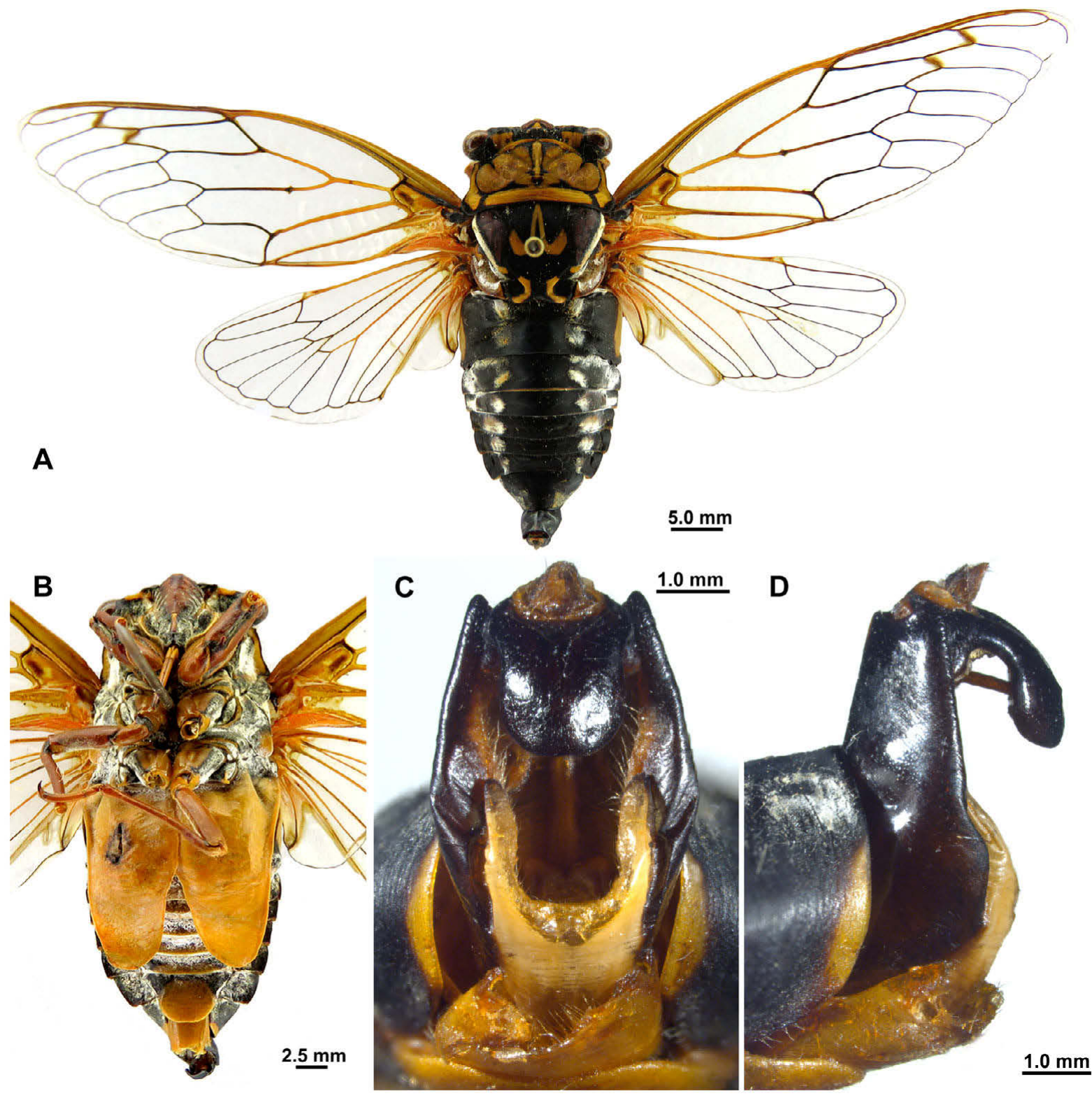

Fig. 24. Auritibicen daoxianensis sp. n. (male, holotype). A - habitus, dorsal view; B - head, thorax and abdomen, ventral view; $\mathrm{C}-$ male pygofer, ventral view; D - male pygofer, lateral view.

r, r-m crossveins, base of apical cell 3 , $\mathrm{m}$ and $\mathrm{m}$-cu crossveins; base of ulnar cell 2 as long as base of ulnar cell 3; base of apical cell 1 longer than base of apical cell 2. Hind wing without infuscation. Basal half of wing veins yellow.

Abdomen (Fig. 20A, B). Cylindrical. Tergites black, with longitudinal series of white powdery spots sublaterally on each abdominal segment; lateral length of tergite 4 as long as median length; tergite 8 longer than tergites 6 and 7 combined. Abdominal sternites and epipleurites black with yellow margins; sternite VIII as long as sternite VII. Timbal covers black with yellow lateral margins. Opercula ochraceous, inner margins separate; lateral margins straight, strongly turned upwards; posterior margins convexly rounded, and reaching posterior margin of abdominal sternite II.

Male genitalia (Figs 20C, D, 37M, 38M). Pygofer barrelshaped. Basal lobes of pygofer yellow with apex black and curved outwardly in ventral view. Uncal lobe black and rounded apically with apical half of uncal lobe curved inwardly at about $100^{\circ}$ in lateral view.

Distribution. China (Sichuan, Guangxi).

Female. Unknown.

Remarks. Cicada flammata recorded from W. China by Melichar (1902) is identical to this species.

\section{Auritibicen tsaopaonensis (Chen, 1943)}

Tibicen tsaopaonensis Chen, 1943: 26.

Lyristes tsaopaonensis: Chou et al., 1997: 282.

Auritibicen tsaopaonensis: Lee, 2015: 241.

Subsolanus tsaopaonensis: Hill et al., 2015: 229.

Material examined. $1 \hat{\sigma}$ (NWAFU), China: Mount Emei, Sichuan Province, 1800 m, 11.vi.1980, Huang Keren leg.; $3 \hat{\jmath}$ (NWAFU), China: Yiliang County, Zhaotong City, Yunnan Prov-

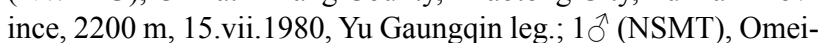
shan, Szechwan, W. China, 10.ix.1985, T. Hasegawa leg; $1{ }^{\Uparrow}$ 


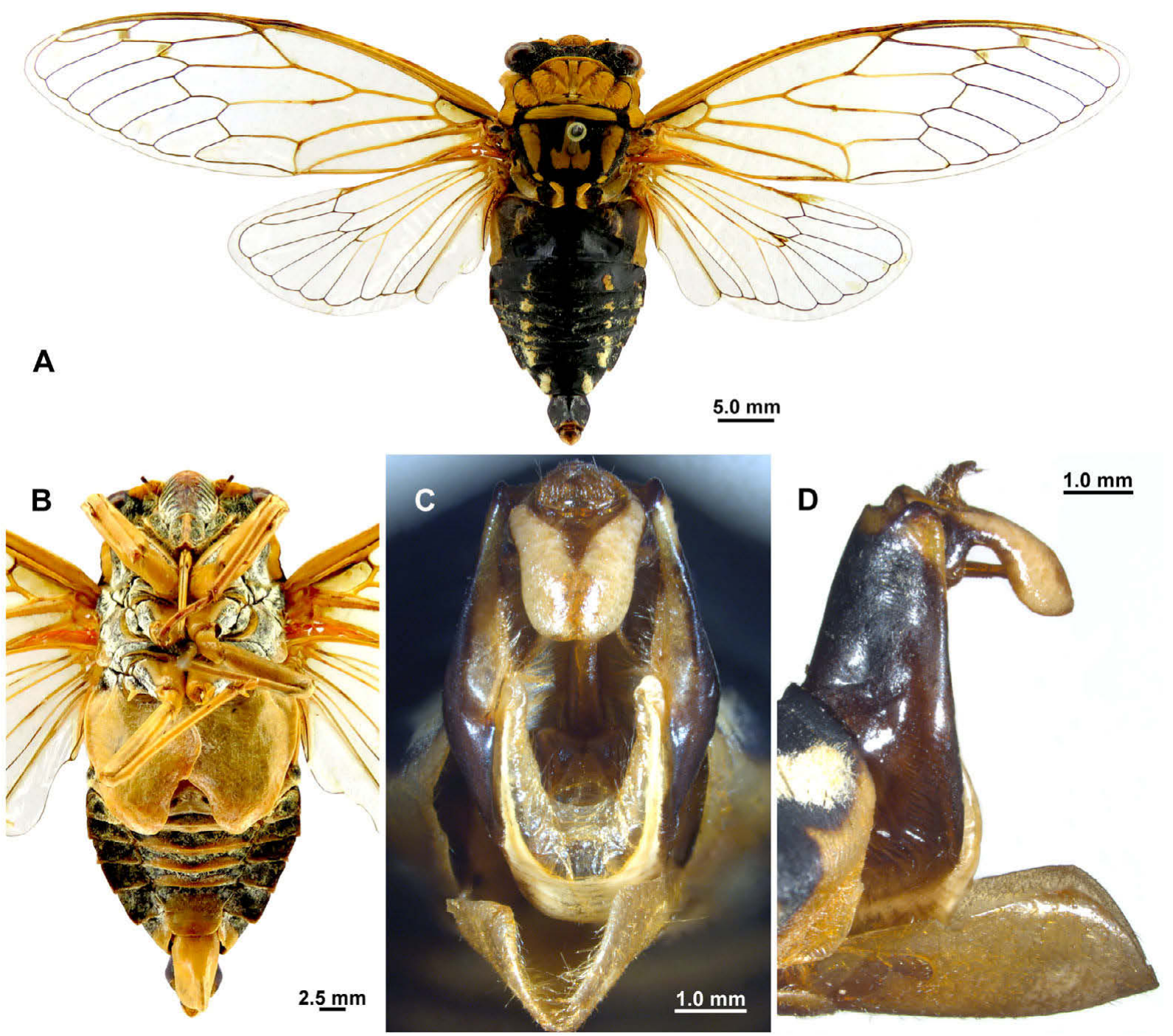

Fig. 25. Auritibicen pallidus sp. n. (male, holotype). A - habitus, dorsal view; B - head, thorax and abdomen, ventral view; C - male pygofer, ventral view; D - male pygofer, lateral view.

(TUA), China: Dayi primeval forest (= Mt. Xi-ling), Szechwan, 8.viii.1991, J. Aoyama leg.

Measurements. $(4 \overbrace{}^{\Uparrow})$. Body length: 32.1-33.0; fore wing length: 38.0-39.4; fore wing width: 13.1; width of head including eyes: 11.6-13.2; pronotum width (including pronotal collar): 11.8-13.5; mesonotum width: 9.610.3; expanse of fore wings: 32.1-33.0.

Description of male. Head (Fig. 21A, B). Black, with a pair of yellowish spots on posterolateral angles of vertex; small black spot within each yellowish spot. Eyes fuscous; ocelli yellow. Supra-antennal plates yellow. Postclypeus yellow with a pair of ochraceous spots near frontoclypeal suture in dorsal view. Transverse grooves ochraceous. Lora black with yellow margins. Rostrum yellow with apical part black, and reaches mid trochanter.

Thorax (Fig. 21A). Inner area of pronotum yellow, with three pairs of black spots longitudinally. Anterior margin of inner area yellow. Pronotal collar yellow, with markings. Posterior margin of pronotal collar black. Mesonotum black, with the following yellow markings: a continuous $\mathrm{W}$-shaped marking in front of cruciform elevation; a pair of large yellow tongue-shaped markings on lateral sigilla; longitudinal fasciae along lateral margins. Cruciform elevation yellow with a large black spot medially.

Wings (Fig. 21A). Hyaline. Fore wing with a wide zigzag infuscated band coinciding with base of apical cells, only broken at base of apical cell 6 ; base of ulnar cell 2 as long as base of ulnar cell 3; base of apical cell 1 shorter than base of apical cell 2. Hind wing without infuscation. Basal half of wing veins yellow.

Abdomen (Fig. 21A, B). Cylindrical. Tergites black, with only one pair of white powdery spots sublaterally on tergite 1; posterior margins of tergite 7 and 8 yellowish; lateral length of tergite 4 as long as median length; tergite 8 longer than tergites 6 and 7 combined. Abdominal sternites and epipleurites black with yellow margins; sternite VIII longer than sternite VII. Timbal covers black with yellow lateral margins. Opercula ochraceous, inner margins separate, angulated apically, and just extending beyond posterior margin of abdominal sternite II.

Male genitalia (Figs 21C, D, 37N, 38N). Pygofer barrelshaped. Basal lobes of pygofer yellow and curved inward- 

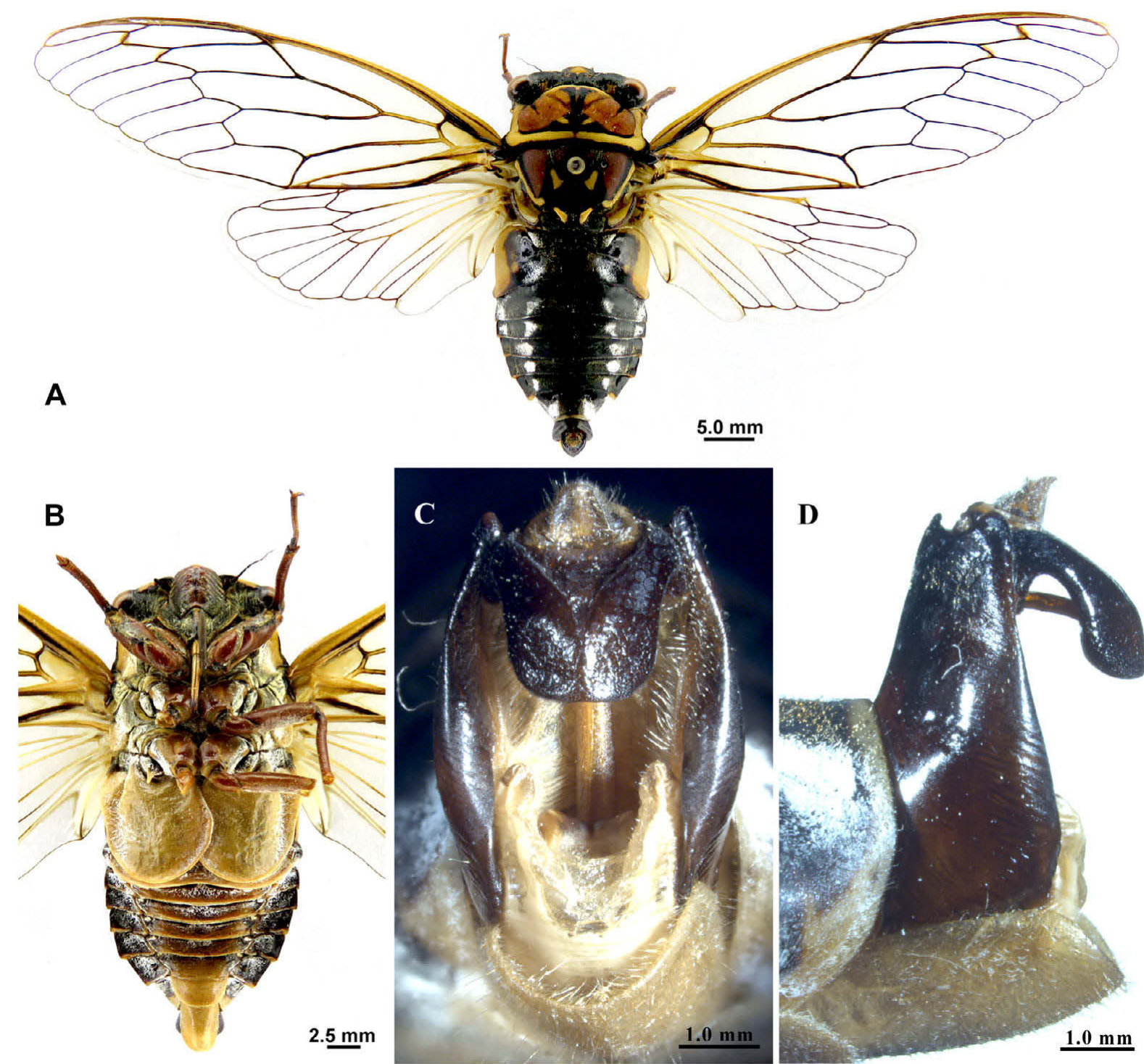

Fig. 26. Auritibicen rotundus sp. n. (male, holotype). A - habitus, dorsal view; B - head, thorax and abdomen, ventral view; C - male pygofer, ventral view; D - male pygofer, lateral view.

ly in ventral view. Uncal lobe ochraceous with truncated apex.

Female. Unknown.

Distribution. China (Sichuan, Yunnan).

\section{Auritibicen aethus sp. $\mathrm{n}$.}

ZooBank taxon LSID:

56292330-0066-4697-B387-624FA4350FC6

Type material. Holotype: ô (NWAFU), China: Longquan City, Zhejiang Province, 1.viii.1983. Paratype: $1+$ (NWAFU), China: Mt. Meihua, Fujian Province, 20.vii.1987.

Etymology. The species name is a Latin masculine adjective meaning "reddish brown", signifying the colouration of the inner area of the pronotum.

Measurement of types. $(1 \hat{\jmath}, 1 \uparrow)$ : Body length: male 44.6, female 40.6; fore wing length: male 51.7, female 53.4; fore wing width: male 16.6 , female 18.1 ; width of head including eyes: male 16.6, female 15.6; pronotum width (including pronotal collar): male 17.1, female 16.7; mesonotum width: male 12.7, female 12.9; expanse of fore wings: male 116.9 , female 113.8 .

Description of male. Head (Fig. 22A, B). Slightly wider than mesonotum. Almost black, with a pair of small yellowish spots on posterolateral angles of vertex; small black spot within each yellowish spot. Eyes yellowish green; ocelli yellow. Supra-antennal plates yellow. Postclypeus moderately swollen, black with a large yellow spot near frontoclypeal suture in dorsal view. Rostrum black with apical part yellow, extending to the posterior margin of mid coxa.

Thorax (Fig. 22A). Inner area of pronotum mostly reddish brown, with anterior margin yellow; a yellow central longitudinal fascia surrounded by a black hourglassshaped marking on anterior half, thereafter with a large somewhat black patch. Pronotal collar mostly yellow, with very narrow black posterior margin, and black margin dilated inward medially. Mesonotum black, with a yellow discontinuous $\mathrm{W}$-shaped marking in front of cruciform ele- 

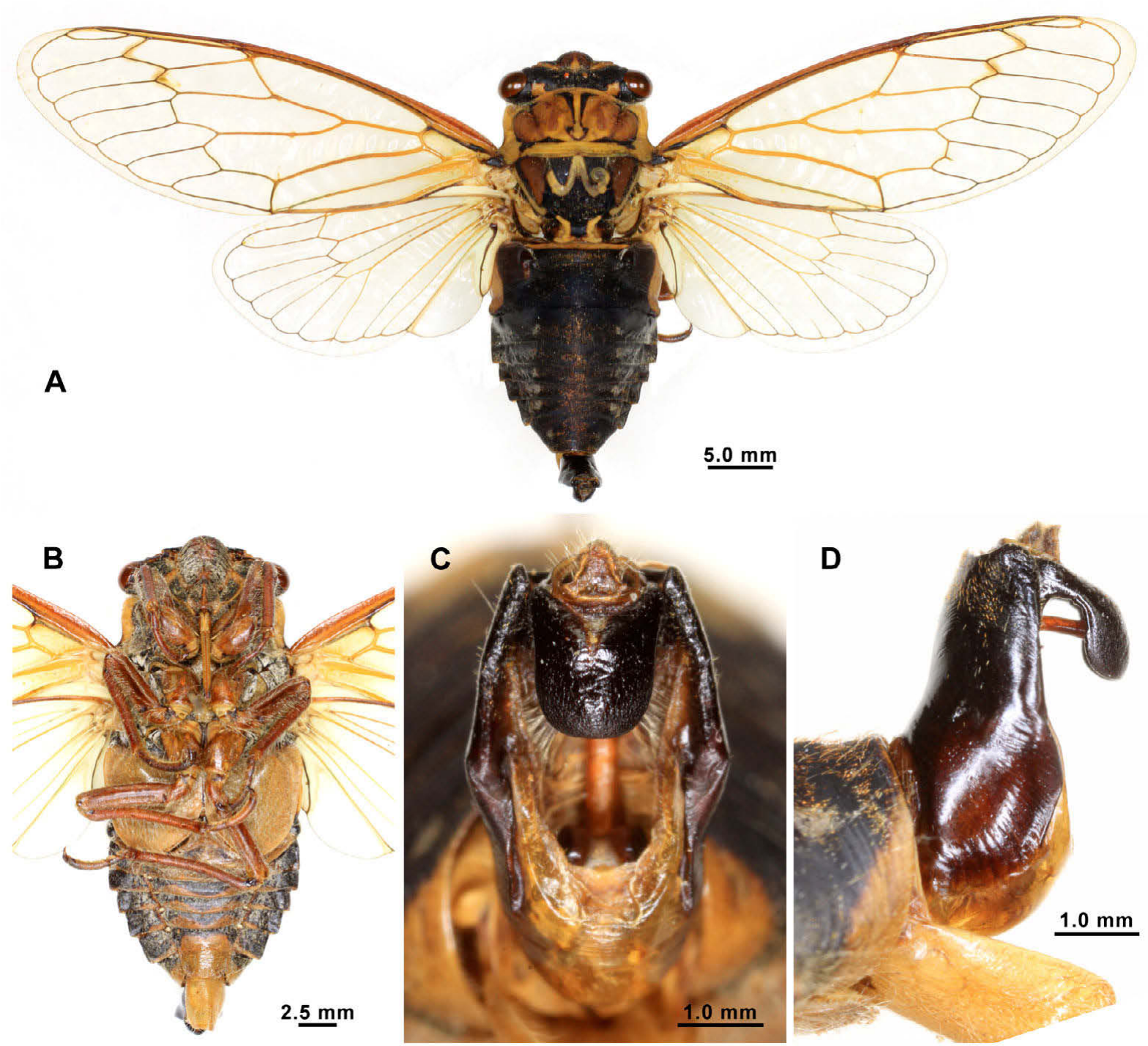

Fig. 27. Auritibicen gracilis sp. n. (male, holotype). A - habitus, dorsal view; B - habitus, ventral view; C - male pygofer, ventral view; $\mathrm{D}$ - male pygofer, lateral view.

vation; a pair of yellow fasciae along lateral margins of mesonotum; cruciform elevation yellow with a large black spot medially.

Wings (Fig. 22A). Hyaline. Fore wing with infuscation on $\mathrm{r}, \mathrm{r}-\mathrm{m}$ crossveins, base of apical cell 3 , base of apical cell $4, \mathrm{~m}$ and $\mathrm{m}$-cu crossveins (the holotype without medial crossvein in right fore wing, which is a deformation in the fore wing venation). Ulnar cell 2 shorter than base of ulnar cell 3; base of apical cell 1 longer than base of apical cell 2. Hind wing without infuscation. Basal half of wing veins black.

Abdomen (Fig. 22A, B). Cylindrical. Tergites black, with a pair of small white pollinosity spots sublaterally on tergites $1-8$, respectively; lateral length of tergite 4 shorter than median length; tergite 8 distinctly longer than tergites 6 and 7 combined. Abdominal sternites opaque, black basally and ochraceous distally; sternite VIII shorter than sternite VII; epipleurites fuscous with yellow posterior margins. Timbal covers black, completely covering timbals. Opercula ochraceous, inner margins not overlapping, reaching beyond anterior margin of abdominal sternite $\mathrm{V}$.
Male genitalia (Figs 22C, D, 37O, 38O). Pygofer barrelshaped. Basal lobes of pygofer yellow with apex black, erect in ventral view. Uncal lobe black, truncated apically in ventral view and curved inwardly in lateral view.

Female (Fig. 23). Opercula small, posterior margin not reaching abdominal sternite II. Abdominal segment 9 black in dorsal view and yellow in ventral view; ovipositor sheath black, not protruding beyond segment 9 , incision in the middle of the posterior margin of abdominal sternite VII. Other characteristics similar to male.

Distribution. China (Zhejiang, Fujian).

Remarks. This new species is similar to A. bihamatus, but can be distinguished by its much larger body-size, the colouration of uncal lobes, the shape of basal lobes and the length of male opercula. The holotype of A. aethus sp. $\mathrm{n}$. is unusual in lacking crossveins between ulnar cell 3 and apical cell 5 in the right fore wing, which is a deformation in the venation of the fore wings.

This new species is also similar to $A$. jai, but can be distinguished by the following characters: inner margins of male opercula seperate (contiguous or overlap in A. jai); 

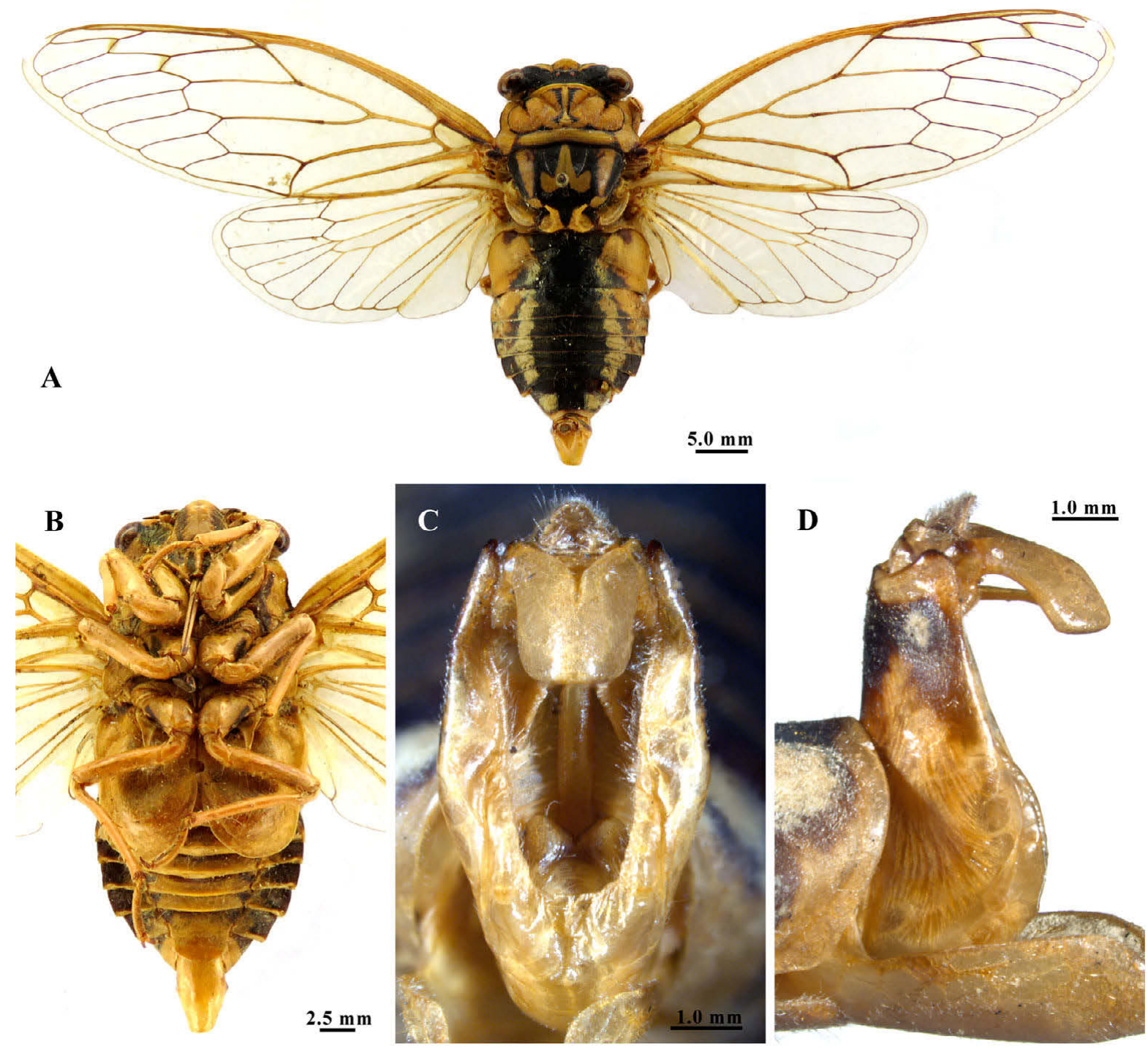

Fig. 28. Auritibicen septatus sp. n. (male, holotype). A - habitus, dorsal view; B - head, thorax and abdomen, ventral view; $\mathrm{C}-$ male pygofer, ventral view; D - male pygofer, lateral view.

basal cell of fore wing with black markings (lack black markings in $A$. jai); posterior margin of pronotum without a pair of yellow markings (with a pair of yellow markings in $A$. jai).

\section{Auritibicen daoxianensis sp. $\mathbf{n}$.}

ZooBank taxon LSID:

\section{A2AB6D28-139E-49C7-9E6B-6174A1445B9B}

Type material. Holotype: $\hat{\sigma}$ (NWAFU), China: Daoxian County, Hunan Province, 28.viii.1982.

Etymology. The species name is derived from the type locality.

Measurements of type. $\left(10^{\lambda}\right)$ : Body length: 38.2 ; fore wing length: 47.7 ; fore wing width: 14.8 ; width of head including eyes: 13.4; pronotum width (including pronotal collar): 14.0; mesonotum width: 11.1; expanse of fore wings: 105.3 .

Description of male. Head (Fig. 24A, B). Slightly wider than mesonotum. Black, with a pair of yellowish spots on posterolateral angles of vertex; a pair of small black spots on posterior margin of vertex. Eyes fuscous; ocelli red. Postclypeus moderately swollen, red with a yellowish green upside-down triangular marking near frontoclypeal suture, which has black margins. Transverse grooves black with white pollinosity. Lora black with yellow margins and white pollinosity. Rostrum yellow to ochraceous with apical part black, extending to the anterior margin of mid coxae.

Thorax (Fig. 24A). Inner area of pronotum with narrow anterior yellow and narrow lateral and posterior margins black. A yellow central longitudinal fascia surrounded by irregular black markings; a pair of black triangular spots on the posterior margin of inner area. Pronotal collar broad and yellow, with black margins and a pair of black markings on each posterolateral area. Mesonotum black, with a narrow, continuous W-shaped marking in front of cruciform elevation; large brown tongue-shaped markings on lateral sigilla; lateral margin of mesonotum yellow, with white pollinosity; cruciform elevation yellow with a large spot medially and a pair of black spots on anterior angles. 


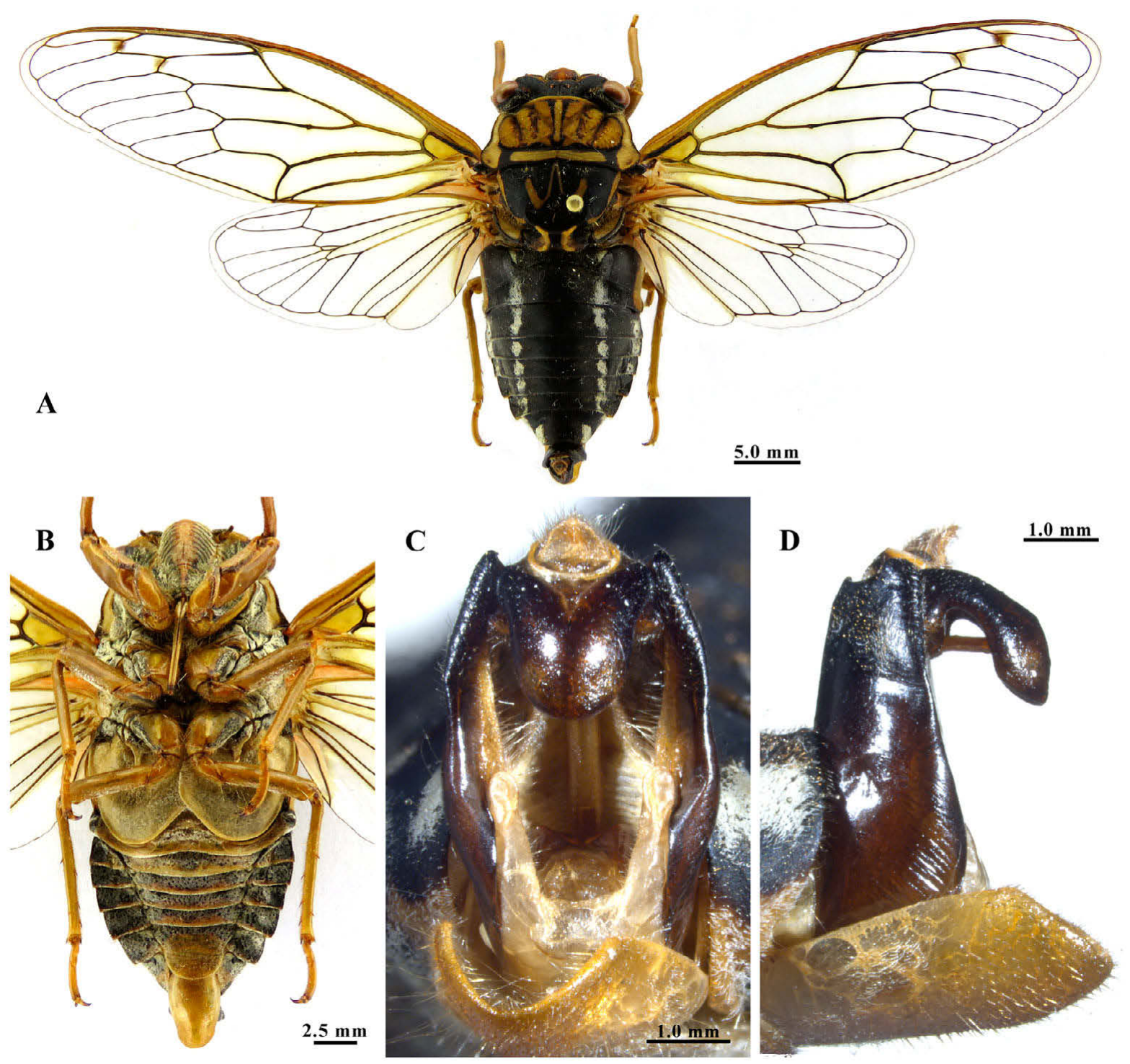

Fig. 29. Auritibicen lijiangensis sp. n. (male, holotype). A - habitus, dorsal view; B - head, thorax and abdomen, ventral view; $\mathrm{C}-$ male pygofer, ventral view; D - male pygofer, lateral view.

Wings (Fig. 24A). Hyaline. Fore wing with infuscation on $\mathrm{r}$ and $\mathrm{r}-\mathrm{m}$ crossveins; base of ulnar cell 2 shorter than base of ulnar cell 3; base of apical cell 1 longer than base of apical cell 2. Hind wing without infuscation. Basal half of wing veins yellow.

Abdomen (Fig. 24A, B). Cylindrical. Tergites black, with longitudinal series of white pollinosity spots on tergites $1-8$, respectively; lateral length of tergite 4 as long as median length, tergite 8 distinctly longer than tergites 6 and 7 combined. Abdominal sternites opaque, black basally and ochraceous distally, with white pollinosity; sternite VIII shorter than sternite VII; epipleurites black with yellow posterior margins. Timbal covers black and completely covering timbal. Opercula ochraceous, inner margins overlap for about $1 / 2$ of the length from base, and reach posterior margin of abdominal sternite VI.

Male genitalia (Figs 24C, D, 37P, 38P). Pygofer barrelshaped. Basal lobes of pygofer yellow, with apex black and curved outwardly in ventral view. Uncal lobe black and truncated apically; apex curved inwardly in lateral view.
Female. Unknown.

Distribution. China (Hunan).

Remarks. This new species is similar to A. leechi, but can be distinguished by the colouration of abdominal sternites and the shape of opercula. This new species is also similar to A. esakii, but can be distinguished by the length of the male opercula.

\section{Auritibicen pallidus sp. $\mathbf{n}$.}

ZooBank taxon LSID:

DC37887B-8FEA-4CCB-9AFB-0D7DBDF01DCE

Type material. Holotype: $\delta$ (NWAFU), China: Xichang City, Sichuan Province, vii. 1980.

Etymology. The species name is a Latin masculine adjective meaning "light-coloured", signifying the light-coloured uncal lobes.

Measurements of type. $\left(1{ }^{1}\right)$ : Body length: 35.7 ; fore wing length: 45.7; fore wing width: 15.2; width of head including eyes: 12.2 ; pronotum width (including pronotal collar): 13.0; mesonotum width: 9.9; expanse of fore wings: 100.2 . 

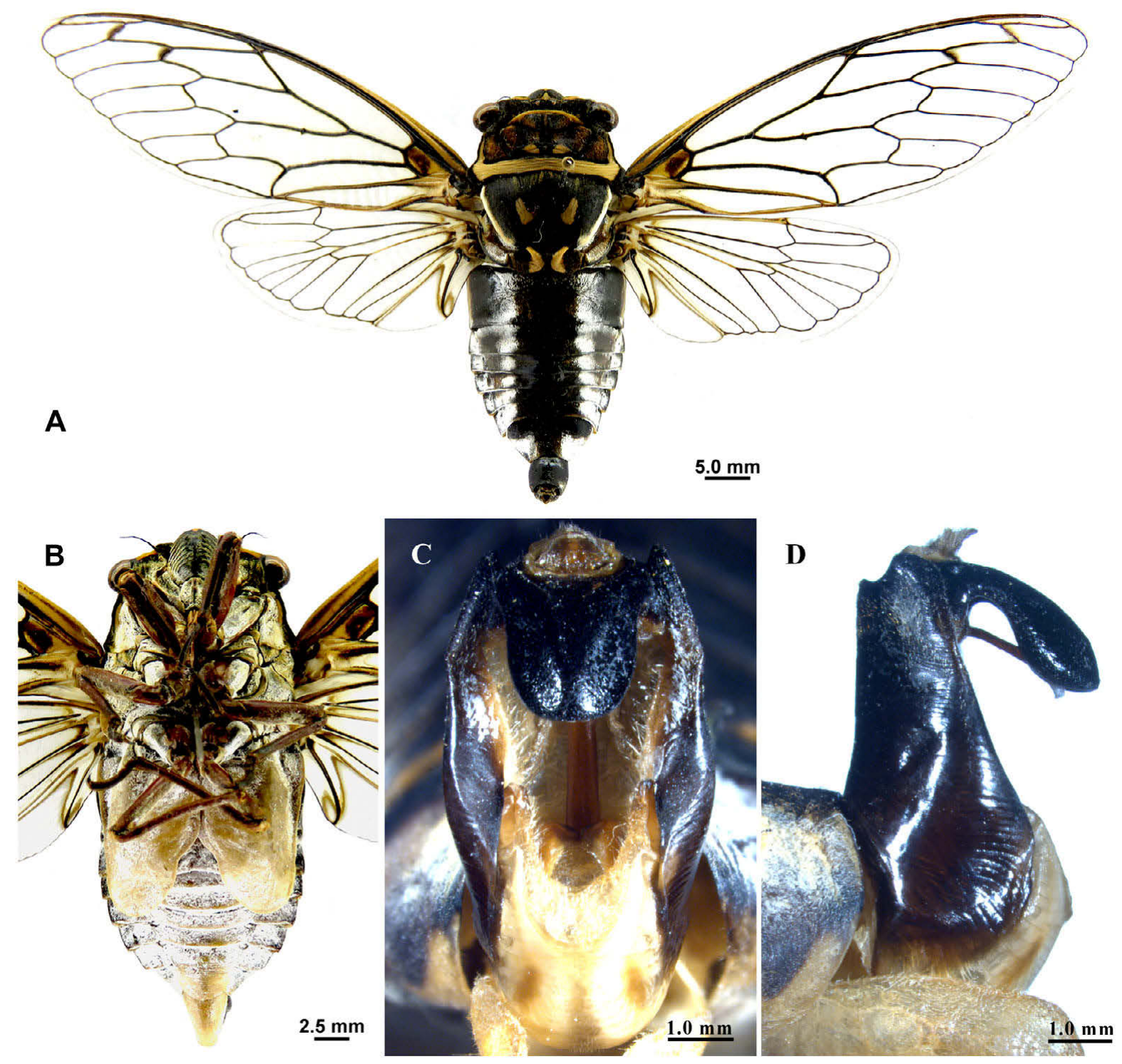

Fig. 30. Auritibicen curvatus sp. n. (male, holotype). A - habitus, dorsal view; B - head, thorax and abdomen, ventral view; C - male pygofer, ventral view; D - male pygofer, lateral view.

Description of male. Head (Fig. 25A, B). Black, with no markings. Eyes fuscous; ocelli red. Supra-antennal plates yellow. Postclypeus moderately swollen and ochraceous. Transverse grooves black with white pollinosity. Lora black with yellow margins and white pollinosity. Rostrum yellow with apical part black, extending to the anterior margin of mid coxae.

Thorax (Fig. 25A). Inner area of pronotum yellow, with irregular black markings near anterior and posterior margins. Lateral and posterior margins of inner area black. Pronotal collar broad and yellow, with a pair of black straight markings laterally on the posterior margin. Mesonotum black, with the following yellow markings: a rather distinct, continuous $\mathrm{W}$-shaped marking in front of cruciform elevation; a pair of large tongue-shaped markings on lateral sigilla; a pair of very short fasciae in front of anterior angles of cruciform elevation. Cruciform elevation yellow with a large spot medially and a pair of black spots on anterior angles.
Wings (Fig. 25A). Hyaline. Fore wing with faint infuscation on $\mathrm{r}$ and $\mathrm{r}-\mathrm{m}$ crossveins; base of ulnar cell 2 as long as base of ulnar cell 3; base of apical cell 1 shorter than base of apical cell 2. Hind wing without infuscation. Basal half of wing veins yellow.

Abdomen (Fig. 25A, B). Cylindrical. Tergites black, with a pair of large white pollinosity spots on tergites $1-8$, respectively; lateral length of tergite 4 shorter than median length; tergite 8 as long as tergites 6 and 7 combined. Abdominal sternites opaque, black basally and ochraceous distally; sternite VIII longer than sternite VII; epipleurites black. Timbal covers fuscous medially and yellow laterally and completely covering timbal. Opercula yellow, inner margins overlap for about $1 / 2$ of the length from base, angular and triangulate apically, and extend beyond posterior margin of abdominal sternite III.

Male genitalia (Figs 25C, D, 37Q, 38Q). Pygofer barrelshaped. Basal lobes of pygofer yellow and erect in ventral view. Uncal lobe mostly yellow and rounded apically. 


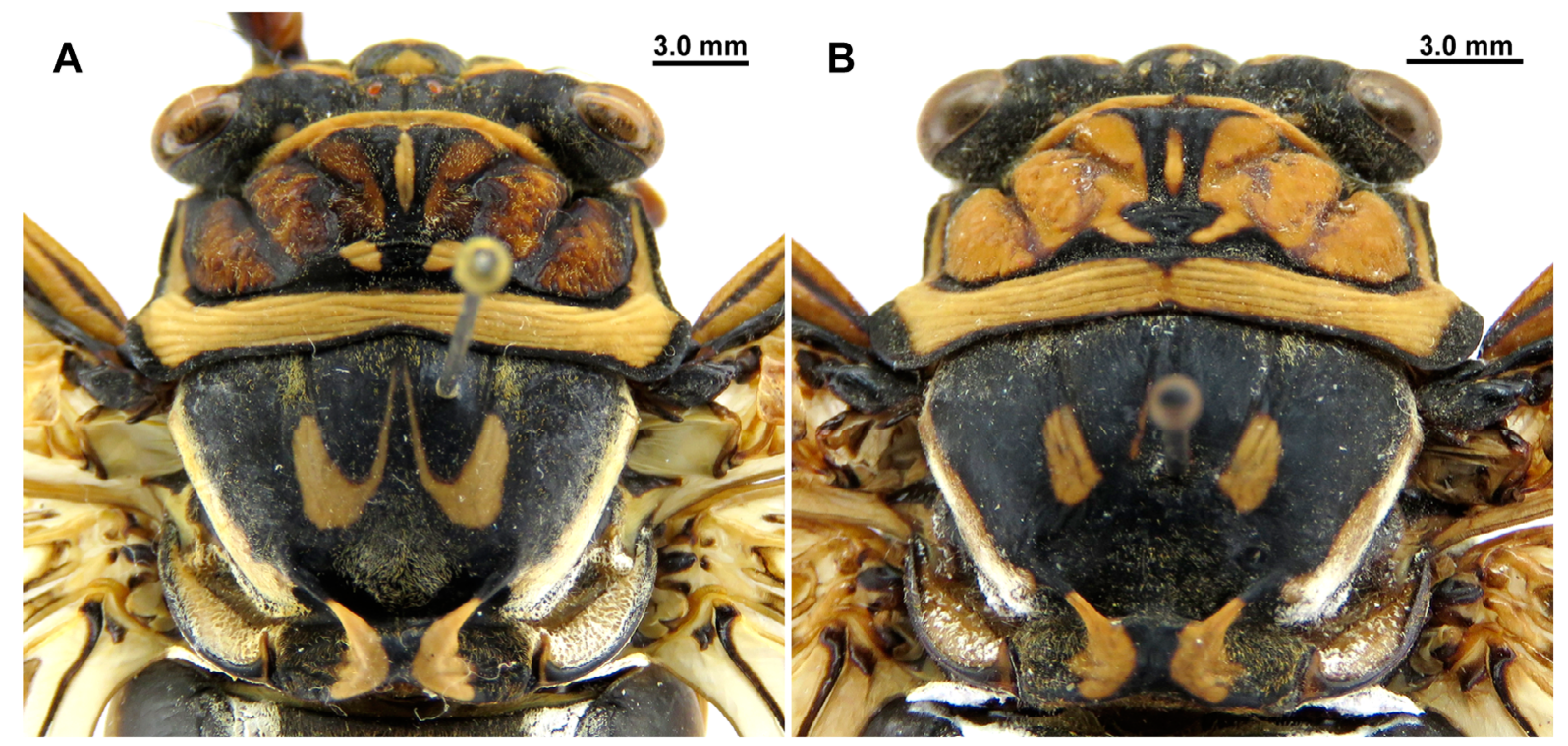

Fig. 31. Auritibicen curvatus sp. n. (males). A \& B - habitus, dorsal view, showing intraspecific variation.

Female. Unknown.

Distribution. China (Sichuan).

Remarks. This new species is similar to A. pekinensis, but can be distinguished by the shape of the opercula. This new species is also similar to A. purus sp. n., but can be distinguished by its different body size, markings on the pronotal collar, and the colour of its sternites.

\section{Auritibicen rotundus sp. $\mathrm{n}$.}

ZooBank taxon LSID:

B71684F6-8E07-4519-8602-5181C6C1EC70

Type material. Holotype: $\delta$ (NWAFU), China: Mts Shennongjia, Hubei Province, 13.viii.2004, Shiqing Xu leg.

Etymology. The species name is a Latin masculine adjective meaning "rounded", signifying the rounded posterior margin of the opercula.

Measurements of type. $\left(1 \delta^{\Uparrow}\right)$. Body length: 38.4 ; fore wing length: 48.6; fore wing width: 16.0; width of head including eyes: 14.2 ; pronotum width (including pronotal collar): 15.0; mesonotum width: 12.1 ; expanse of fore wings: 110.0 .

Description of male. Head (Fig. 26A, B). Black, with a pair of small faint yellow spots on posterolateral angles of vertex. Eyes fuscous; ocelli yellow. Supra-antennal plates black. Postclypeus moderately swollen, castaneous with a large yellow spot near frontoclypeal suture in dorsal view. Lora black with yellow margins. Rostrum ochraceous with apical part black, extends to the anterior margin of mid coxae.

Thorax (Fig. 26A). Inner area of pronotum ochraceous, with yellow narrow anterior and narrow black lateral and posterior margins. A black central longitudinal fascia curved outward and dilated both anteriorly and posteriorly; a pair of black short fasciae along lateral fissures; a pair of yellow spots near posterior margin of inner area. Pronotal collar broad and yellow, with posterior margin black. Mesonotum black, with a discontinuous W-shaped mark- ing in front of cruciform elevation; a pair of large brown tongue-shaped markings on lateral sigilla; a pair of yellow longitudinal fasciae along lateral margin of mesonotum. Cruciform elevation black with a yellow spot on each anterior angle.

Wings (Fig. 26A). Hyaline. Fore wing with infuscation on $\mathrm{r}$ and $\mathrm{r}-\mathrm{m}$ crossveins; base of ulnar cell 2 shorter than base of ulnar cell 3; base of apical cell 1 as long as base of apical cell 2. Hind wing without infuscation. Basal half of wing veins black.

Abdomen (Fig. 26A, B). Cylindrical. Tergites black, with longitudinal series of white pollinosity spots on tergites 1-8, respectively; lateral length of tergite 4 shorter than median length; tergite 8 shorter than tergites 6 and 7 combined. Abdominal sternites opaque and ochraceous, with anterior part of each sternite black; sternite VIII as long as sternite VII; epipleurites black, with yellow posterior margins. Timbal covers half black and half yellow and completely covering timbal. Opercula yellow, inner margins overlapping, with rounded posterior margin just reaching abdominal sternite II.

Male genitalia (Figs 26C, D, 37R, 38R). Pygofer barrelshaped. Basal lobes of pygofer yellow and curved inwardly. Uncal lobe black and truncated apically; apex curved inwardly in lateral view.

Female. Unknown.

Distribution. China (Hubei).

Remarks. This new species is similar to A. lijiangensis sp. n., but can be distinguished by the pair of large tongueshaped markings on lateral sigilla.

\section{Auritibicen gracilis sp. $\mathbf{n}$.}

ZooBank taxon LSID:

2ED87856-2905-4436-ABDC-8BFF476D8D9D

Type material. Holotype: $\widehat{\jmath}$ (SNSD), China: Kiŭlŭng Bez., Tatsienlǔ, Sz'Tschwan [= Sichuan Province]: Friedrich, 22.viii.1937, coll. A. Jacobi; Paratype $1 \widehat{\partial}$ (SNSD): Osaschi Bez., Tatsienlŭ, Sz'Tschwan: 22.viii.1937, coll. A. Jacobi. 

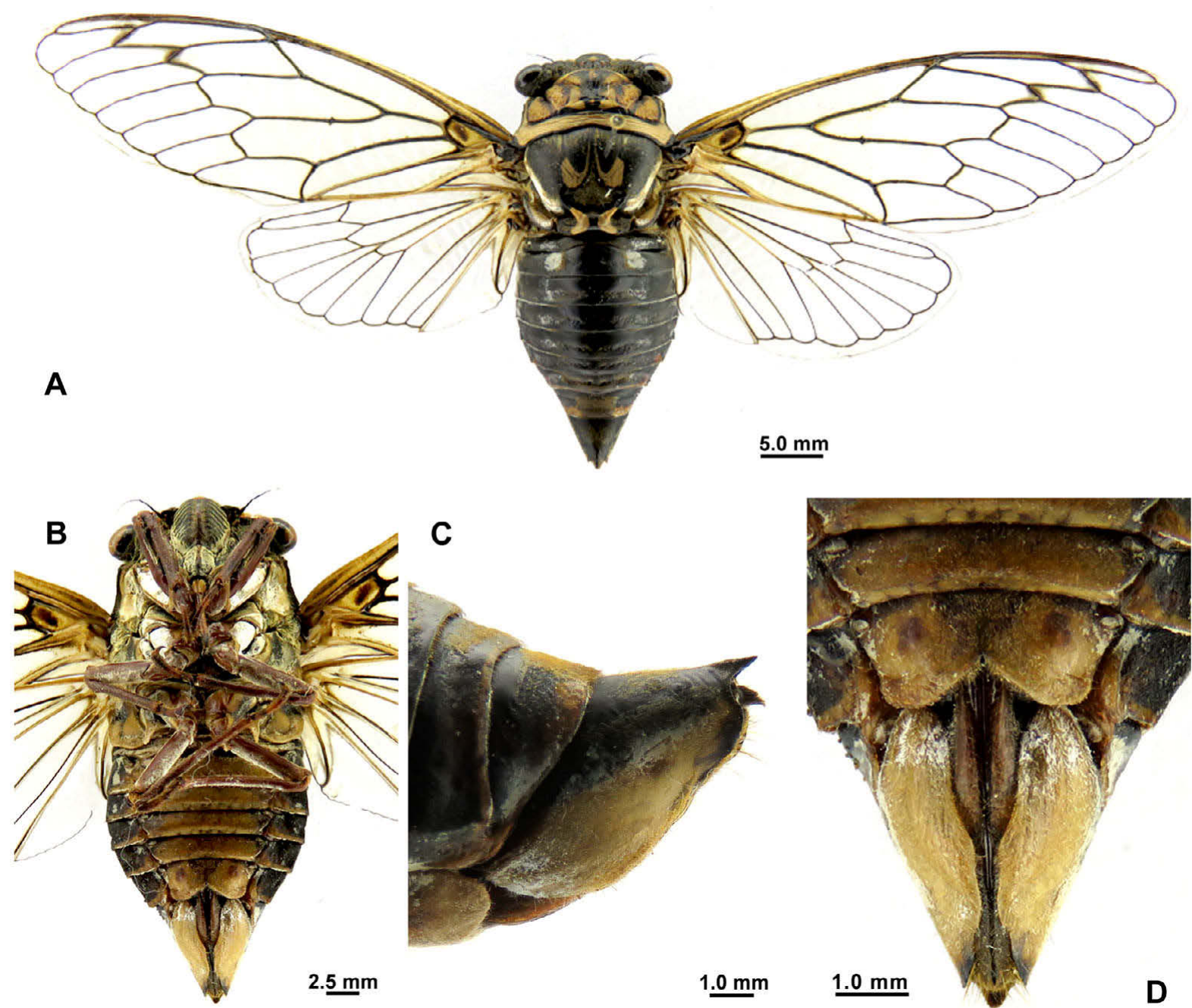

Fig. 32. Auritibicen curvatus sp. n. (female, paratype). A - habitus, dorsal view; B - head, thorax and abdomen, ventral view; $C$ - female terminalia, lateral view; D - female terminalia, ventral view.

Etymology. The species name is a Latin masculine adjective meaning "slender", signifying the slender W-shaped marking on the thorax.

Measurements of type. $(2 \precsim)$ : Body length: $32.6-33.5$; fore wing length: $37.2-37.5$; fore wing width: $12.5-13.1$; width of head including eyes: 11.5-12.1; pronotum width (including pronotal collar): 11.9-12.0; mesonotum width: 9.7-10.0; expanse of fore wings: 83.5.

Description of male. Head (Fig. 27A, B). Black, with a pair of small irregular yellow spots on posterolateral angles of vertex. Eyes castaneous; ocelli orange red. Supraantennal plates yellow. Postclypeus moderately swollen, castaneous with a large yellow upside-down triangular spot near frontoclypeal suture in dorsal view. Lora black with yellow margins. Rostrum yellow with apical part fuscous, extending to the anterior margin of mid coxae.

Thorax (Fig. 27A). Inner area of pronotum rather brownish ochraceous, with separate black markings along margins. A yellow central anchor shaped fascia with black edges. Pronotal collar broad and yellowish green, with two lateral black markings. Mesonotum black, with a slender, continuous $\mathrm{W}$-shaped marking in front of cruciform eleva- tion, ca. $1.6 \times$ as wide as long, evenly curved and constantly narrowed; a pair of large brown tongue-shaped markings on lateral sigilla; a pair of yellow longitudinal fasciae along lateral margins of mesonotum. Cruciform elevation yellow with a large black spot medially.

Wings (Fig. 27A). Hyaline. Fore wing with infuscation on $\mathrm{r}$ and $\mathrm{r}-\mathrm{m}$ crossveins; base of ulnar cell 2 shorter than base of ulnar cell 3; base of apical cell 1 shorter than base of apical cell 2; distal part of fore wing after nodal line is not elongate, rather shortened; ulnar cells becoming shorter. Hind wing without infuscation. Basal half of wing veins yellow.

Abdomen (Fig. 27A, B). Cylindrical. Tergites black, with a pair of small white pollinosity spots on lateral sides of each tergite. Abdominal sternites dull ochreceous; sternite VIII as long as sternite VII; epipleurites black with yellow posterior margins. Opercula ochraceous, inner margins not overlapping, and not reaching posterior margin of abdominal sternite II.

Male genitalia (Figs 27C, D, 37S, 38S). Pygofer wider near middle. Basal lobes narrow but elongate, reaching middle of pygofer. Uncal lobe black, slightly and gently narrows apically with evenly rounded margins. 

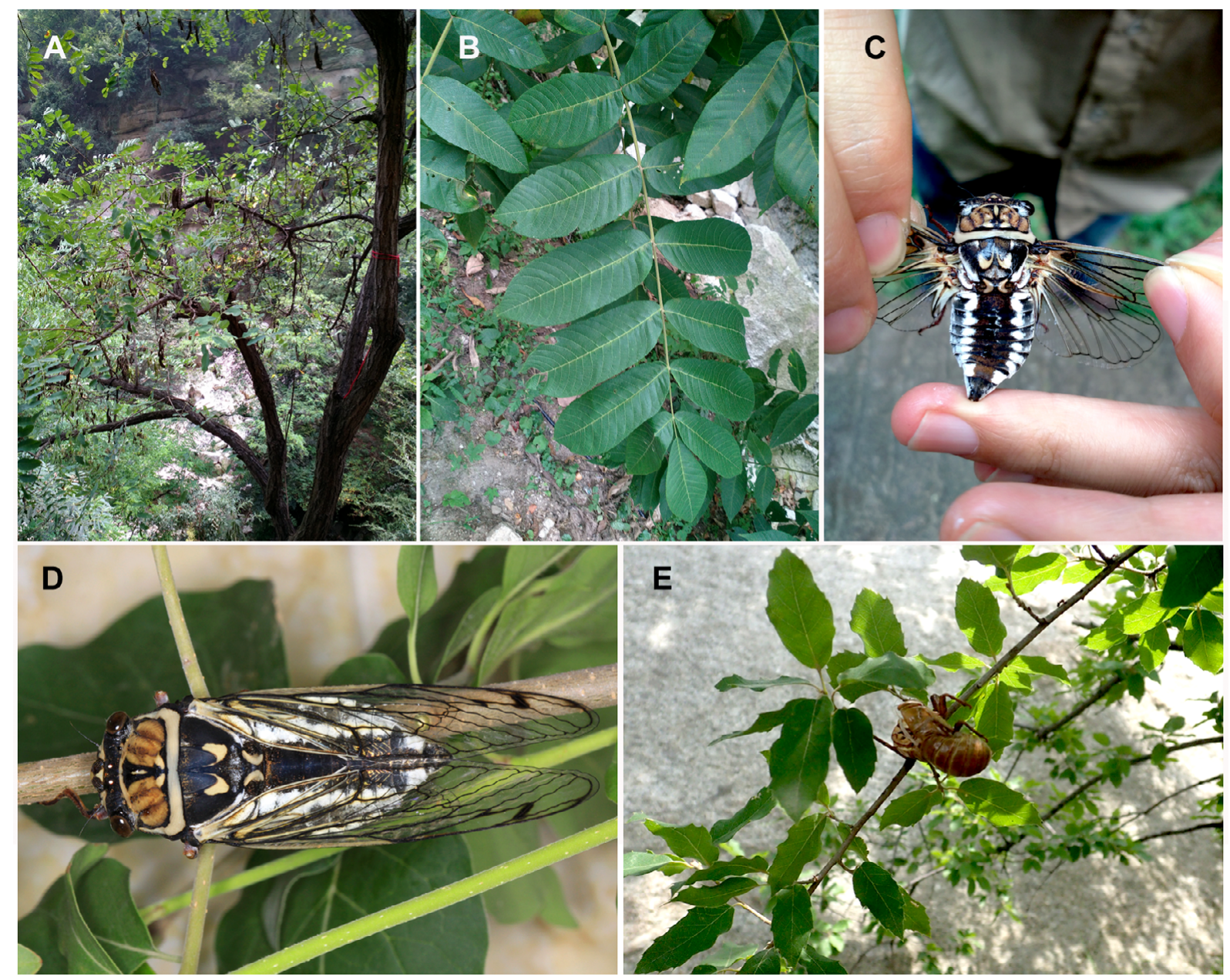

Fig. 33. A - habitat of Auritibicen curvatus sp. n.; $\mathrm{B}$ - host plant (Juglans regia) of $A$. curvatus sp. $\mathrm{n}$.; $\mathrm{C}-\mathrm{a}$ captured male individual of $A$. curvatus sp. $\mathrm{n}$. in Mt. Huashan; D - a male individual of $A$. curvatus sp. n. perching on a branch; $\mathrm{E}-$ exuvia of $A$. curvatus sp. $\mathrm{n}$. in Mt. Huashan.

Female. Unknown.

Distribution. China (Sichuan).

Remarks. This new species is similar to $A$. chujoi, but can be distinguished by its smaller body-size and different $\mathrm{W}$-shaped marking on mesonotum.

\section{Auritibicen septatus sp. $\mathrm{n}$.}

ZooBank taxon LSID:

A7D4ACC1-3D9D-45C0-A600-91381A5DA754

Type material. Holotype: $\widehat{\jmath}(\mathrm{MNHN})$, Yunnan, Se-Tchouen, Thibet, Lieut Grillières, 1904.

Etymology. The species name is a Latin masculine adjective meaning "separate", signifying the non-overlapping opercula.

Measurements of type. $\left(10^{\Uparrow}\right)$ : Body length: 38.6 ; fore wing length: 47.7; fore wing width: 15.7; width of head including eyes: 12.8 ; pronotum width (including pronotal collar): 14.1; mesonotum width: 10.6; expanse of fore wings 104.5.

Description of male. Head (Fig. 28A, B). Black, without markings. Eyes castaneous; ocelli orange. Supra-antennal plates yellow. Postclypeus moderately swollen, yellowish green with a central narrow brown longitudinal fascia in ventral view; a series of black lateral, transverse grooves in frontal view. Lora black with yellow margins. Rostrum yellow with apical part fuscous, extending to the anterior margin of mid coxae.

Thorax (Fig. 28A). Inner area of pronotum yellowish green, with a pair of central longitudinal fasciae black, extending from anterior margin of pronotum to pronotal collar, curved outward and dilated both anteriorly and posteriorly; margins of inner area black, with a pair of triangular spots near posterior margin. Pronotal collar broad and yellowish green, with two black narrow longitudinal fasciae laterally. Mesonotum black, with a broad, continuous yellow $\mathrm{W}$-shaped marking in front of cruciform elevation; a pair of large yellow tongue-shaped markings on lateral sigilla. Cruciform elevation yellow with a large black triangular spot medially.

Wings (Fig. 28A). Hyaline. Fore wing with faint infuscation on $\mathrm{r}$ and $\mathrm{r}-\mathrm{m}$ crossveins; base of ulnar cell 2 shorter than base of ulnar cell 3; base of apical cell 1 as long as base of apical cell 2. Hind wing without infuscation. Basal half of wing veins yellow.

Abdomen (Fig. 28A, B). Cylindrical. Tergites black, with longitudinal series of white pollinosity spots on each tergite; lateral length of tergite 4 about equal to median length; tergite 8 distinctly longer than tergites 6 and 7 combined. Abdominal sternites opaque, mostly yellow; sternite 

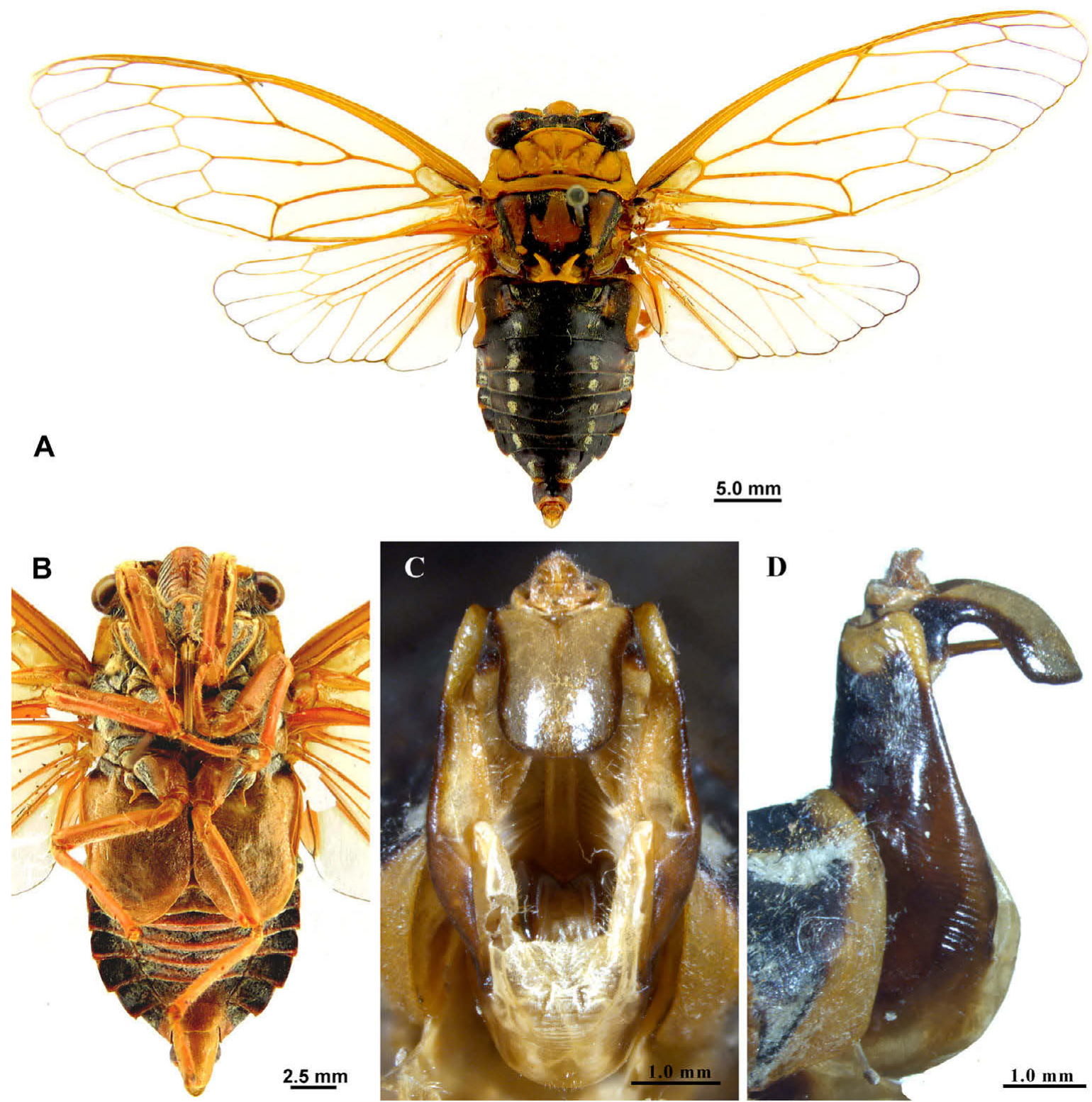

Fig. 34. Auritibicen purus sp. n. (male, holotype). A - habitus, dorsal view; B - head, thorax and abdomen, ventral view; C - male pygofer, ventral view; $\mathrm{D}$ - male pygofer, lateral view.

VIII as long as sternite VII; Epipleurites fuscous with yellow posterior margins. Timbal covers mostly yellow and completely cover timbal. Opercula castaneous, inner margins not overlapping, with widely rounded apex which protrudes beyond posterior margin of abdominal sternite III.

Male genitalia (Figs 28C, D, 37T, 38T). Pygofer barrelshaped. Basal lobes of pygofer slightly fuscous apically, elongate and divergent. Uncal lobe yellow and truncated apically.

Female. Unknown.

Distribution. China (Yunnan).

Remarks. This new species is similar to A. bihamatus, but can be distinguished by the pair of large tongue-shaped markings on lateral sigilla of mesonotum.

\section{Auritibicen lijiangensis sp. $\mathbf{n}$.}

ZooBank taxon LSID:

25E35E26-373F-49D1-8DDC-6AE23598C41C
Type material. Holotype: $\widehat{\jmath}$ (TUA), China: Baishui River, Naxi Minority Autonomous County, Lijiang City, Yunnan Province, 19.vii.1987.

Etymology. The species name is derived from the type locality.

Measurements of type. $\left(10^{\lambda}\right)$ : Body length: 32.5 ; fore wing length: 37.2 ; fore wing width: 12.8; width of head including eyes: 10.7; pronotum width (including pronotal collar): 12.7 ; mesonotum width: 8.9 ; expanse of fore wings: 85.0.

Description of male. Head (Fig. 29A, B). Black, without distinct markings. Eyes castaneous; ocelli yellow. Supra-antennal plates yellow. Postclypeus moderately swollen, castaneous with a series of black lateral, transverse grooves in frontal view. Lora black with yellow margins. Rostrum yellow with apical part black, extending to the anterior margin of mid coxae.

Thorax (Fig. 29A). Inner area of pronotum castaneous, with a pair of black central longitudinal fasciae, extend- 

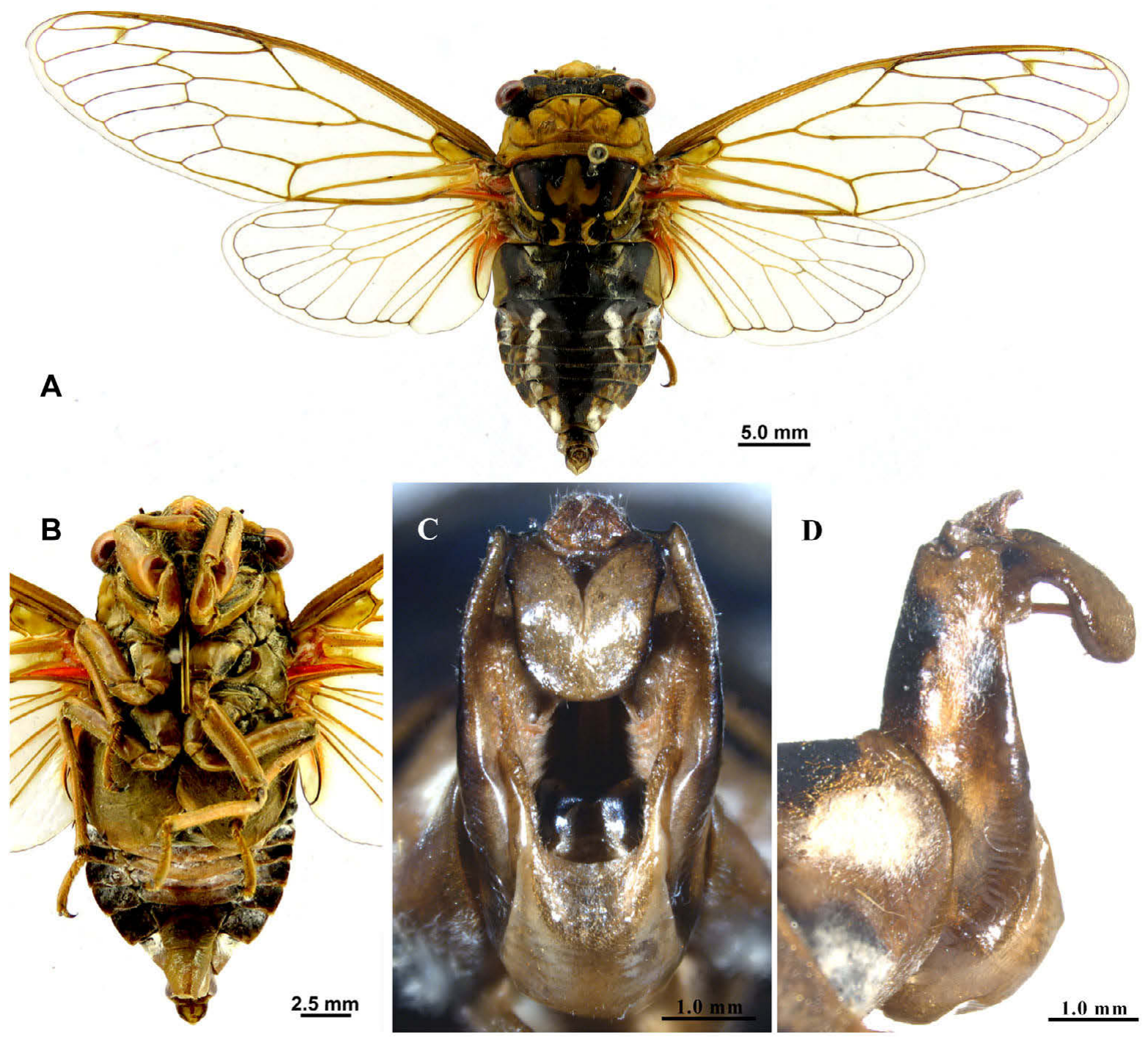

Fig. 35. Auritibicen parvus sp. n. (male, holotype). A - habitus, dorsal view; B - head, thorax and abdomen, ventral view; C - male pygofer, ventral view; $\mathrm{D}$ - male pygofer, lateral view.

ing from anterior margin of pronotum to pronotal collar, curved outward and dilated both anteriorly and posteriorly; paramedian fissures and lateral fissures fuscous; margins of inner area black, with a pair of triangular spots near posterior margin. Pronotal collar broad and yellowish green, with two black broad longitudinal fasciae laterally. Mesonotum black, with a narrow, continuous yellow W-shaped marking in front of cruciform elevation; a pair of narrow, yellow fasciae along lateral margins of mesonotum. Cruciform elevation yellow with a large black triangular spot medially.

Wings (Fig. 29A). Hyaline. Fore wing with faint infuscation on $\mathrm{r}$ and $\mathrm{r}-\mathrm{m}$ crossveins; base of ulnar cell 2 shorter than base of ulnar cell 3; base of apical cell 1 shorter than base of apical cell 2. Hind wing without infuscation. Basal half of wing veins black.

Abdomen (Fig. 29A, B). Cylindrical. Tergites black, with longitudinal series of white pollinosity spots on each tergite; lateral length of tergite 4 about equal to median length; tergite 8 as long as tergites 6 and 7 together. Abdominal sternites opaque, black basally and ochraceous distally, with black anterior part; sternite VIII longer than sternite VII; epipleurites black, with yellow posterior margins. Sternites and epipleurites covered with white pollinosity. Timbal covers black and completely cover timbal. Opercula ochraceous, inner margins overlapping; not reaching posterior margin of abdominal sternite III and rounded apically.

Male genitalia (Figs 29C, D, 37U, 38U). Pygofer barrelshaped. Basal lobes of pygofer yellow, and erect in ventral view. Uncal lobe fuscous to yellow and rounded apically.

Female. Unknown.

Distribution. China (Yunnan).

Remarks. This new species is very similar to $A$. pekinensis, but can be distinguished by the shape of the Wshaped marking on mesonotum.

\section{Auritibicen curvatus sp. $\mathbf{n}$.}

ZooBank taxon LSID:

8A2F635A-61AC-45B9-94F1-97D177D6123F

Type material. Holotype: $\widehat{\jmath}$ (NWAFU), China: Mt. Huashan, Weinan City, Shaanxi Province, 24.vii.2014. Paratype: 1ठำ (NWAFU), China: Mt. Nanwutai, Xi'an, Shaanxi Province, 

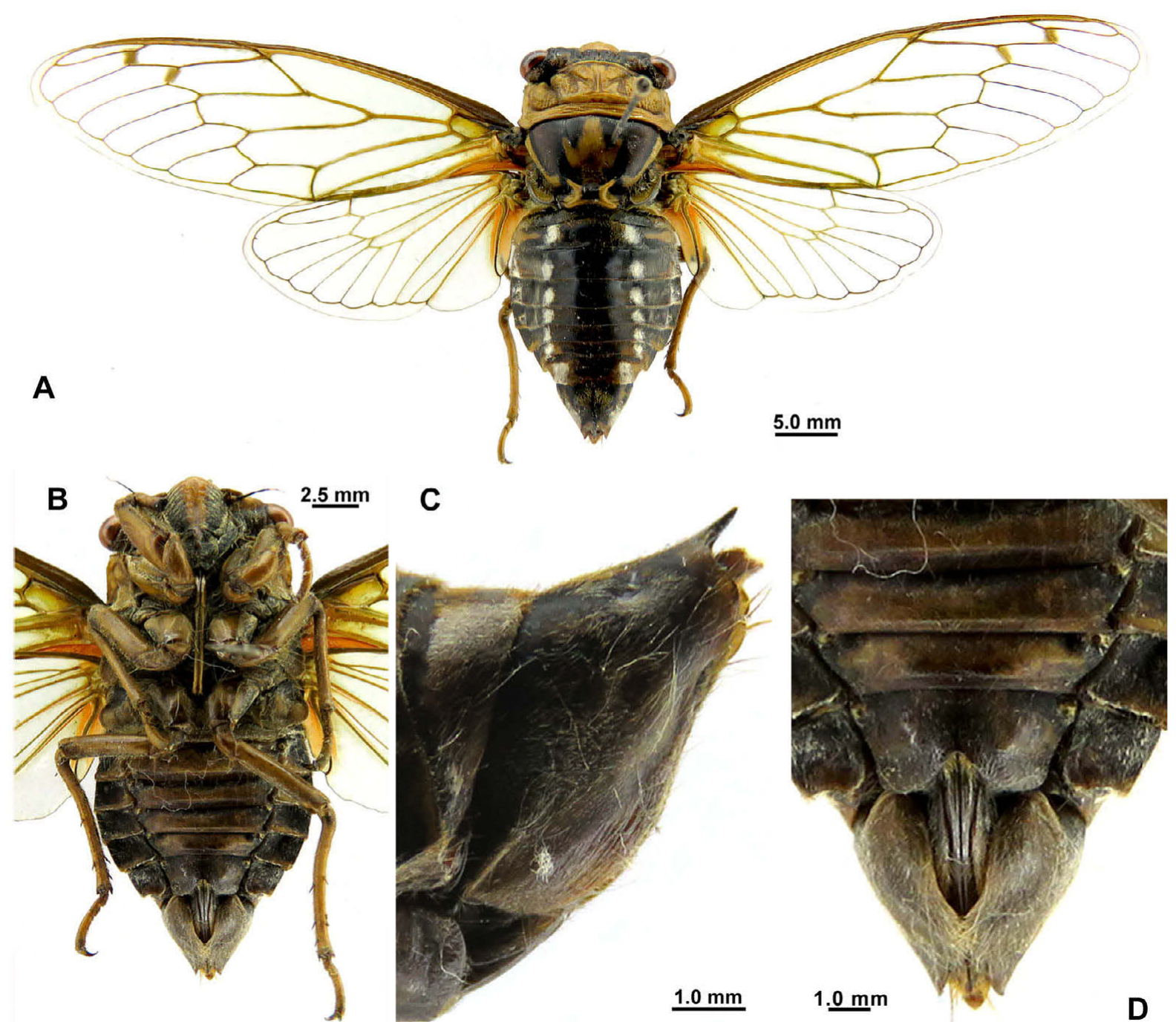

Fig. 36. Auritibicen parvus sp. n. (female, paratype). A - habitus, dorsal view; B - head, thorax and abdomen, ventral view; $C$ - female terminalia, lateral view; D - female terminalia, ventral view.

27.vi.1951; $1 ð$ (NWAFU), same data except 24.vii.1951; $3 ð$, 5 (NWAFU), same data except viii.1957; $2 \hat{\jmath}$ (NWAFU), same data except vii.1980; $1 \widehat{\jmath}$ (NWAFU), China: Mts Qinling, Shaanxi Province, vii.2010; 12 $\hat{\jmath}, 7$ 으 (NWAFU), China: Mt. Hua, Weinan City, Shaanxi Province, 24.vii.2014; $2 \hat{\jmath}, 1 q$ (TUA), same data except 17.vii.2016.

Etymology. The species name is a Latin masculine adjective meaning "curved", signifying the curved opercula.

Measurements of types. $(22 \hat{\jmath}, 13 \bigcirc)$ : Body length: male 38.1-42.5, female 36.2-40.0; fore wing length: male 46.5-52.5, female 48.9-53.1; fore wing width: male 14.717.0, female 15.2-16.7; width of head including eyes: male 12.6-14.4, female 13.6-14.2; pronotum width (including pronotal collar): male 14.5-16.8, female 14.9-15.8; mesonotum width: male 11.7-12.7, female 12.2-12.7; expanse of fore wings: male 104.7-111.4, female 106.9-114.3.

Description of male. Head (Fig. 30A, B). Black, without distinct markings. Eyes dark blue in live specimens; ocelli fuscous. Supra-antennal plates yellow. Postclypeus moderately swollen, black with a small yellow spot near frontoclypeal suture in dorsal view. A series of transverse grooves covered with white pollinosity. Lora black, with yellow margins and white pollinosity. Rostrum ochraceous with apical part black, extending to the anterior margin of mid coxae.

Thorax (Figs 30A, B, 31). Inner area of pronotum ochraceous (or yellow), with some irregular black markings; anterior margin yellow and posterior margin black; a pair of spots near posterior margin yellow. Pronotal collar broad and yellow, with black margins. Mesonotum black, with a thin medially and broad laterally continuous W-shaped marking in front of cruciform elevation (or discontinuous W-shaped marking); a pair of yellow fasciae along lateral margin of mesonotum, which is covered with white pollinosity; cruciform elevation yellow with a small black spot medially. Legs almost entirely crimson to brownish ochraceous.

Wings (Fig. 30A). Hyaline. Fore wing with infuscation on $\mathrm{r}, \mathrm{r}-\mathrm{m}$ crossveins, base of apical cell 3, base of apical cell $4, \mathrm{~m}$ and $\mathrm{m}$-cu crossveins and those along the latter two much weaker; base of ulnar cell 2 shorter than base of ulnar cell 3; base of apical cell 1 as long as base of apical 

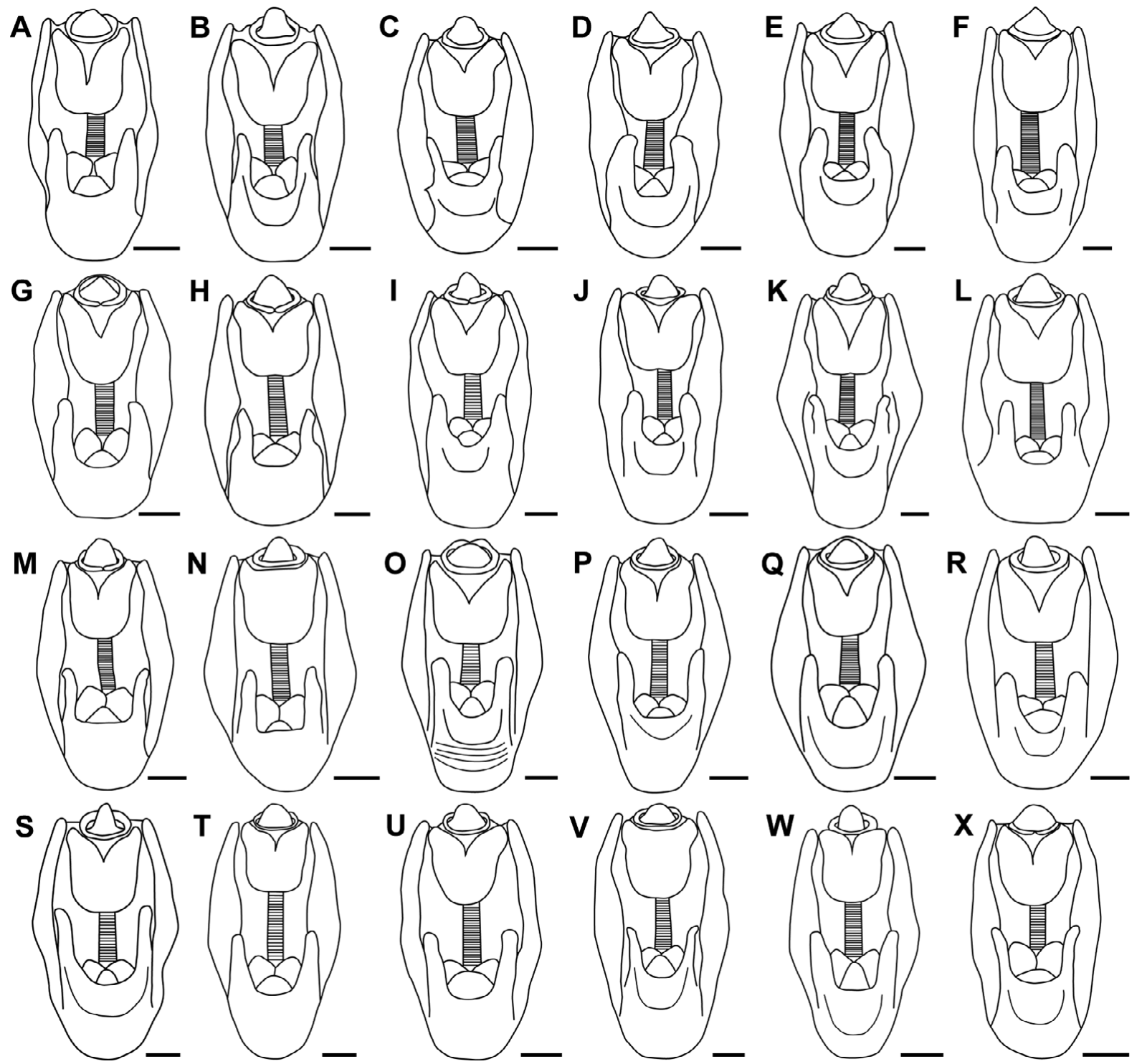

Fig. 37. Male genitalia of the species of Auritibicen in vental view. A - A. atrofasciatus; $\mathrm{B}-A$. bihamatus; C - A. chujoi; $\mathrm{D}-\mathrm{A}$. esakii; $\mathrm{E}$ - A. flammatus; F - A. flavomarginatus; G - A. intermedius; $\mathrm{H}-A$. jai; I - A. japonicus; J - A. kyushyuensis; $\mathrm{K}-A$. leechi; $\mathrm{L}-A$. pekinensis; $\mathrm{M}-$ A. slocumi; $\mathrm{N}-A$. tsaopaonensis; $\mathrm{O}-A$. aethus sp. n.; $\mathrm{P}-A$. daoxianensis sp. $\mathrm{n}$.; $\mathrm{Q}-A$. pallidus sp. $\mathrm{n}$.; $\mathrm{R}-A$. rotundus $\mathrm{sp}$. $\mathrm{n}$.; $\mathrm{S}-A$. gracilis sp. n.; T - A. septatus sp. n.; U - A. lijiangensis sp. n.; V - A. curvatus sp. n.; W $-A$. purus sp. n.; $\mathrm{X}-A$. parvus sp. $\mathrm{n}$. Scale bar is $1.0 \mathrm{~mm}$.

cell 2. Hind wing without infuscation. Basal half of wing veins black.

Abdomen (Fig. 30A, B). Cylindrical, longer than distance from head to cruciform elevation. Tergites black, with longitudinal series of white pollinosity spots sublaterally on each tergite; lateral length of tergite 4 about equal to median length; tergite 8 distinctly longer than tergites 6 and 7 combined. Abdominal sternites opaque and ochraceous, covered with white pollinosity; sternite VIII longer than sternite VII; epipleurites black with yellow posterior margins, covered with white pollinosity. Timbal covers black, with yellow margins and covered with white pollinosity. Opercula yellow, inner margins continuous for about $1 / 2$ their length, separated and curved inward apically, and reach middle of abdominal sternite $\mathrm{V}$.

Male genitalia (Figs 30C, D, 37V, 38V). Pygofer barrelshaped. Basal lobes of pygofer yellow with apex fuscous and erect in ventral view. Uncal lobe narrow and black and rounded apically, curved inwardly in lateral view.

Female (Fig. 32). Operculum small, posterior margin not reaching abdominal sternite II. Abdominal segment 9 black in dorsal view and yellow in ventral view; ovipositor sheath black, not protruding beyond segment 9 , incision in the middle of the posterior margin of abdominal sternite VII. Other characteristics similar to male.

Distribution. China (Shaanxi).

Ecology. This new species was collected at four locations in Shaanxi Province. Among these specimens, 20 individuals were collected on Mt. Hua at an altitude of 870 to $1600 \mathrm{~m}$. The main host plants are Robinia pseudoacacia L. (Fabaceae), Quercus baronii Skan (Fagaceae), Sambucus sieboldiana L. var. pinnatisecta G.Y. Luo \& P.H. Huang. (Caprifoliaceae) and Juglans regia L. (Juglandaceae) (Fig. 32). 

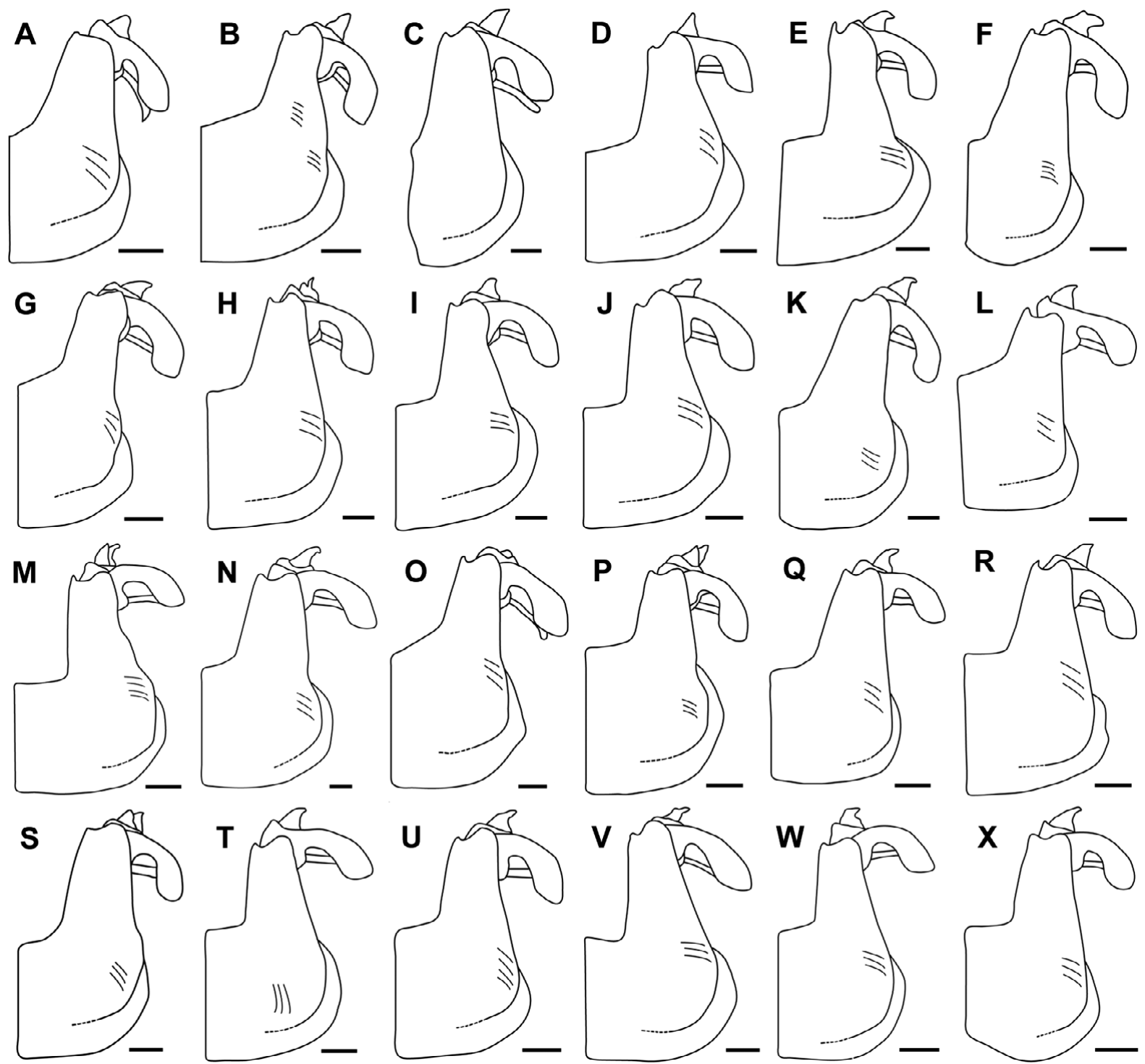

Fig. 38. Male genitalia of the species of Auritibicen in lateral view. A - A. atrofasciatus; B - A. bihamatus; C - A. chujoi; D - A. esakii; E - A. flammatus; $\mathrm{F}-\mathrm{A}$. flavomarginatus; $\mathrm{G}-\mathrm{A}$. intermedius; $\mathrm{H}-\mathrm{A}$. jai; I - A. japonicus; J - A. kyushyuensis; $\mathrm{K}-\mathrm{A}$. leechi; $\mathrm{L}-\mathrm{A}$. pekinensis; $\mathrm{M}-A$. slocumi; $\mathrm{N}-A$. tsaopaonensis; $\mathrm{O}-A$. aethus sp. n.; $\mathrm{P}-A$. daoxianensis sp. $\mathrm{n}$.; $\mathrm{Q}-A$. pallidus $\mathrm{sp}$. $\mathrm{n}$.; $\mathrm{R}-A$. rotundus $\mathrm{sp}$. $\mathrm{n}$.; $\mathrm{S}-$ A. gracilis sp. $\mathrm{n}$.; $\mathrm{T}-A$. septatus sp. $\mathrm{n}$.; $\mathrm{U}-A$. lijiangensis $\mathrm{sp}$. n.; $\mathrm{V}-$ A. curvatus $\mathrm{sp} . \mathrm{n}$.; $\mathrm{W}-A$. purus $\mathrm{sp} . \mathrm{n}$.; $\mathrm{X}-A$. parvus $\mathrm{sp}$. $\mathrm{n}$. Scale bar is $1.0 \mathrm{~mm}$.

Remarks. Intraspecific variability in Auritibicen curvatus sp. n. is mainly in the $\mathrm{W}$-shaped marking on the mesonotum. Type I: thin medially and broad laterally, continuous W-shaped marking; Type II: discontinuous W-shaped marking (Fig. 31). This new species is similar to A. leechi, but can be distinguished by the shape of its operculum: inner margins of opercula overlap for about $1 / 2$ of their length from the base in A. curvatus sp. n., but overlap for about $2 / 3$ of the length from the base in $A$. leechi. This new species is also similar to $A$. japonicus, but can be distinguished by the following characters: fore wing with infuscation merely at bases of second and third apical areas (fore wing with other infuscation besides those at bases of second and third apical areas in A. japonicus); basal 1/3 of the inner margins of male opercula overlap and are separate for the final 2/3 (inner margins of male opercula mostly overlap in $A$. japonicus). This new species is also similar to A. jai, but can be distinguished by the follow- ing characters: basal cell of fore wing with black markings (basal cell of fore wing without black markings in A. jai); male opercula with truncated apex (male opercula with angulated apex in $A$. jai).

\section{Auritibicen purus sp. $\mathbf{n}$.}

ZooBank taxon LSID:

2B2A767F-9B5F-46D9-A87C-BB4C8DF7FE1B

Type material. Holotype: $\widehat{\delta}$ (NWAFU), China: Mt. Yulong, Lijiang City, Yunnan Province, 10.viii.1962, Shimei Song leg. Paratype: $1 \widehat{\jmath}$ (NWAFU), China: Mt. Yulong, Lijiang City, Yunnan Province, 21.vii.1979; $1 \widehat{\jmath}$ (NWAFU), China: Mt. Yulong, Lijiang City, Yunnan Province, 8.vii.1962; $1 \hat{\delta}$ (NWAFU), same locality, 12.vii.1962, Shimei Song leg.

Etymology. The species name is a Latin masculine adjective meaning "pure", signifying the pure snow of Jade Dragon Snow Mountain (Mt. Yulong).

Measurements of types. $\left(4 \circlearrowleft^{\Uparrow}\right)$ : Body length: $31.0-31.8$; fore wing length: $36.2-39.4$; fore wing width: 11.5-12.4; 


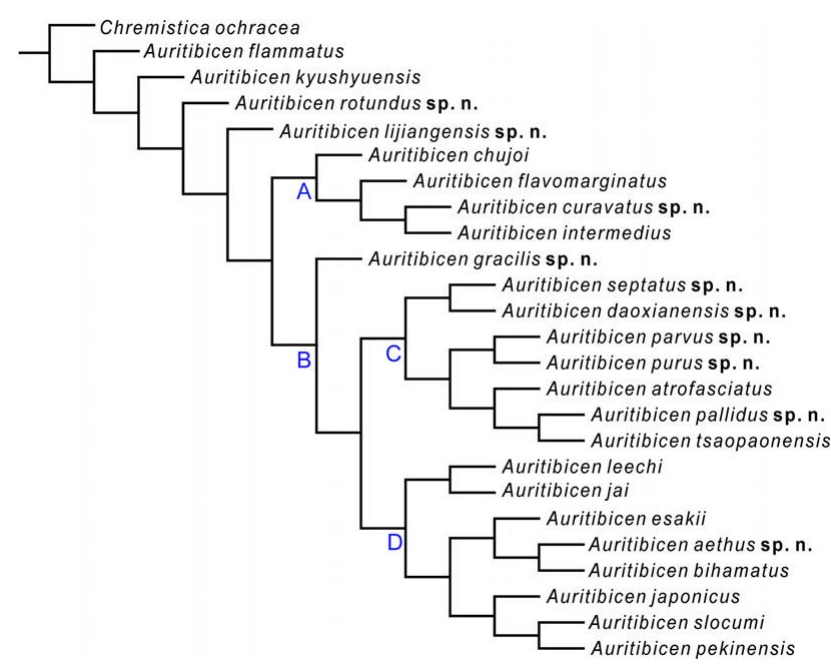

Fig. 39. A strict consensus tree of the phylogenetic relationships of the genus Auritibicen derived from an exact search (traditional search) using the program TNT (L: 209; Cl: 27; Al: 44).

width of head including eyes: 10.5-11.3; pronotum width (including pronotal collar): 11.2-12.6; mesonotum width: 8.9-9.5; expanse of fore wings: 79.1-85.6.

Description of male. Head (Fig. 34A, B). Black, with a pair of small triangular yellow spots on posterolateral angles of vertex. Eyes and ocelli fuscous. Postclypeus moderately swollen and castaneous. Transverse grooves black with white pollinosity. Lora black, with yellow margins and covered with white pollinosity. Rostrum yellow with basal part brown and apical part black, reaching mid trochanter.

Thorax (Fig. 34A). Inner area of pronotum yellow, with two black minute spots on posterior margin; posterior margin of inner area black. Pronotal collar broad and yellow, with no distinct markings. Mesonotum black, with a broad, continuous W-shaped marking in front of cruciform elevation; a pair of large yellow tongue-shaped markings on lateral sigilla; a pair of round spots in front of anterior angles of cruciform elevation. Cruciform elevation yellow with medially a small spot.

Wings (Fig. 34A). Hyaline. Fore wing without infuscation; base of ulnar cell 2 shorter than base of ulnar cell 3; base of apical cell 1 shorter than base of apical cell 2. Hind wing without infuscation. Basal half of wing veins yellow.

Abdomen (Fig. 34A, B). Cylindrical. Tergites black, with a pair of small white pollinosity spots sublaterally on each tergite; lateral length of tergite 4 shorter than median length; tergite 8 distinctly longer than tergites 6 and 7 combined. Abdominal sternites opaque, black basally and red distally; sternite VIII longer than sternite VII; epipleurites black, with red posterior margins. Timbal covers black medially and yellow laterally and completely cover timbal. Opercula yellow, inner margins parallel, and just extending beyond posterior margin of abdominal sternite III.

Male genitalia (Figs 34C, D, 37W, 38W). Pygofer barrel-shaped. Basal lobes of pygofer yellow and curved outwardly in ventral view. Uncal lobe ochraceous with black margins and truncated apically.

Female. Unknown.
Distribution. China (Yunnan).

Remarks. This new species is similar to A. pallidus sp. n., but can be distinguished by its different body size, markings on the pronotal collar and fore wings and the colour of sternites. This new species is also similar to A. atrofasciatus, but can be distinguished by the different $\mathrm{W}$-shaped marking on mesonotum and no markings on the fore wing.

\section{Auritibicen parvus sp. $\mathrm{n}$.}

ZooBank taxon LSID:

AC10CD14-244D-46D0-A8C1-CEBBA6D40F1A

Type material. Holotype: $\delta$ (NWAFU), China: Mt. Lu Shan, Xichang City, Sichuan Province, 12.viii.2014. Paratype: 29 (NWAFU), same data as holotype.

Etymology. The species name is a Latin masculine adjective meaning "small", signifying the small body size for specimens of this species.

Measurements of types. $(1 \hat{\sigma}, 2 q)$ : Body length: male 28.4, female 26.5-31.0; fore wing length: male 35.1, female 35.1-37.4; fore wing width: male 11.3, female 11.612.5; width of head including eyes: male 11.0, female 10.8-11.8; pronotum width (including pronotal collar): male 11.3, female 11.3-11.9; mesonotum width: male 8.9 , female 9.4-10.6; expanse of fore wings: male 75.7, female 75.6 .

Description of male. Head (Fig. 35A, B). Black, a pair of yellowish rectangular spots on posterolateral angles of vertex. Eyes castaneous; ocelli yellow. Supra-antennal plates yellow. Postclypeus moderately swollen and yellow. Transverse grooves black with golden pollinosity. Lora black with yellow margins and covered with golden pollinosity. Rostrum yellow with apical part fuscous, reaching mid trochanter.

Thorax (Fig. 35A). Inner area of pronotum yellow, with a pair of minute black spots near anterior margin. Pronotal collar broad and yellow, with posterior margin ochraceous. Mesonotum black, with a continuous W-shaped marking in front of cruciform elevation; a pair of large brown tongueshaped markings on lateral sigilla; a pair of long yellow fasciae along lateral margins of mesonotum. Cruciform elevation yellow with a large black spot medially.

Wings (Fig. 35A). Hyaline. Fore wing with faint infuscation on $\mathrm{r}$ and $\mathrm{r}-\mathrm{m}$ crossveins; base of ulnar cell 2 as long as base of ulnar cell 3; base of apical cell 1 as long as base of apical cell 2. Hind wing without infuscation. Basal half of wing veins yellow.

Abdomen (Fig. 35A, B). Cylindrical. Tergites black, with irregular yellow markings and white pollinosity spots sublaterally on each tergite; lateral length of tergite 4 about equal to median length; tergite 8 distinctly longer than tergites 6 and 7 combined. Abdominal sternites opaque and ochraceous to fuscous; sternite VIII as long as sternite VII; epipleurites black, with yellow posterior margin. Timbal covers fuscous medially and green laterally and completely cover timbal. Opercula yellow, inner margins overlapping for about $1 / 2$ their length from base, and reaching posterior margin of abdominal sternite III.

Male genitalia (Figs 35C, D, 37X, 38X). Pygofer barrelshaped. Basal lobes of pygofer yellow with apex fuscous 


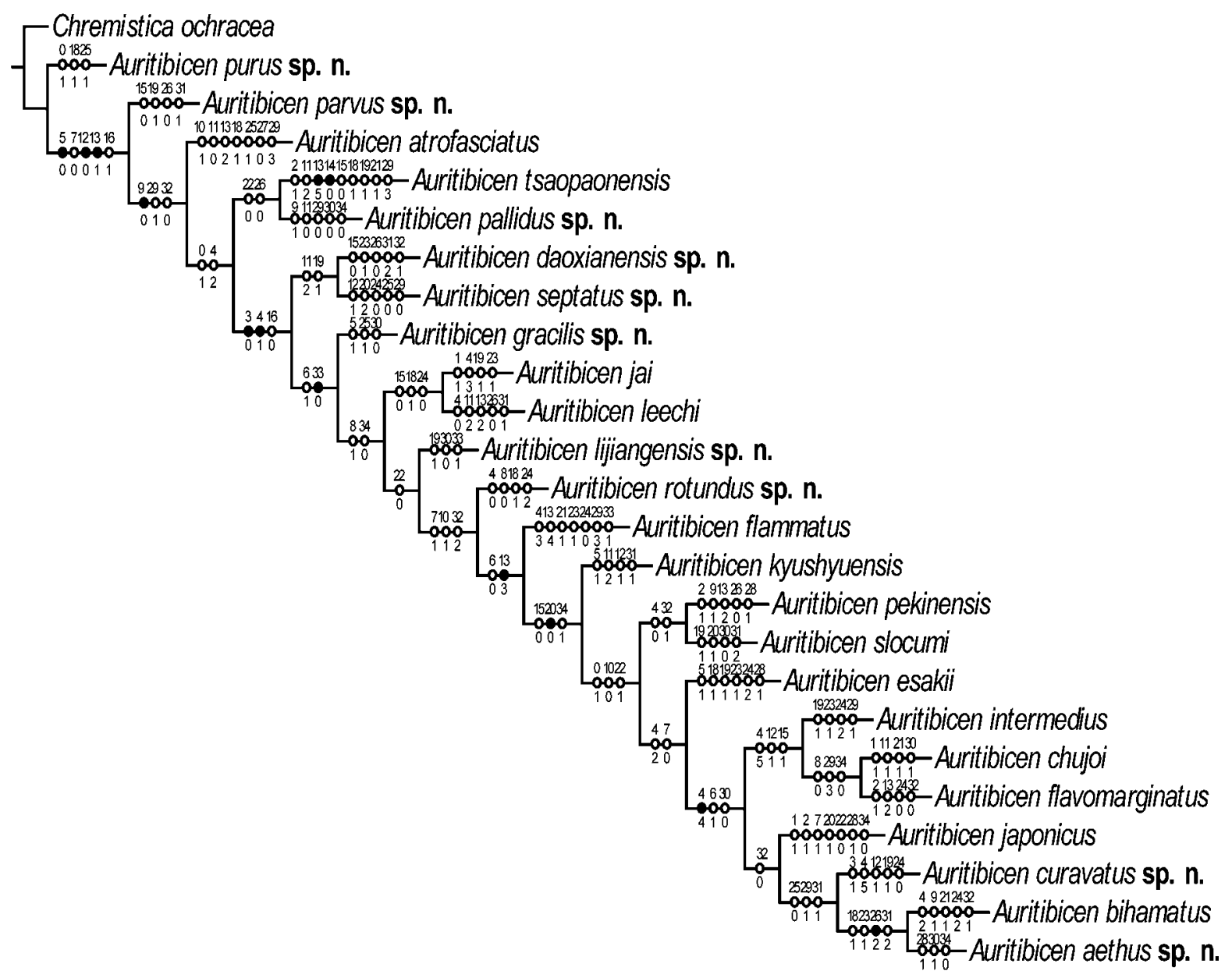

Fig. 40. A selected tree of the phylogenetic relationships of the genus Auritibicen based on 10 MPTs using the program WinClada, unambiguous apomorphies mapped on branches, black circles indicate nonhomoplasious changes.

and curved outwardly in ventral view. Uncal lobe ochraceous, with black margins, fused into one, not bifurcate, rounded apically.

Female (Fig. 36). Operculum small, posterior margin not reaching abdominal sternite II. Abdominal segment 9 black in dorsal view and yellow in ventral view; ovipositor sheath black, not protruding beyond segment 9 , incision in the middle of posterior margin of abdominal sternite VII. Other characteristics similar to male.

Distribution. China (Sichuan).

Remarks. This new species is similar to A. pallidus sp. n., but can be distinguished by the following characters: head with a pair of yellow spots near eyes (head without spots in A. pallidus sp. n.); male opercula curved inwards apically (male opercula not curved inwards apically in $A$. pallidus sp. n.).

\section{RESULTS OF PHYLOGENETIC ANALYSIS BASED ON MORPHOLOGICAL CHARACTERS}

This study uses a cladistic analysis to elucidate the relationships within the genus Auritibicen. A phylogenetic analysis of the morphological dataset for all the Auritibicen taxa (Table 1) using TNT yielded one strict consensus tree (Fig. 39). This indicates that A. flammatus was the first and $A$. kyushyuensis the second divergence, and A. rotun- $d u s$ sp. n. is the sister group of the remaining ingroup taxa. A. lijiangensis $\mathrm{sp} . \mathrm{n}$. is the sister group of others, which are divided into clades $\mathrm{A}$ and $\mathrm{B}$. Clade A contains $A$. chujoi + (A. flavomarginatus + (A. curvatus sp. n. + A. intermedius)). In clade $\mathrm{B}, A$. gracilis $\mathrm{sp}$. $\mathrm{n}$. is the sister group of the remaining ingroup taxa, which are divided into clades $C$ and D. Clade $\mathrm{C}$ comprises two major clades: the first clade containing $A$. septatus sp. n. and $A$. daoxianensis sp. n.; the second (A. parvus sp. n. + A. purus sp. n.) + (A. atrofasciatus $+($ A. pallidus sp. n. + A. tsaopaonensis $))$. Clade $\mathrm{D}$ is divided into two major clades: the first containing $A$. leech $i$ and $A$. jai; the second (A. esakii $+(A$. aethus sp. n. $+A$. bihamatus $))+($ A. japonicus $+(A$. slocumi + A. pekinensis $))$.

The tree selected from the 10 most parsimonious trees of the phylogenetic relationships of Auritibicen obtained using program WinClada 1.0 is provided in Fig. 40. The monophyly of Auritibicen is well supported by a number of undisputed characters. A. purus sp. n. is the first divergence, which has the following synapomorphies: a median body size (char. 0: 1), base of apical cell 4 of fore wing shorter than twice length of $\mathrm{r}-\mathrm{m}$ vein (char. 18: 1), and inner margins of male opercula adjoined but not overlapping (char. 25: 1). The remaining species of Auritibicen have several synapomorphies, i.e., posterior margin of pronotal collar heterochromous (char. 5: 0), cruciform eleva- 


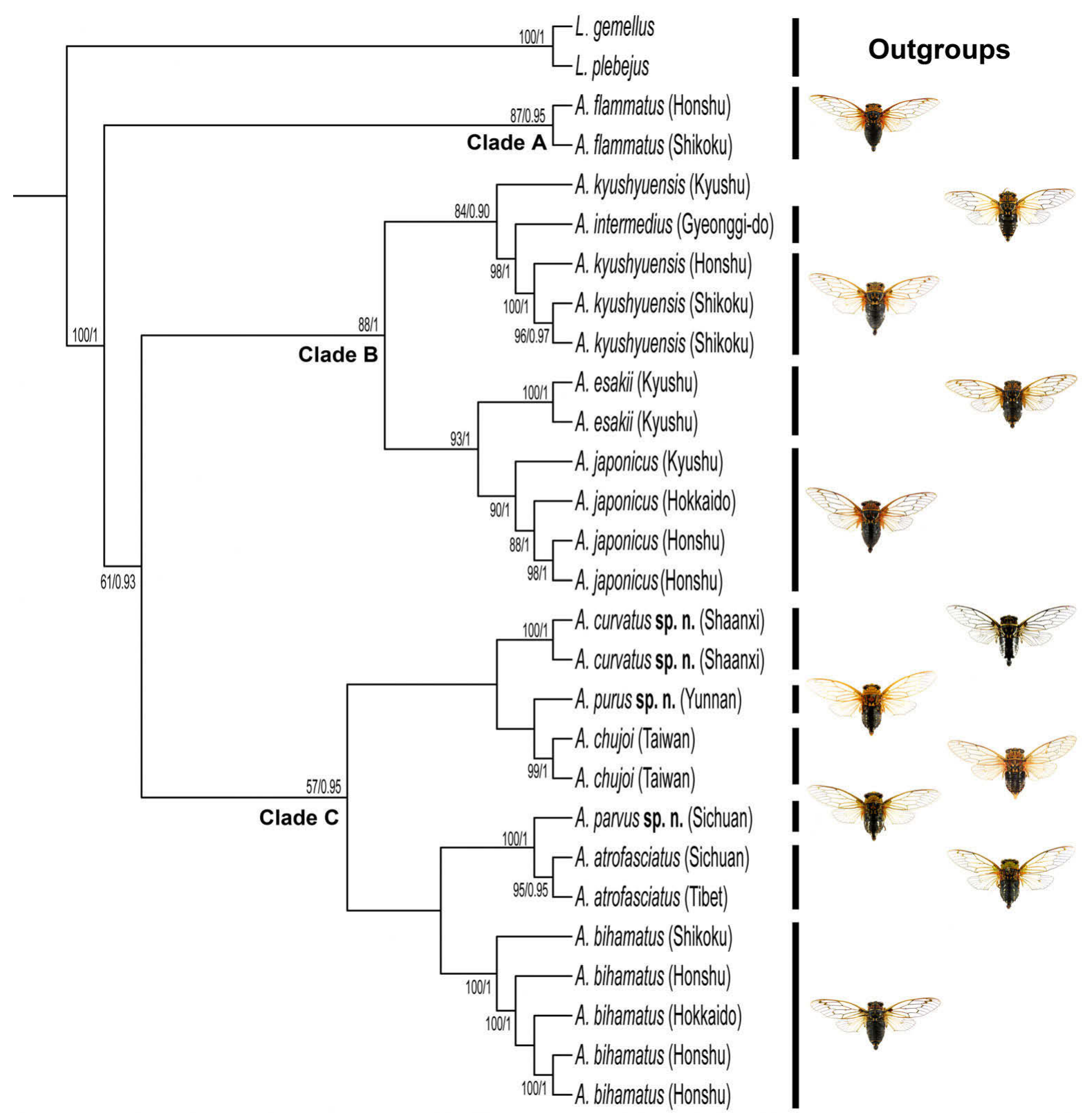

Fig. 41. Phylogenetic tree of Auritibicen species based on mitochondrial COI. Nodal values above the line indicate bootstrap support and posterior probabilities of $\mathrm{ML} / \mathrm{BI}$. The pictures on the right are the male habitus in dorsal view, from top to bottom: $A$. flammatus, $A$. intermedius, A. kyushyuensis, A. esakii, A. japonicus, A. curvatus sp. n., A. purus sp. n., A. chujoi, A. parvus sp. n., A. atrofasciatus and A. bihamatus, respectively.

tion with a large black median spot (char. 12: 0), and fore wing with infuscation on $\mathrm{r}$ and $\mathrm{r}-\mathrm{m}$ crossveins (char. 13: 1). A. parvus sp. $\mathrm{n}$. is the sister to the remaining taxa due to fore wing with black markings in basal cell (char. 15: 0 ), lateral length of tergite 4 about equal to median length (char. 19: 1), male opercula angulated apically (char. 26: 0 ), and basal lobes of pygofer yellow, with apex fuscous (char. 31: 1). The sister pair A. tsaopaonensis + A. pallidus sp. n. have two homoplasies, i.e., length of tergite 8 as long as or shorter than tergites 6 and 7 combined (char. 22: 0), and male opercula angulated apically (char. 26: 0). The sister pair $A$. daoxianensis sp. n. + A. septatus sp. n. have two homoplasies, i.e., length of posterior angles of cruciform elevation slightly longer than anterior angles (char. 11: 2), and lateral length of tergite 4 about equal to median length (char. 19: 1). The sister pair A. jai + A. leechi share homoplasies as follows: fore wing with black markings in basal cell (char. 15: 0), base of apical cell 4 of fore wing shorter than twice length of $\mathrm{r}-\mathrm{m}$ vein (char. 18: 1), and abdominal sternites yellow or ochraceous (char. 24: 0). A. lijiangensis sp. $\mathrm{n}$. is the sister to the remaining taxa, with lateral length of tergite 4 about equal to median length (char. 19: 1), uncal lobe rounded apically in ventral view (char. 30: 0 ) and dorsal beak higher than distal shoulders in lateral view (char. 33: 1). The sister pair A. pekinensis $+A$. slocu$m i$ have two homoplasies, i.e., a spot in median part and pair of spots on margins of pronotal collar (char. 4: 0), and basal lobes curved outwardly in ventral view (char. 32: 1). A. intermedius is the sister group of the sister pair $A$. chujo $i$ + A. flavomarginatus, which have three homoplasies, i.e., 


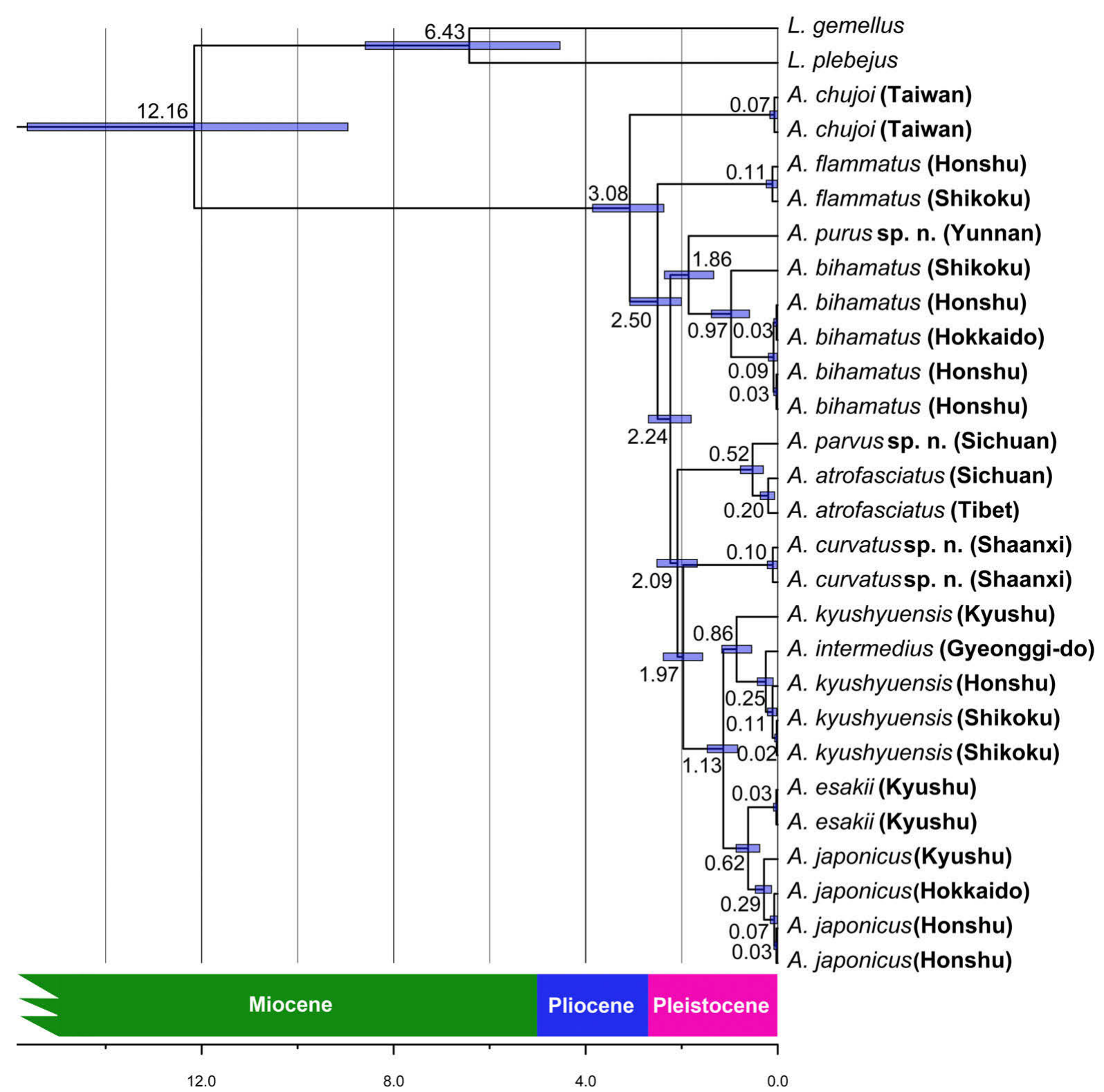

Fig. 42. Chronogram of the tmes of divergence Auritibicen estimated using the BEAST analysis with a Bayesian relaxed lognormal clock. The numbers at nodes indicate the mean ages and blue bars the $95 \%$ highest posterior density intervals for the ages of the nodes.

pronotal collar without markings (char. 4: 5), cruciform elevation with small black median spot (char. 12: 1), and fore wing without black markings in basal cell (char. 15: 1). A. japonicus is the sister to the clade A. curvatus sp. n. + (A. aethus sp. n. + A. bihamatus $)$, with basal lobes erect in ventral view (char. 32: 0).

\section{RESULTS OF PHYLOGENETIC ANALYSIS BASED ON MOLECULAR DATA}

In total, only $26 C O I$ sequences of Auritibicen were obtained in this study, since PCR amplification for some Auritibicen species was not successful due to degradation of the DNA in very old specimens. We obtained a robust phylogenetic tree based on the COI gene for 11 species of Auritibicen and two outgroup species. The topology of the ML tree is identical to that of the BI tree (Fig. 41). Related species of Auritibicen are divided into three clades, with
A. flammatus being a sister to all the other species. The remaining taxa are split into two clades. The three populations of A. kyushyuensis, from Kyushu, Honshu and Shikoku, respectively, are closely related to A. intermedius from Korea. A. esakii is the sister to the three populations of $A$. japonicus. A. curvatus sp. n. forms a sister group with (A. purus sp. n. + A. chujoi). A. parvus sp. n. is related to $A$. atrofasciatus from China and forms a sister group with A. bihamatus.

The phylogram from the Bayesian analysis of the combined morphological and molecular data sets (Fig. S1) is provided as a supplementary document. The aligned DNA sequence dataset included 1488 positions of COI including indels. In the combined dataset of both morphology and DNA sequences, the 1488 characters were constant. The topology of the tree based on the combined datasets is similar to the ML/BI topologies derived only based on the 
molecular data, but the internal relationships within Clade $\mathrm{C}$ are poorly resolved.

\section{INTERSPECIFIC GENETIC DISTANCES OF AURITIBICEN AND THE OUTGROUP SPECIES}

The pairwise corrected genetic distances based on $\mathrm{COI}$ sequences of Auritibicen and the outgroup species are shown in Table 3. Interspecific genetic distances of $\mathrm{Au}$ ritibicen (0.005-0.090) are distinctly lower than those between Auritibicen and the outgroup species (0.153-0.185). This indicates that the divergences of various species of Auritibicen have not reached the genus level. Among the species of Auritibicen, the interspecific genetic distances between $A$. chujoi and A. esakii is the greatest (Table 3).

\section{Estimates of the times of divergence}

A chronogram showing the times of divergence of $\mathrm{Au}$ ritibicen is presented in Fig. 42, in which the branch length indicates mean age. The divergence of Auritibicen from Lyristes occurred approximately 12.16 mya (million years ago). The age of the most recent common ancestor (tMRCA) of Auritibicen is estimated to be $\sim 3.08$ mya (95\% highest posterior density interval, HPDI, 2.37-3.85 mya). A. flammatus diverged from the others $\sim 2.50$ mya (95\% HPDI, 2.01-3.08 mya). The divergence of $A$. purus sp. n. from $A$. bihamatus occurred approximately 1.86 mya (95\% HPDI, $1.33-2.36$ mya). $A$. parvus sp. n. and $A$. atrofasciatus diverged from each other $\sim 0.52$ mya $(95 \%$ HPDI, 0.30-0.78 mya). A. curvatus sp. n. diverged from the others $\sim 1.97$ mya (95\% HPDI, 1.56-2.38 mya). The remaining taxa diverged into two lineages, "A. kyushyuensis
$+A$. intermedius", and a lineage containing " $A$. esakii $+A$. japonicus", which occurred during the middle Pleistocene.

\section{DISCUSSION}

The species in the genus Auritibicen are difficult to identify because they are all morphologically very similar and, probably, also because there is little differentiation between related species. Sound-production in cicadas is important in their courtship and reproductive behaviour (Hayashi, 1977b). The production of species-specific, acoustic signals by males seems to be related to the configuration of male opercula (Young, 1990; Luo et al., 2015). In previous studies, species of Auritibicen were classified into three groups according to the configuration of male opercula (Kurosawa, 1969; Hayashi, 1977b; Hayashi \& Saisho, 2015). Despite the length of male opercula in a couple of species being variable, male opercula of the 24 species of Auritibicen can be catalogued into three types, i.e., Type I: opercula rather flimsy and more or less undulate, not overlapping at base, divergently extending far beyond abdominal sternite II (A. bihamatus, A. aethus sp. n., A. septatus sp. n.); Type II: opercula long, extending to abdominal sternite II, somewhat quadrate toward apex in most cases (A. japonicus, A. esakii, A. leechi, A. flavomarginatus, A. jai, A. daoxianensis sp. n., A. pallisus sp. n., A. curvatus sp. n., A. purus sp. n., A. parvus sp. n.); and Type III (general condition in Auritibicen): opercula rather thick, evenly rounded with narrow margin, not extending beyond abdominal sternite II (A. flammatus, A. intermedius, A. kyushyuensis, A. pekinensis, A. chujoi, A. atrofasciatus, A. slocumi, A. tsaopaonensis, A. rotundus sp. n., A. gracilis

Table 3. Interspecific genetic distances of species of Auritibicen and outgroups based on $\mathrm{COI}$ gene.

\begin{tabular}{|c|c|c|c|c|c|c|c|c|c|c|c|c|c|c|c|c|c|c|c|c|c|c|c|c|c|c|c|c|}
\hline & 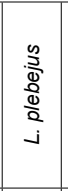 & 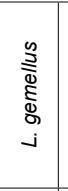 & 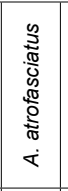 & 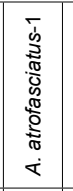 & 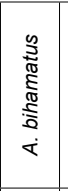 & 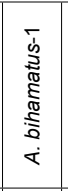 & 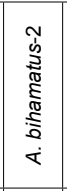 & 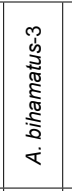 & 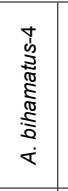 & 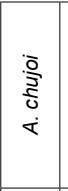 & $\begin{array}{l}\frac{\pi}{0} \\
\frac{1}{3} \\
0 \\
0 \\
\dot{\pi}\end{array}$ & $\begin{array}{l}:= \\
\mathbb{3} \\
\mathbb{8} \\
0 \\
\dot{<}\end{array}$ & 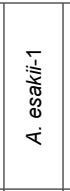 & 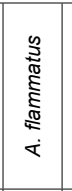 & 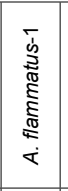 & 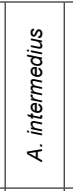 & 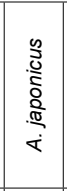 & 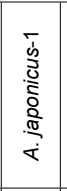 & 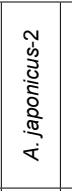 & 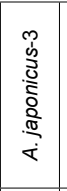 & 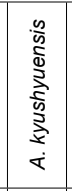 & 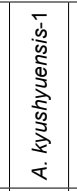 & 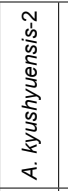 & 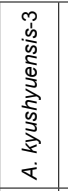 & 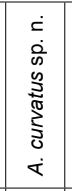 & 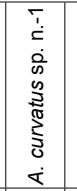 & 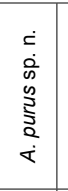 & 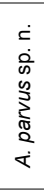 \\
\hline \multicolumn{29}{|l|}{ L. plebejus } \\
\hline L. gemellus & 0.140 & & & & & & & & & & & & & & & & & & & & & & & & & & & \\
\hline A. atrofasciatus & 0.167 & 0.170 & & & & & & & & & & & & & & & & & & & & & & & & & & \\
\hline A. atrofasciatus -1 & 0.166 & $0.165 \mathrm{C}$ & 0.006 & & & & & & & & & & & & & & & & & & & & & & & & & \\
\hline A. bihamatus & 0.175 & $0.175 \mathrm{C}$ & 0.051 & 0.053 & & & & & & & & & & & & & & & & & & & & & & & & \\
\hline A. bihamatus-1 & 0.175 & $0.175 \mathrm{C}$ & 0.051 & 0.053 & 0.000 & & & & & & & & & & & & & & & & & & & & & & & \\
\hline A. bihamatus-2 & 0.175 & $0.175 \mathrm{C}$ & 0.051 & 0.053 & 0.000 & 0.000 & & & & & & & & & & & & & & & & & & & & & & \\
\hline A. bihamatus- 3 & 0.175 & $0.175 \mathrm{C}$ & 0.051 & 0.0530 & 0.000 & 0.000 & 0.000 & & & & & & & & & & & & & & & & & & & & & \\
\hline A. bihamatus-4 & 0.173 & $0.169 \mathrm{C}$ & 0.065 & $0.067 \mathrm{C}$ & 0.026 & 0.026 & 0.026 & 0.026 & & & & & & & & & & & & & & & & & & & & \\
\hline A. chujoi & 0.170 & $0.169 \mathrm{C}$ & 0.078 & 0.080 & 0.071 & 0.071 & 0.071 & $0.071 \mathrm{C}$ & 0.083 & & & & & & & & & & & & & & & & & & & \\
\hline A. chujoi-1 & 0.170 & $0.169 \mathrm{C}$ & 0.077 & 0.078 & 0.070 & 0.070 & 0.070 & 0.070 & $0.081 \mathrm{C}$ & 0.001 & & & & & & & & & & & & & & & & & & \\
\hline A. esakii & 0.173 & $0.175 \mathrm{C}$ & 0.071 & 0.0730 & 0.055 & 0.055 & 0.055 & 0.055 & $0.059 \mathrm{C}$ & 0.089 & 0.090 & & & & & & & & & & & & & & & & & \\
\hline A. esakii-1 & 0.173 & $0.175 \mathrm{C}$ & 0.071 & 0.0730 & 0.055 & 0.055 & 0.055 & 0.055 & $0.059 \mathrm{C}$ & 0.089 & 0.090 & 0.000 & & & & & & & & & & & & & & & & \\
\hline A. flammatus & 0.163 & $0.156 \mathrm{C}$ & 0.064 & 0.068 & 0.054 & 0.054 & 0.054 & 0.054 & $0.057 \mathrm{C}$ & 0.067 & 0.065 & 0.061 & 0.061 & & & & & & & & & & & & & & & \\
\hline A. flammatus-1 & 0.163 & $0.153 \mathrm{C}$ & 0.067 & 0.071 & 0.057 & 0.057 & 0.057 & 0.057 & $0.057 \mathrm{C}$ & 0.069 & 0.068 & 0.064 & 0.064 & 0.003 & & & & & & & & & & & & & & \\
\hline A. intermedius & 0.169 & $0.182 \mathrm{C}$ & 0.065 & 0.070 & 0.047 & 0.047 & 0.047 & 0.047 & $0.058 \mathrm{C}$ & 0.083 & 0.084 & 0.041 & 0.041 & 0.057 & 0.060 & & & & & & & & & & & & & \\
\hline A. japonicus & 0.173 & $0.177 \mathrm{C}$ & 0.066 & $0.067 \mathrm{C}$ & 0.054 & 0.054 & 0.054 & 0.054 & $0.061 \mathrm{C}$ & 0.083 & 0.084 & 0.023 & 0.023 & $0.061 \mathrm{C}$ & 0.064 & 0.035 & & & & & & & & & & & & \\
\hline A. japonicus-1 & 0.173 & $0.177 \mathrm{C}$ & 0.066 & 0.067 & 0.054 & 0.054 & 0.054 & 0.054 & $0.061 \mathrm{C}$ & 0.083 & 0.084 & 0.023 & 0.023 & 0.061 & 0.064 & 0.035 & 0.000 & & & & & & & & & & & \\
\hline A. japonicus-2 & 0.175 & $0.179 \mathrm{C}$ & 0.067 & 0.068 & 0.056 & 0.056 & 0.056 & 0.056 & $0.063 \mathrm{C}$ & 0.084 & 0.086 & 0.025 & 0.025 & 0.063 & 0.065 & 0.036 & 0.001 & 0.001 & & & & & & & & & & \\
\hline A. japonicus-3 & 0.176 & $0.180 \mathrm{C}$ & 0.068 & 0.067 & 0.053 & 0.053 & 0.053 & 0.053 & $0.063 \mathrm{C}$ & 0.086 & 0.087 & 0.021 & 0.021 & 0.064 & 0.067 & 0.034 & 0.008 & 0.008 & 0.009 & & & & & & & & & \\
\hline A. kyushyuensis & 0.169 & $0.185 \mathrm{C}$ & 0.064 & 0.0680 & 0.053 & 0.053 & 0.053 & $0.053 \mathrm{C}$ & $0.061 \mathrm{C}$ & 0.084 & 0.086 & 0.041 & 0.041 & $0.061 \mathrm{C}$ & 0.064 & 0.026 & 0.031 & 0.031 & 0.032 & 0.034 & & & & & & & & \\
\hline A. kyushyuensis-1 & 0.174 & $0.183 \mathrm{C}$ & 0.070 & 0.071 & 0.050 & 0.050 & 0.050 & 0.050 & $0.061 \mathrm{C}$ & 0.083 & 0.084 & 0.043 & 0.043 & 0.058 & 0.061 & 0.008 & 0.038 & 0.038 & 0.039 & 0.036 & 0.028 & & & & & & & \\
\hline A. kyushyuensis-2 & 0.174 & $0.183 \mathrm{C}$ & 0.070 & 0.071 & 0.050 & 0.050 & 0.050 & 0.050 & $0.061 \mathrm{C}$ & 0.083 & 0.084 & 0.043 & 0.043 & 0.058 & $0.061 \mathrm{C}$ & 0.008 & 0.038 & 0.038 & 0.039 & 0.036 & 0.028 & 0.000 & & & & & & \\
\hline A. kyushyuensis-3 & 0.171 & $0.183 \mathrm{C}$ & 0.067 & 0.0710 & 0.047 & 0.047 & 0.047 & $0.047 \mathrm{C}$ & $0.058 \mathrm{C}$ & 0.080 & 0.081 & 0.041 & 0.041 & 0.0550 & 0.058 & 0.005 & 0.035 & 0.035 & 0.036 & 0.034 & 0.0260 & 0.0030 & 0.003 & & & & & \\
\hline A. curvatus sp. $\mathrm{n}$. & 0.178 & $0.170 \mathrm{C}$ & 0.064 & 0.066 & 0.050 & 0.050 & 0.050 & 0.050 & $0.054 \mathrm{C}$ & 0.081 & 0.080 & 0.060 & 0.060 & 0.060 & 0.062 & 0.059 & 0.069 & 0.069 & 0.070 & 0.066 & 0.0610 & 0.0610 & $0.061 \mathrm{C}$ & 0.059 & & & & \\
\hline A. curvatus sp. $\mathrm{n} .-1$ & 0.174 & $0.170 \mathrm{C}$ & 0.064 & 0.066 & 0.053 & 0.053 & 0.053 & 0.053 & $0.057 \mathrm{C}$ & 0.078 & 0.077 & 0.063 & 0.063 & 0.060 & 0.062 & 0.061 & 0.072 & 0.072 & 0.073 & 0.069 & 0.0640 & 0.0640 & $0.064 \mathrm{C}$ & $0.061 \mathrm{C}$ & 0.003 & & & \\
\hline A. purus sp. $\mathrm{n}$. & 0.171 & $0.180 \mathrm{C}$ & 0.067 & 0.0670 & 0.043 & 0.043 & 0.043 & $0.043 \mathrm{C}$ & $0.047 \mathrm{C}$ & 0.077 & 0.075 & 0.067 & 0.067 & 0.058 & 0.061 & 0.054 & 0.070 & 0.070 & 0.071 & 0.068 & 0.0650 & 0.0540 & $0.054 \mathrm{C}$ & $0.051 \mathrm{C}$ & 0.056 & 0.058 & & \\
\hline A. parvus sp. $\mathrm{n}$. & 0.162 & $0.181 \mathrm{C}$ & 0.017 & 0.021 & 0.056 & 0.056 & 0.056 & 0.056 & $0.067 \mathrm{C}$ & 0.088 & 0.087 & 0.070 & 0.070 & 0.068 & 0.071 & 0.070 & 0.070 & 0.070 & 0.071 & 0.070 & 0.068 & 0.0740 & $0.074 \mathrm{C}$ & $0.071 \mathrm{C}$ & 0.065 & $0.065 \mid 0$ & 0.065 & \\
\hline
\end{tabular}


sp. n., A. lijiangensis sp. n.). However, this grouping of species of Auritibicen according to the male opercula is supported neither by the morphological or the molecular phylogeny trees. Moreover, in many cicadas the shape and relative length of opercula do not always reflect the phylogenetic relationships (Hayashi, 1987). In this study, only morphological characters of adults were used in the phylogenetic analyses, because specimens of many species of Auritibicen are very rare and, furthermore, a few species are very variable. In addition, only the $C O I$ gene was used in the phylogenetic analyses, because PCR amplification was not successful for some species, including the five new species, due to degradition of the DNA in very old specimens. Thus, the phylogeny within Auritibicen merits further study based on more morphological features and additional molecular data.

To date, all the known species of Auritibicen occur in Asia. According to the current data, ten species of Auritibicen occur in the Oriental Region, ten in the Palaearctic Region and the other four in both regions. Regarding the 18 species endemic to mainland Asia, most of them occur in Southeast China: eight in Sichuan Province and six in Yunnan Province (for detailed distribution of each species, see Table 4). Sichuan and Yunnan Provinces are mountainous areas at the northern margin of tropical Southeast Asia (Zhu et al., 2003). Based on the distribution and phylogeny of Auritibicen, we infer that the centre of distribution of Auritibicen could be Southwest China (e.g., Sichuan and Yunnan Provinces). Mountainous areas in Southwest China might have been the potential refugia for species of Auritibicen in the last ice age, which led to the formation of new lineages/taxa and contributed to the high diversity of this genus. i.e., from where this group spread northeastward to Shaanxi, Hubei and adjacent areas along the Daba and Qinling Mountains, then further northeastwards to

Table 4. Species of Auritibicen and their distributions.

\begin{tabular}{|c|c|}
\hline Species & Distribution \\
\hline Auritibicen atrofasciatus & China (Sichuan, Yunnan, Fujian, Tibet) \\
\hline Auritibicen bihamatus & Japan, Russia \\
\hline Auritibicen chujoi & China (Taiwan) \\
\hline Auritibicen esakii & Japan \\
\hline Auritibicen flammatus & a (Hubei, Sichuan, Shaanxi; Japan, Korea?) \\
\hline Auritibicen flavomarginatus & China (Taiwan) \\
\hline Auritibicen intermedius & Russia, Korea \\
\hline Auritibicen jai & China (Hebei, Shaanxi, Zhejiang, Jiangxi) \\
\hline Auritibicen japonicus & China (Shaanxi, Jiangxi); Japan, Korea? \\
\hline Auritibicen kyushyuensis & Japan \\
\hline Auritibicen leechi & China (Sichuan, Yunnan) \\
\hline Auritibicen pekinensis & China (Tibet) \\
\hline Auritibicen slocumi & China (Sichuan, Guangxi) \\
\hline Auritibicen tsaopaonensis & China (Sichuan, Yunnan) \\
\hline Auritibicen aethus sp. $\mathrm{n}$. & China (Zhejiang, Fujian) \\
\hline Auritibicen daoxianensis sp. $\mathrm{n}$. & China (Hunan) \\
\hline Auritibicen pallidus sp. $\mathrm{n}$. & China (Sichuan) \\
\hline Auritibicen rotundus sp. $\mathrm{n}$. & China (Hubei) \\
\hline Auritibicen gracilis sp. $\mathrm{n}$. & China (Sichuan) \\
\hline Auritibicen septatus sp. $\mathrm{n}$. & China (Yunnan) \\
\hline Auritibicen lijiangensis $\mathrm{sp} \mathrm{n}$. & China (Yunnan) \\
\hline Auritibicen curvatus sp. $\mathrm{n}$. & China (Shaanxi); \\
\hline Auritibicen purus sp. $\mathrm{n}$. & China (Yunnan) \\
\hline Auritibicen parvus sp. $\mathrm{n}$. & China (Sichuan) \\
\hline
\end{tabular}

Hebei Province in China, and also to Far East Russia, the Korean Penisula and Japan.

Past geologic events and climatic fluctuations in the Pleistocene had profound effects on the phylogeographic structure and genetic patterns of organisms (Hewitt, 2000, 2004; van Tuinen \& Dyke, 2004; Song et al., 2009). This resulted in a high diversity in subtropical and tropical regions in southern China (Crowe et al., 2006; Dong et al., 2013). The tremendous climatic changes during the Pleistocene influenced the distribution and evolution of many plants and animals (Dyke \& van Tuinen, 2004; Huang et al., 2010; Ding et al., 2011). Results of our molecular phylogenetic analysis indicate that species of Auritibicen are structured phylogeographically, with related species clustered in three lineages (Fig. 41). Our results indicate that the divergence of Auritibicen from Lyristes occurred during the Miocene and the most recent common ancestor (tMRCA) of Auritibicen during the Pliocene. However, the times of the main divergence of species of Auritibicen were mainly during the Pleistocene. The rapid change in climate and long-period of low temperatures should have resulted in the divergence of species and/or population differentiation in Auritibicen during this period. The eastern areas of Sino-Japanese region stretch along more than $1,500 \mathrm{~km}$ in an east-west direction, ranging from the Chinese mainland to Japan and the Korean Peninsula, and to Taiwan and the Ryukyu Islands (Holt et al., 2013). Auritibicen purus sp. n.occurring in China diverged from A. bihamatus occurring in Janpan approximately 1.86 mya (Fig. 42), which corresponds to the East China Sea (ECS) land bridge formation and connection between the Eurasian continent and the Japanese Islands approximately 1.3-2.0 mya (Kimura, 2003). Biogeography of Auritibicen occurring on the East Asian mainland and adjacent island archipelagos needs to be investigated further when more material are available, which will improve our understanding of the phylogeographic relationships and genetic differention in this cicada genus.

Our investigation is the first phylogenetic study of $A u$ ritibicen that includes all the species. We combined a morphological analysis with molecular analysis. Our results reveal the relationships within Auritibicen. Obviously, this is not the "final word" concerning the phylogenetic relationships of Auritibicen taxa. In the molecular analysis, A. kyushyuensis from Japan is closely related to A. intermedius from Korea (Fig. 41), and the "interspecific" genetic distances between $A$. intermedius and some samples of A. kyushyuens are lower than the intraspecific genetic distances recorded for A. kyushyuensis (Table 3). This indicates that these two species might be identical (Sota et al., 2016). However, the inconsistent result between the gene tree and the morphological tree might be due to stochastic or incomplete lineage sorting (Ballard \& Whitelock, 2004; Maddison \& Knowles, 2006), particularly for the molecular phylogenetic analysis, which was based on very few specimens of related species. We tentatively treat $A$. intermedius and A. kyushyuensis as two independent species as they differ morphologically. However, the identity 
and relationship between these two species needs further investigation based on more material. In addition, all the characters in our morphological analysis are external characteristics, since too few species were studied well enough to include other data (e.g., acoustic characters, biological data, and nymphal characters) in the phylogenetic analyses. We also describe some of the new species based only on the male holotype, which has been delayed for a long time due to the unsuccessful endeavour to obtain more specimens. Generally, the collecting of Auritibicen cicadas is difficult, because they perch high up in trees or near the tip of twigs and most species do not fly to light. A phylogenetic analysis based only on adult morphology and without female characters is highly likely to be imperfect. Overall, the analyses of combined molecular and morphological data yielded a phylogenetic topology largely congruent with the molecular-based phylogeny, because 35 morphological characteristics offer too little information for the combined dataset. Despite the shortcomings, the systematics of Auritibicen is elucidated for the first time based on both molecular data and morphological characters. These results will help in future studies on the phylogeography and evolution of this genus and other related species of cicada occurring in East Asia.

ACKNOWLEDGMENTS. We would like to express our sincere thanks to M. Webb (BMNH), S. Kamitani (ELKU), J. Constant (ISNB), H. Hoch and J. Deckert (MFNB), M. Boulard and J. Sueur (MNHN), M. Tomokuni (NSMT), C. Schmidt (SNSD), I. Malenovský (MZM), M. Yago (UMUT) and V. Gnezdilov and A. Emeljanov (ZIN) for the loan of material. We thank P. Švácha (Institute of Entomology, BC CAS, České Budějovice) for editorial corrections. This work was supported by the National Natural Science Foundation of China (Grant No. 31572302, 31772505).

\section{REFERENCES}

Ballard J.W.O. \& Whitelock M.C. 2004: The incomplete natural history of mitochondria. - Mol. Ecol. 13: 729-744.

Boulard M. 1979: Cigales nouvelles des Iles Salomon et des Iles Sous-le-vent. Notes biogeographiques (Hom. Cicadoidea). Rev. Fr. Entomol. (N.S.) 1: 49-60.

Boulard M. 1986a: Cigales de la Forêt de Taï (Côte d'Ivoire) et compléments à la faune cicadéenne Aftrotropicale (Homoptera, Cicadoidea). - Rev. Fr. Entomol. (N.S.) 7: 223-239.

BOULARD M. 1986b: Une singulière évolution morphologique: celle d'un appareil stridulant sur les genitalia des mâles de Carineta. Description de cinq espèces nouvelles (Hom. Tibicinidae). - Ann. Soc. Entomol. Fr. (N.S.) 22: 191-204.

Boulard M. 1988a: Taxonomie et nomenclature supérieures des Cicadoidea. Histoire, problèmes et solutions. - EPHE, Biol. Evol. Insectes 1: 1-89.

Boulard M. 1988b: Les Lyristes d'Asie Mineure (Hom. Cicadidae). 1. Sur deux formes éthospécifiques syntopiques et description de deux espèces nouvelles. - Entomologiste 44: 153-167.

Boulard M. 1998: Nomenclature et taxonomie supérieures des Cicadoidea ou vraies cigales: histoire, problèmes et solutions (Rhynchota, Homoptera, Cicadomorpha). - EPHE, Biol. Evol. Insectes 10: 79-129.

Boulard M. \& Puissant S. 2014: Comments on Tibicina Amyot, 1847 and Lyristes Horváth, 1926 (Insecta, Hemiptera, Homoptera): proposed conservation by the suppression of Tibicen
Berthold, 1827 (Case 239). — Bull. Zool. Nomencl. 71: 119131.

CHEN K.F. 1933: A list of Chinese known Cicadidae. - Entomol. Phytopathol. (Suppl. 1): 1-48.

CHen K F. 1943: New genera and species of Chinese cicadas with synonymical and nomenclatorial notes. - J. N. Y. Entomol. Soc. 51: 19-53.

Chou I., Lei Z., Li L., Lu X., Yao W. 1997: The Cicadidae of China (Homoptera: Cicadoidea). Tianze Eldoneio, Hong Kong, 380 pp., $4+16$ pls [in Chinese with English abstr.].

Crowe T., Bowie R., Bloomer P., Mandiwana T.G., Hedderson T.A.J., Randi E., Pereira S.L. \& Wakeling J. 2006: Phylogenetics, biogeography and classification of, and character evolution in, gamebirds (Aves: Galliformes): effects of character exclusion, data partitioning and missing data. - Cladistics 22: 495-532.

Ding L., Gan X., He S. \& Zhao E. 2011: A phylogeographic, demographic and historical analysis of the short-tailed pit viper (Gloydius brevicaudus): evidence for early divergence and late expansion during the Pleistocene. - Mol. Ecol. 20: 1905-1922.

Distant W.L. 1890: Descriptions of Chinese species of the homopterous family Cicadidae. - Entomologist 23: 90-91.

Distant W.L. 1889-1892: A Monograph of Oriental Cicadidae. Indian Museum, Calcutta, xiv+158 pp., 15 pls.

Distant W.L. 1904: Rhynchotal notes. XXVII. - Ann. Mag. Nat. Hist. (Ser. 7) 14: 329-336.

Dong L., Heckel G., Liang W. \& Zhang Y. 2013: Phylogeography of Silver Pheasant (Lophura nycthemera L.) across China: aggregate effects of refugia, introgression and riverine barriers. - Mol. Ecol. 22: 3376-3390.

Drummond A.J., Suchard M.A., XIE D. \& Rambaut A. 2012: Bayesian phylogenetics with BEAUti and the BEAST 1.7. Mol. Biol. Evol. 29: 1969-1973.

Dyke G.J. \& VAN TUINEN M. 2004: The evolutionary radiation of modern birds (Neornithes): reconciling molecules, morphology and the fossil record. - Zool. J. Linn. Soc. 141: 153-177.

EsAKI T. 1935: A new species of Cicadidae from Formosa. Proc. Imp. Acad. Jpn. 11: 201-202.

Felsenstein J. 1985: Confidence limits on phylogenies: an approach using the bootstrap. - Evolution 39: 783-791.

Goloboff P.A., Farris J.S. \& Nixon K.C. 2003: T.N.T.: Tree Analysis Using New Technology. Program and Documentation. URL: http://www.zmuc.dk/public/phylogeny/tnt.

GolobofF P.A., Farris J.S. \& Nixon K.C. 2008: TNT, a free program for phylogenetic analysis. - Cladistics 24: 774-786.

Gómez-Menor O.J. 1961: Monografia de cicadidos (Homoptera) de España. - Mem. R. Acad. Cienc. Exact. Fis. Nat. Madrid 69: 1-87.

Haupt H. 1924: Die Homoptera der Tibetreise W. Stötzners. Dt. Entomol. Z. 1923: 295-306.

Hayashi M. 1977a: A new species of the genus Tibicen Latreille (Homoptera, Cicadidae) from Taiwan. - Kontyû (Tokyo) 45: 185-191.

HAYASH M. 1977b: A Revision of the Japanese Cicadidae, with Special Reference to the Zoogeographic Distribution (Homoptera, Auchenorrhyncha). PhD Thesis, Kyushu University, Fukuoka, xii+214 pp., 31 pls.

HAYASHI M. 1987: A revision of the genus Cryptotympana (Homoptera, Cicadidae) Part I. - Bull. Kitakyushu Mus. Nat. Hist. 6: 119-212.

HAYASH M. \& SAISHO Y. 2015: The Cicadidae of Japan. 2nd Ed. Seibundo-shinko-sha, Tokyo, 224 pp. [in Japanese].

HewitT G. 2000: The genetic legacy of the Quaternary ice ages. - Nature 405: 907-913. 
Hewitt G. 2004: Genetic consequences of climatic oscillations in the Quaternary. - Philos. Trans. R. Soc. (B) 359: 183-195.

Hill K.B.R., Marshall D.C., Moulds M.S. \& Simon C. 2015: Molecular phylogenetics, diversification, and systematics of Tibicen Latreille 1825 and allied cicadas of the tribe Cryptotympanini, with three new genera and emphasis on species from the U.S.A. and Canada (Hemiptera: Auchenorrhyncha: Cicadidae). - Zootaxa 3985: 219-251.

Holt B.G., Lessard J.P., Borregaard M.K., Fritz S.A., AraúJo M.B., Dimitrov D., Fabre P.H., Graham C.H., Graves G.R., Jønsson K.A. ET AL. 2013: An update of Wallace's zoogeographic regions of the World. - Science 339: 74-78.

HuA L.Z. 2000: List of Chinese Insects. Vol. 1. Zhongshan (Sun Yat-sen) Universisty Press, Guangzhou, 448 pp. [in Chinese].

Huang Z., Liu N., Liang W., Zhang Y., Liao X., Ruan L. \& Yang Z. 2010: Phylogeography of Chinese bamboo partridge, Bambusicola thoracica thoracica (Aves: Galliformes) in south China: Inference from mitochondrial DNA control-region sequences. - Mol. Phylogenet. Evol. 56: 273-280.

IsHIHARA T. 1961: Hemiptera of Southeast Asia collected by the Osaka City University biological expedition to Southeast Asia 1957-1958. — Nat. Life Southeast Asia 1: 224-257.

IsHiHARA T. 1968: The Cicadidae of the Ryukyu Archipelago (Hemiptera). - Trans. Shikoku Entomol. Soc. 9: 129-148, pls 2-4.

JACOBI A. 1944: Die Zikadenfauna der Provinz Fukien in Sudchina und ihre tiergeographischen Beziehungen. - Mitt. Münch. Entomol. Ges. 34: 5-66.

Kato M. 1925: Japanese Cicadidae, with descriptions of new species. - Trans. Nat. Hist. Soc. Formosa 15: 1-47 [in Japanese].

Kato M. 1926: Japanese Cicadidae, with descriptions of four new species. — Tran. Nat. Hist. Soc. Formosa 16: 171-176 [in Japanese with English descriptions].

Kato M. 1930: Notes on the distribution of Japanese Cicadidae. — Insect World (Gifu) 34: 146-150 [in Japanese].

Kato M. 1931: Semi (2). — Kontyû (Tokyo) 5: 64-68 [in Japanese].

Kato M. 1933a: Three Colour Illustrated Insects of Japan. Fasc. 3 (Homoptera). Kôseikaku, Tokyo, 9+50+11 pp., 50 pls.

Kato M. 1933b: Homoptera. Catalog of Japanese Insects 1. Konchushumi-no-kai, Tokyo, 1+38 pp.

Kato M. 1934: Notes on Chinese Cicadidae. - Entomol. World (Tokyo) 2: 144-161 [in Japanese].

Kato M. 1937: Semi (12). — Entomol. World (Tokyo) 5: 382-387 [in Japanese].

Kato M. 1939: Studies on Japanese Cicadidae (2). — Bull. Cicadidae Mus. 4: 7-13 [in Japanese].

Kato M. 1940: Studies on Japanese Cicadidae (6). — Bull. Cicadidae Mus. 10: 1-7 [in Japanese].

Kaто M. 1958: New cicada species of Yakushima. - Kontŷu (Tokyo) 26: 247.

Kaто M. 1959: On the cicadas belonging to the genus Tibicen in Japan. - J. Biol. Educ. 1(2): 21-28 [in Japanese].

KIMURA M. 2003: Land connections between Eurasian continent and Japanese Islands related to human migration. - Migrat. Diffus. 4: 14-33.

KirKaldy G.W. 1909: Hemiptera, old and new, No. 2. - Can. Entomol. 41: 388-392.

Kunosawa Y. 1969: Is Tibicen esakii identical to T. bihamatus? Discussion on the zoogeography of the genus Tibicen in Japan. - Nat. Sci. Mus. (Tokyo) 36: 11-20 [in Japanese]

LeE Y.J. 1995: The Cicadas of Korea. Jonah, Seoul, 157 pp., 9 pls [in Korean].

LEE Y.J. 2008: Revised synonymic list of Cicadidae (Insecta: Hemiptera) from the Korean Peninsula, with the description of a new species and some taxonomic remarks. - Proc. Biol. Soc. Wash. 121: 445-467.

LeE Y.J. 2015: Description of a new genus, Auritibicen gen. nov., of Cryptotympanini (Hemiptera: Cicadidae) with redescriptions of Auritibicen pekinensis (Haupt, 1924) comb. nov. and Auritibicen slocumi (Chen, 1943) comb. nov. from China and a key to the species of Auritibicen. - Zootaxa 3980: 241-254.

LeE Y.J. 2017: Resurrection of Auritibicen shikokuanus (Kato, 1959) stat. rev. \& comb. nov. (Hemiptera: Cicadidae: Cryptotympanini) from Ehime and Hiroshima of Japan. - J. AsiaPac. Biodiv. 10: 59-64.

Liu K.C. 1939: Notes on the Cicadidae of the Heude Museum, Shanghai. - Notes Entomol. Chin. 6: 149-159.

Luo C., Wei C. \& Nansen C. 2015: How do "mute" cicada produce their calling songs? - PLOS ONE 10(2): e0118554, 16 pp.

MADDISON W.P. \& KNOWLES L.L. 2006: Inferring phylogeny despite incomplete lineage sorting. - Syst. Biol. 55: 21-30.

Marshall D.C. \& Hill K.B.R. 2014: Comments on Tibicina Amyot, 1847 and Lyristes Horváth, 1926 (Insecta, Hemiptera, Homoptera): proposed conservation by the suppression of Tibicen Berthold, 1827 [?Latreille, 1825], and concerning the type species of Cicada Linnaeus, 1758. Comment (1). - Bull. Zool. Nomencl. 71: 103-107.

Matsumura S. 1898: A summary of Japanese Cicadidae with description of a new species. - Annot. Zool. Jap. 2: 1-20.

Matsumura S. 1904: Thousand insects of Japan by Matsumura. - Annot. Zool. 5: 53 [in Japanese].

Matsumura S. 1936: A new cicada species from Honshu. - Insecta Matsum. 11: 38.

Matsumura S. 1939: On the genus Lyristes Horváth and two new species of Cicadidae. - Insecta Matsum. 13: 47-51.

Melichar L. 1902: Homopteren aus West-China, Persien und dem Süd-Ussuri-Gebiete. - Annu. Mus. Zool. Acad. Imp. Sci. St. Pétersbourg 7: 76-146.

Metcalf Z.P. 1963: General Catalogue of the Homoptera. Fascicle VIII. Cicadoidea. Part 1. Cicadidae. Section I. Tibiceninae. Waverly Press, Baltimore, MD, $585 \mathrm{pp}$

Mori T. 1931: Cicadidae of Korea. - J. Chosen Nat. His. Soc. 12: 10-24, pls 1-2 [in Japanese].

MotschUlsky V.I. 1861: Insectes du Japon, Homoptères. Études Entomol. 10: 4-24.

MouldS M.S. 2005: An appraisal of the higher classification of cicadas (Hemiptera: Cicadoidea) with special reference to the Australian fauna. - Rec. Austral. Mus. 57: 375-446.

Moulds M.S. 2012: A review of the genera of Australian cicadas (Hemiptera: Cicadoidea). - Zootaxa 3287: 1-262.

Nixon K.C. 2002: WinClada Ver. 1.00.08. Published by the author, Ithaca, NY.

OKadA M. 2000: A record of an exuviae of Tibicen atrofasciatus from Alishan, Taiwan. — Cicada 15: 18-19 [in Japanese with English abstr.].

ÔuchI Y. 1938: Contributiones ad cognitionem insectrum (sic!) Asiae Orientalis. V. A preliminary note on some Chinese cicadas with two new genera. - J. Shanghai Sci. Ins. 3-4: 75-111.

Papadopoulou A., Anastasiou I. \& Vogler A.P. 2010: Revisiting the insect mitochondrial molecular clock: the mid-Aegean trench calibration. - Mol. Biol. Evol. 27: 1659-1672.

RoNQUist F. \& HuELSENBECK J.P. 2003: MrBayes 3: Bayesian phylogenetic inference under mixed models. - Bioinformatics 19: $1572-1574$.

Puissant S., Boulard M., Lee Y.J., Hayashi M., Wei C. \& Sueur J. 2015: Comments on Tibicina Amyot, 1847 and Lyristes Horváth, 1926 (Insecta, Hemiptera, Homoptera): proposed conservation by the suppression of Tibicen Berthold, 1827 [?Latreille, 
1825], and concerning the type species of Cicada Linnaeus, 1758. - Bull. Zool. Nomencl. 72: 219-220.

SAnBorn A. 2014: Comments on Tibicina Amyot, 1847 and Lyristes Horváth, 1926 (Insecta, Hemiptera, Homoptera): proposed conservation by the suppression of Tibicen Berthold, 1827 [?Latreille, 1825], and concerning the type species of Cicada Linnaeus, 1758. Comment (2). - Bull. Zool. Nomencl. 71: 108-118.

SANBORN A.F. 2015: New combinations for six species belonging to Cryptotympanini Handlirsch (Hemiptera: Cicadidae), former members of the genus Tibicen Latreille, 1825. - Zootaxa 4027: 447-450.

Schmidt E. 1932: Verzeichnis der Cicaden des chinesischen Reiches. - Pek. Nat. Hist. Bull. 7: 117-133.

Simon C., Frati F., Beckenbach A., Crespi B., Liu H. \& Flook P. 1994: Evolution, weighting, and phylogenetic utility of mitochondrial gene sequences and a compilation of conserved polymerase chain reaction primers. - Ann. Entomol. Soc. Am. 87: $651-701$.

Silvestro D. \& Michalak I. 2012: RaxmlGUI: a graphical frontend for RAxML. - Organisms Divers. Evol. 12: 335-337.

Song G., Qu Y., YIN Z., Li S., Liu N. \& Lei F. 2009: Phylogeography of the Alcippe morrisonia (Aves: Timaliidae): long population history beyond late Pleistocene glaciations. - BMC Evol. Biol. 9: 143.

Sota T., Kojima T., Lee Y.J. \& Lin C.P. 2016: Phylogenetic relationships of Japanese Auritibicen species (Hemiptera: Cicadidae: Cryptotympanini) inferred from mitochondrial and nuclear gene sequences. - Zool. Sci. 33: 401-406.

Tamura K., Stecher G., Peterson D., Filipski A. \& Kumar S. 2013: MEGA6: Molecular Evolutionary Genetics Analysis Version 6.0. - Mol. Biol. Evol. 30: 2725-2729.

vAN TUINEN M. \& DYKe G. 2004: Calibration of galliform molecular clocks using multiple fossils and genetic partitions. - Mol. Phylogen. Evol. 30: 74-86.

Wang X., Hayashi M. \& Wei C. 2015: Taxonomic note on two Lyristes cicadas described by E. Schmidt from China. - Entomotaxonomia 37: 1-4.
Young D. 1990: Do cicadas radiate sound through their eardrums? - J. Exp. Biol. 151: 41-56.

Zhu H., Wang H., Li B. \& Sirirugsa P. 2003: Biogeography and floristic affinities of the limestone flora in southern Yunnan, China. - Ann. Missouri Bot. Gard. 90: 444-465.

Received July 6, 2017; revised and accepted December 13, 2017 Published online February 23, 2018

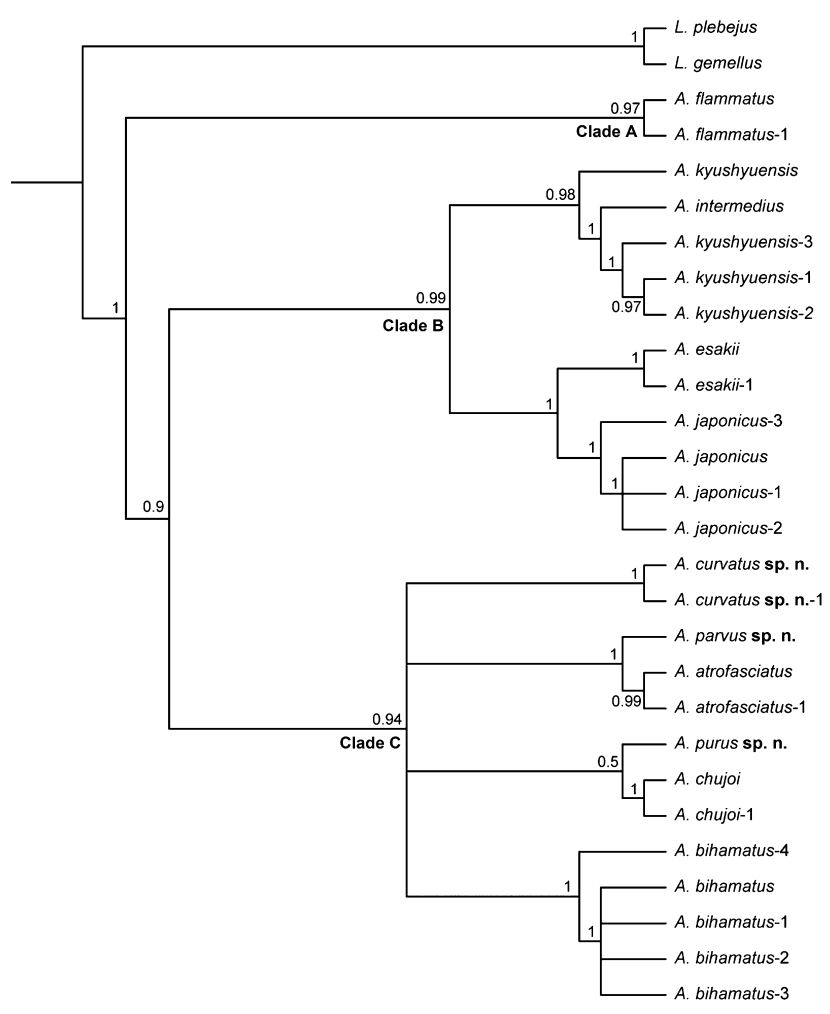

Fig. S1. Bayesian consensus phylogram of Auritibicen. Phylogram based on Bayesian analysis of combined dataset of $\mathrm{COI}+$ morphology. Numbers above branches are Bayesian posterior probability (PP) values. 